\title{
The evaluation of research for promotion and tenure: An organizational perspective
}

\author{
Elsa G. Nadler \\ West Virginia University
}

Follow this and additional works at: https://researchrepository.wvu.edu/etd

\section{Recommended Citation}

Nadler, Elsa G., "The evaluation of research for promotion and tenure: An organizational perspective" (1999). Graduate Theses, Dissertations, and Problem Reports. 3672.

https://researchrepository.wvu.edu/etd/3672

This Dissertation is protected by copyright and/or related rights. It has been brought to you by the The Research Repository @ WVU with permission from the rights-holder(s). You are free to use this Dissertation in any way that is permitted by the copyright and related rights legislation that applies to your use. For other uses you must obtain permission from the rights-holder(s) directly, unless additional rights are indicated by a Creative Commons license in the record and/ or on the work itself. This Dissertation has been accepted for inclusion in WVU Graduate Theses, Dissertations, and Problem Reports collection by an authorized administrator of The Research Repository @ WVU.

For more information, please contact researchrepository@mail.wvu.edu. 


\title{
The Evaluation of Research for Promotion and Tenure: An Organizational Perspective
}

\author{
Elsa G. Nadler
}

Dissertation submitted to the Faculty of The College of Human

Resources and Education at West Virginia University in partial fulfillment of the requirements for the degree of

Doctor of Education

in

Higher Education Administration

Department of Advanced Educational Studies

Richard A. Hartnett, Chair

John O. Andes

Van O’Dell Dempsey, III

Frank J. Calzonetti

Ernest R. Goeres

1999

Morgantown, West Virginia

Keywords: Education Administration, Authority Structure, Sociology of Education, Promotion and Tenure

Copyright 1999, Elsa G. Nadler 


\section{Dedication}

This dissertation is dedicated to my husband, Sam B. Nadler, Jr., who had the patience and understanding to put up with the many disruptions my classes and research and writing caused in our home life. The successful completion of this dissertation is largely due to his exhortations. 


\section{Acknowledgments}

I wish to acknowledge the guidance of the members of my committee and to heartily thank Richard A. Hartnett, my chair, and John O. Andes, Ernest Goeres, Van O. Dempsey and Frank Calzonetti. Without their helpful comments and patience, I would never have succeeded in completing the task of which this document is the summation. I thank Magdalena Niewadomska-Bugaj, who did the statistical analysis of institutional demographics and valiantly tried to find some correlations. I owe a special debt of gratitude to my workplace supervisor, William W.

Reeves, who understood and never questioned my absences from work because of class or meetings related to my dissertation. 


\section{Table of Contents}

Chapter I

Introduction

Chapter II

Literature Review ................................................... 15

Chapter III

Methodology

Chapter IV

Discussion and Analysis

32

Chapter V

Conclusions

References

Appendix A .... 155

Appendix B 158

Appendix C 161

Appendix D 163

Appendix E 164

Abstract 168 


\section{List of Tables}

Table 1: "Measures" Considered in the Literature ....................... 16

Table 2: Studies Categorized by Discipline .............................. 17

Table 3: Biglan's Disciplinary Categories-An Example ................. 25

Table 4: Interviews Conducted ........................................... 29

Table 5: Graphic Representation of Analysis of Faculty

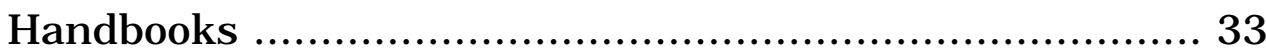

Table 6: Departmental Promotion and Tenure Committees

at Three Universities ............................................... 44

Table 7: Outline of Promotion and Tenure Committee

Structure and Function at Bureaucratic U ................... 115

Table 8: Outline of Promotion and Tenure Committee

Structure and Function at Shared-Governance U ........... 116

Table 9: Outline of Promotion and Tenure Committee

Structure and Function at Collegial U ......................... 117 


\section{Chapter I}

\section{Introduction}

In contemporary research universities, promotion and tenure decisions represent a major investment and have far-reaching repercussions for the individual department and the university as a whole. A general assumption is that the academic reputation of an institution hinges on the reputation of the faculty, an assumption upheld by several papers ([Anderson et al., 1978], [Blume and Sinclair, 1973], [Beyer and Stevens, 1977], [Crane, 1965], [Cole and Cole, 1967], [Carrter, 1977], [ Elton and Rose, 1972], [Fulton and Trow, 1974], Gaston, 1970], [King and Wolfe, 1987], [Kroc, 1984], [Long et al., 1979], [Lightfield, 1971]).

On the contrary, Long and McGinnis [1981] found that organizational context affects scientists' productivity rather than the scientists' productivity affecting the prestige of the place. They found that, although prior productivity (volume of papers published) and citations are predictors of present productivity, those positive effects disappear six years after a person changes organizational contexts (either moves to another position or to another university). Could this finding be an anomaly or is it an indication of the organization's influence on its members? Although the authors did not say so, we might surmise a certain amount of selfselection is occurring - namely that highly motivated and productive individuals are likely to seek jobs in places that reward those activities and where there are others with similar attitudes; and those who change 
organizational contexts after six years do so because they have a change in attitude and motivation.

A study by Manis (1950] concluded that "occupational and institutional conditions [such as time spent in various endeavors, research interests and preferences, financial support of research, size of department and institution, institutional and departmental reputations, library size] influence the volume and merit of the publishing output of individuals" [Manis, p. 1219]. This is another instance of the organizational context, culture and climate affecting "productivity."

The logical conclusion thus, regardless of whether individual faculty research records affect the reputation of the institution or whether the institution's characteristics affect the individual researcher, is that the institution's reputation attracts other faculty and graduate students. And institutional reputation is often related to the success of applications for external funding, which has further impact on reputation. The award of tenure means that the university seeks to retain the faculty member, and that retention means that the professional activities of the tenured person contribute to the institution's reputation and mission. Therefore, reputation of a university is often considered to be no greater than the "quality" of its tenured faculty.

Of the factors entering into promotion and tenure decisions in a research university, research is considered by many to be the most important. The criteria and procedures used in arriving at these decisions are therefore of utmost importance. Once a faculty member receives tenure, that individual has an academic position until retirement (barring a decision to move to another university or dismissal for cause). Once the university has committed itself to that individual, the economic 
consequences of the tenure decision often exceed $\$ 1.25$ million in projected salary and benefits.

In considering tenure, decision makers must decide if the candidate will continue to contribute to the three functions of higher education and the professoriate: (1) the maintenance and storage of knowledge, (2) the transmission of knowledge and (3) the production of new knowledge. Will she contribute to the successful transmission of knowledge? Will she contribute to the growth of knowledge? Will she contribute positively to the institution's reputation through her scholarship? Will she draw other faculty to come to be her colleagues? Will she attract students to work with her, students who will then move on to positions both within and without higher education and further increase the university's standing? Will she provide meaningful service to the community and the discipline?

These questions of the individual's contributions to the institution are also valid with respect to Keohane's "hybrid model" of the university [1993], which considers the German research university grafted onto the Oxford and Cambridge models of collegiate teaching and then given the peculiarly American characteristic of knowledge in service to the nation: "The modern research university is a company of scholars engaged in discovering and sharing knowledge, with a responsibility to see that such knowledge is used to improve the human condition." This definition is particularly apt for the land-grant institutions which are the subject of this study. Keohane also noted that, with "universities under attack for failing in our basic purposes and falling away from our historic character, it is of singular importance that we explain clearly and forcefully why our work is crucial, and what it is we are doing that matters so much to 
the world." The important part of the entire process, Keohane says, is the dialogue "that comes from thinking seriously about what you are doing in the company of others" engaged in the same activity. "The real treasure is in the activity, the exercise itself, and the enrichment of common understanding of our purpose."

Both tenure and the research endeavor, however, have come under attack. Controversy abounds over the value of voluminous, specialized research. Articles and commentaries have appeared condemning the trivialization of research. Some researchers have examined the contribution of an active research career to dynamic teaching and have found little correlation, despite observations to the contrary. There is a perceived rift between teaching and research. And the perception is that faculty devote too much time to research and attendance at meetings and conferences, with the consequence that parents and legislators think students are slighted. Numerous articles have questioned the value of tenure, and several states initiated movements to abolish it. Prewitt [1994] provides a lengthy list of books that are vehemently critical of the university, claiming they are "guilty of fraud and failure." And although Prewitt says this "confessional literature" is indicative of an erosion, or even demise, of public confidence in higher education and its loss of credibility, he finds that the opposite is in fact the case.

Political and cultural elements also impinge on perceptions of research and the university research function. A current of pragmatism, utility and vocationalism runs through today's universities-all good research is not equal, either in the eyes of those on the inside who balance the books or in the eyes of those on the outside who perceive curiosity-driven research and research in the humanities as a waste of time 
and taxpayers' dollars. In this utilitarian view of the university, there are many who promote it as an engine of economic development (for the local region and for the state) and as a source of cures for society's ills-thoroughly forgetting (or ignoring) that most of the utilitarian research they find so valuable is ultimately based on the curiosity-driven research that preceded it.

With respect to the economic value of research, a 1998 survey conducted by the Education Commission of the States found that governors believe universities devote too much time to research that does not directly benefit their states. Of interest here is the inclination of governors in the Middle Atlantic states to see their public universities as agents of regional economic development while western governors are more willing to countenance radical academic change (Schmidt, 1998].

We can thus infer, in light of what appears to be the increasing importance of the practical and pragmatic, that the "responsibility to use knowledge to improve the human condition" of Keohane's hybrid model has become paramount in land-grant universities whose mission is service to the state. This shift in emphasis has had its impact on the stated goals of the university. Has it also had an impact at the department and disciplinary level?

We recall F. Burton Clark's statement that "[a]cademic activities are divided and grouped in two basic ways: by discipline and by enterprise." He defines the enterprise, or individual institution, as a "comprehensive grouping, in that it links together . . disparate specialists." The discipline "is a specialized form of organization" that knits together specialists across a "craftlike community of interest" rather than across a geographic locale [Clark, pp. 28-29]. Clark says that "[d]isciplines pres- 
sure institutions to be scholarly, and sometimes to be interested in research. Institutions pressure disciplines to be student-centered, and sometimes to be cognizant of other fields of study" [Clark, p. 32]. The two arenas meet in a matrix structure that provides crosscutting bases of groupings and is an organizational way to "have your cake and eat it, too" [Clark, p. 31]. Alpert [1983] uses this matrix structure to describe the flow of influence within and between enterprises and disciplines.

Given that enterprise and discipline are sometimes working at cross purposes, how do they interact in the evaluation of research? It is this dialogue between enterprise and discipline that is the subject of the research reported here-how the two entities, the bureaucracy and the collegium, interact with respect to goals, structure and process.

\section{Significance}

Received wisdom tells us that research and scholarship are the essence of higher education and the research university in particular. Assuming that research and scholarship are essential elements of the promotion and tenure process, and that the process itself and the resultant decision represent a major commitment on the part of the department, the college and the university, we should have a thorough understanding of how the components fit together and complement each other. Such an understanding may help universities perform this chore more efficiently and effectively-if you understand where you are going and how you are going to get there, the trip is more likely to be made with fewer pitfalls and dead ends, with greater confidence and competence, and with more 
satisfaction for all those involved in the decision than it would be without that knowledge.

A decade has passed since researchers have devoted any energy to examining the methodologies and mechanisms involved in evaluating research. In those ten years, much has changed. Universities have grown larger, student bodies more diverse. Disciplines have grown and multiplied (and a few have all but disappeared). The explosion of knowledge and continuing specialization of subdisciplines add to the difficulty of finding persons expert enough to review individual work. The attitudes of the public, the state, the federal government have changed. The student's approach to education has shifted. The job market in the late 1990s is no longer as fluid as it was in the early 70s when researchers conducted many studies of productivity from many different perspectives. Funding patterns are different-federal and state spending on research in many disciplines (notably the humanities and art) has decreased. Let us note the major exceptions of increased funding for the National Science Foundation and the National Institutes of Health-but even here, much of the funding is directed towards goal-driven and utilitarian research rather than towards the ideal of curiosity-driven research. Additionally, with the rising cost of technology, higher salaries for academic "stars," greatly increased costs of student services and the increasingly competitive "market" in which universities vie with each other for both faculty and students, many (if not most) universities now find themselves either in or fast approaching a financial crisis.

Previous research (from the 70s and early 80s) on research evaluation is replete with articles on the number of publications produced by faculty in various departments (especially in the business and economics 
disciplines and in psychology) and how well citations and peer evaluations correlate with raw publication counts, reputation and student productivity. However, most of this work investigates only the input or output, not the process itself, nor the relationships between goals, operation and structure.

Thus, it is time to take another look, and a deeper one, at a process that is ultimately so important to higher education in this country.

\section{Problem Statement}

One of the most important activities in institutions of higher education is the promotion and tenure process. Since the goal of most institutions of higher education is to keep (and therefore tenure) the "best" faculty, it should be important to know what factors are the operative ones in making promotion and tenure decisions. In universities termed "research institutions," research and scholarship are major criteria of the promotion and tenure decision. Since most disciplines are separate (and distinct) units based in the knowledge domain and are the individual units (or departments) that comprise the academic (rather than the financial, service or promotional) sector of the institution, we should seek to know how congruent the department and the institution are with respect to reviewing or evaluating research for promotion and tenure and how their individual structure, goals and operations interact. We thus must ask

What are the relationships, if any, between the structure, goals and operation of the institution as a whole and the structure, goals and operation of the academic department with respect to the review of an individual's research for promotion and tenure decisions? 
With this question in mind, therefore, we seek to examine the factors and considerations involved in the evaluation of research for promotion and tenure decisions in order to develop a better understanding of how universities and departments undertake this exercise and to examine the level of congruency between the enterprise (see definition at end of chapter) and the departments within it. A common complaint in recent years is the attempt to shovel all academic disciplines into the mold of the scientific disciplines and to give greater priority and prestige to the quantitative rather than the qualitative study. Since most landgrant universities purport to be research universities (of the 49, 1862 Morrill Act, state land-grant universities, 30 have Carnegie classification as Research I and 12 as Research II), it behooves us to know about institutional and department-based authority structures as they relate to the operation of the promotion and tenure decision, how departments and enterprises determine which prospective faculty to tenure and what their ultimate goals are. We need to understand this decision-making process from the perspectives of both the enterprise and the department and how these two entities interact with respect to structure, goals and operation.

\section{Hypothesis and Research Questions}

In light of the research question stated above, the working hypothesis for this study is as follows:

The structure, goals and operation of the enterprise will affect the structure, goals and operation of the academic department with respect to the review of an individual's research for promotion and tenure decisions. 
This hypothesis leads to several research questions in two phases.

\section{Phase I}

Phase I is a content analysis of the promotion and tenure sections of faculty handbooks at 31 state, land-grant universities. Statistical analysis of that information attempts to answer the following research questions:

1. To what extent does structure vary with respect to size, geographic location, history, cultural milieu, stated goals, level of operational control, and external funding in different institutions?

2. To what extent do goals vary with respect to size, geographic location, history, cultural milieu, and external funding in different institutions?

3. To what extent do operations and level of centralized control vary with respect to size, geographic location, history, cultural milieu, mission and goals, and external funding in different institutions?

\section{Phase II}

Phase II of the study was telephone interviews which attempted to elicit information on the following questions:

1. To what extent are the enterprise and departmental authority structures congruent?

2. To what extent are the goals of the enterprise and the department congruent?

3. To what extent are the operating procedures of the enterprise and department congruent? 
4. What are the most important relationships and interactions between the enterprise and the department with respect to structure, goals and operations?

5. How do the actors in this process perceive its relationship to the discipline outside the enterprise? to the institution? [This will elicit information on the clash of values, authority structures, even goals within the departments themselves.]

\section{Definitions}

Discipline: a specialized division based on knowledge domain. Department and discipline will be used interchangeably, recognizing that primary disciplines such as chemistry have subdisciplines such as organic chemistry, physical chemistry and analytic chemistry that could constitute separate departments. Separate disciplines, hence separate and distinct departments, have historically arisen as the knowledge base expands and specialization increases and subdisciplines split into separate departmental divisions within the enterprise (a prime example is the case of mathematics and computer science, which are two departmental divisions in most - though not all-universities today, although at one time they were both housed in "mathematics").

Enterprise: an individual institution (following Burton Clark's definition), in this case an institution of higher education. In cases in which a university has several campuses located in separate cities, the enterprise (institution) will be the main (or home or primary) campus. 
Goals: the mission direction, stated and unstated, of the unit under consideration. For the enterprise, preliminary analysis will consider the institutional mission statement; interviews will attempt to uncover unexpressed agendas. At the disciplinary (departmental) level, the focus will be, for the topic of goals, on what the evaluation of research in the promotion and tenure process is supposed to accomplish for the department (faculty and students).

Academic Governance: the organizational and administrative features of the university. Three primary structures will be considered here: the bureaucratic, the shared-governance and the collegial.

Bureaucratic: Baldridge restates Max Weber's definition of a bureaucracy as an organization in which"the structure is hierarchical and is tied together by formal chains of command and systems of communication [and] ... involves such characteristics as tenure, appointment to office, salaries as a rational form of payment, and competency as the basis of promotion" [Baldridge, p. 2].

Collegium: a community of scholars in which there is full participation by the faculty and all decisions (including strictly administrative ones) are made by consensus and grounded in the faculty's professional or technical competence (see [Baldridge, pp. 5-6] and [Millett, pp. 234235]).

Shared Governance: an amalgamation of the bureaucratic and collegial authority structures in which the community of scholars makes decisions concerning academic affairs and the bureaucratic structure of the institution is concerned only with administrative matters. In practice, 
the actual operation of shared governance is not so clear cut. Talcott Parsons' 1968 paper includes a complete discussion of the organizational structure of the American University, including the position of the lay trustees. He calls the university a "heterocephalous, heteronomous oligarchy" [Parsons, p. 508]. Additionally, he notes that "faculties and departments ... tend to be collegially organised rather than hierarchically in order to create the circumstances for each member to maximise the values of cognitive rationality" [Parsons, p. 509]. Duryea says that universities have essentially two bureaucracies, one for administrative matters and one for academic matters [Duryea, 1973]. As an historical aside, departments as organization units in charge of academic disciplinary matters were well established by 1900 [Duryea, p. 8], and he cites a 1910 report of physics departments that complained they had "too much autonomy."

Operations: the processes, mechanisms and criteria used in the evaluation of research. This includes the selection and composition of committees, the background and credentials of the committee members, the specific criteria used in the evaluation process, how and why those criteria are selected and how they might be weighted.

Research I and Research II: the Carnegie Classifications. Research I institutions "offer a full range of baccalaureate programs, are committed to graduate education through the doctorate, and give high priority to research. They award 50 or more doctoral degrees each year. In addition, they receive annually $\$ 40$ million or more in federal support." [Chronicle 
of Higher Education, 6 April 1994] Research II institutions are described the same as Research I institutions except for the funding criterionthey receive annually between $\$ 15.5$ million and $\$ 40$ million in federal support.

Structure or Authority Structure: the formal authority system that governs the functioning of the unit. The primary authority systems that will be considered in this paper are the bureaucratic, collegial, and shared governance (a system peculiar to higher education). The professional, guild or union, political, and individual or personal will also be discussed where interview comments warrant such considerations.

The next chapter will review the literature on the evaluation of research and on tenure and promotion in higher education. Following this discussion, Chapter III will explain and outline the methodology used in the conduct of the research and interviews. Chapter IV is divided into two sections: the first section provides a brief discussion of the promotion and tenure guidelines as found in faculty handbooks; the second section discusses and analyzes the interviews. Chapter V presents the conclusions derived from the analysis of the interviewees' coments and suggests further research. 


\section{Chapter II}

\section{Review of the Literature}

The literature concerning evaluation of research was at its height during the 1960s and 70s, tapered off in the 80s and largely disappeared by the mid-80s. Published primarily in journals of psychology, economics, finance, and sociology, most of this research has been quantitative, measuring professional output in different disciplines and universities and comparing faculty in different disciplines and universities. Many of these publications also centered on how the three primary evaluative criteria (publications, citations and peer reviews) compare to each other in reliability and "successful" evaluation of faculty. [See Table 1.]

Most authors devoted their attention to the sciences and social sciences, largely ignoring the humanities. As we can see from Table 2, the majority of the literature has examined some aspect of the productivity and evaluation of faculty in the hard sciences (chemistry, physics, biomedical basic sciences such as biochemistry and physiology), with examination of the social sciences (especially sociology, economics and finance) a close second.

It is perhaps instructive to note that the preponderance of these studies has concentrated on a particular "measure" of productivity—or they have attempted to contrast and compare the different measures (citations, publications, journals, awards and honors, student publication rates, peer prestige). In general, these are easily measured or counted factors. Table 1 shows the measures the researchers have studied in the past 30 years. Most have considered publications to be the 
Table 1: "Measures" Considered in the Literature

\begin{tabular}{|c|c|c|c|c|c|c|}
\hline & pubs & citation & $\begin{array}{l}\text { peer/ } \\
\text { prestige }\end{array}$ & $\begin{array}{l}\text { eval/ } \\
\text { salary }\end{array}$ & formula & $\begin{array}{l}\text { general/ } \\
\text { other }\end{array}$ \\
\hline Anderson/Narin/McAllister & $\mathrm{x}$ & $\mathrm{x}$ & $\mathrm{x}$ & & & \\
\hline Arreola & & & & & $x$ & \\
\hline Blume/Sinclair & & $\mathrm{x}$ & & & & \\
\hline Biglan & & & & & & $\mathrm{x}$ \\
\hline Blackburn/clark & & & $\mathrm{x}$ & & & \\
\hline Beyer/Stevens & $x$ & & $\mathrm{x}$ & & & \\
\hline Box/Cotgrove & $\mathrm{x}$ & & & & & \\
\hline Brooks & & & & & $\mathrm{x}$ & \\
\hline Buffardi/Nichols & & $\mathrm{x}$ & & & & \\
\hline Crane (1965) & $x$ & $\mathrm{x}$ & $\mathrm{x}$ & & & \\
\hline Cole/Cole (1967) & $\mathrm{x}$ & $\mathrm{x}$ & $\mathrm{x}$ & & & \\
\hline Creswell/Bean & $\mathrm{x}$ & & & & & \\
\hline Clark & & & & & & $x$ \\
\hline Cole/Cole(1971) & & $\mathrm{x}$ & & & & \\
\hline Cole/Cole (1981) & & & $\mathrm{x}$ & & & \\
\hline Crane (1967) & $\mathrm{x}$ & & & & & \\
\hline Elton/Rose & & & $\mathrm{x}$ & & & \\
\hline Fulton/Trow & $\mathrm{x}$ & & & $\mathrm{x}$ & & \\
\hline Fox & $\mathrm{x}$ & & & & & $\mathrm{x}$ \\
\hline Ferber & $\mathrm{x}$ & & & $\mathrm{x}$ & & \\
\hline Gaston & $\mathrm{x}$ & & $\mathrm{x}$ & & & \\
\hline Gottfredson & $\mathrm{x}$ & $\mathrm{x}$ & $\mathrm{x}$ & & & \\
\hline Gunn & & & & & $\mathrm{x}$ & $\mathrm{x}$ \\
\hline Gaston/lantz/Snyder & $\mathrm{x}$ & & & & & \\
\hline Gray & & $\mathrm{x}$ & & & & \\
\hline Hancock & $\mathrm{x}$ & & & & & \\
\hline Hickson/Stacks/Amsbary & $\mathrm{x}$ & & & & & \\
\hline Jauch/Glueck & $\mathrm{x}$ & $\mathrm{x}$ & $\mathrm{x}$ & & & $\mathrm{x}$ \\
\hline Katz & $\mathrm{x}$ & $\mathrm{x}$ & $\mathrm{x}$ & $\mathrm{x}$ & & \\
\hline King/Wolfe & $\mathrm{x}$ & $\mathrm{x}$ & $\mathrm{x}$ & & & $\mathrm{x}$ \\
\hline Kroc & & $\mathrm{x}$ & & & & \\
\hline Laband (1986) & $x$ & $\mathrm{x}$ & & & & \\
\hline Laband/Sophocleus & & $\mathrm{x}$ & & & & \\
\hline Long/McGinnis & $\mathrm{x}$ & $\mathrm{x}$ & $\mathrm{x}$ & & & $\mathrm{x}$ \\
\hline Levin/Stephan & $\mathrm{x}$ & & & & & \\
\hline Laband & $\mathrm{x}$ & & & & & \\
\hline Lodahl/Gordon & $\mathrm{x}$ & & $\mathrm{x}$ & & & $\mathrm{x}$ \\
\hline Long/Allison/McGinnis & $\mathrm{x}$ & $\mathrm{x}$ & $\mathrm{x}$ & & & \\
\hline Lehman & $\mathrm{x}$ & & & & & \\
\hline Lightfield & $\mathrm{x}$ & $\mathrm{x}$ & $\mathrm{x}$ & & & \\
\hline Manis & $\mathrm{x}$ & & & & & \\
\hline Margolis & & $\mathrm{x}$ & & & & \\
\hline Meltzer/Salter & $\mathrm{x}$ & & & & & \\
\hline Meltzer & $\mathrm{x}$ & & & & & \\
\hline Morgan/Meier & $\mathrm{x}$ & & $\mathrm{x}$ & & & \\
\hline Muffo/Mead/Bayer & $\mathrm{x}$ & & & & & \\
\hline Roskens & & & & $\mathrm{x}$ & & $\mathrm{x}$ \\
\hline Rotton & $\mathrm{x}$ & & & & & $\mathrm{x}$ \\
\hline
\end{tabular}


Table 1 (continued)

$$
\begin{array}{llll}
\text { pubs citation } & \begin{array}{l}
\text { peer/ eval/ formula } \\
\text { salary }
\end{array} & \begin{array}{l}
\text { general/ } \\
\text { prestige }
\end{array} & \text { other }
\end{array}
$$

\begin{tabular}{|c|c|c|c|c|c|}
\hline Roche/Smith & $\mathrm{x}$ & $\mathrm{x}$ & $\mathrm{x}$ & & \\
\hline Ruston/Roediger & & $\mathrm{x}$ & & & \\
\hline Smart/McLaughlin & & & & $\mathrm{x}$ & \\
\hline Smith/Fiedler & & & & & $\mathrm{x}$ \\
\hline Saaty & & & & $\mathrm{x}$ & \\
\hline Stigler/Friedland & & $\mathrm{x}$ & & & \\
\hline Tollison/Goff & & $\mathrm{x}$ & & & \\
\hline Tuckman/Hagemann & & & & $\mathrm{x}$ & \\
\hline White/White & & $\mathrm{x}$ & & & \\
\hline Whitman/Weiss & & & & & $\mathrm{x}$ \\
\hline Zivney/Bertin & $\mathrm{x}$ & & & & \\
\hline Zamarippa & & & & & $\mathrm{x}$ \\
\hline Zuckerman & & & & & $\mathrm{x}$ \\
\hline
\end{tabular}

\section{Table 2: Studies Categorized by Discipline}

Hard Science

Anderson et al. (1978)

Beyer and Stevens* (1977)

Blume and Sinclair (1973)

Cole and Cole (1971)

Crane $(1965,1967)$

Cropley and Field (1969)

Gaston (1970)

Jauch and Glueck (1975)

Jones and Froom (1994)

Levin and Stephan (1991)

Long and McGinnis (1981)

Long et al. (1979)

Margolis (1967)

Meltzer and Salter (1962)

Meltzer (1956, 1962)

Merton (1968)

Muffo* (1987)

Parmerter and Garber (1971)

Roche and Smith* (1978)

Rotton* (1990)

Smart and McLaughlin* (1978)

Smart and Elton* (1975)

Smith and Fiedler* (1971)

Tollison and Goff* (1986)

Zamarripa (1995, 1993)

Zuckerman (1970, 1971)
Social Sciences

Beyer and Stevens* (1977)

Cartter (1977)

Gilley (1986)

Gottfredson (1978)

Hickson et al. (1992)

Laband (1986a, 1986b)

Lightfield (1971)

Lodahl and Beyer

Lodahl and Gordon (1973)

Tuckman and Hagemann (1976)

King and Wolfe* (1987)

Kroc (1984)

Morgan (1981)

Muffo* (1987)

Ruston and Roediger (1978)

Roche and Smith* (1978)

Rotton* (1990)

Smart and McLaughlin* (1978)

Smith and Fiedler* (1971)

Smart and Elton* (1975)

Stigler and Friedland (1975)

Tollison and Goff* (1986)

White and White (1977)

Zivne;y and Bertin (1992)
Humanities

King and Wolfe* (1987)

Larson (1993)

Muffo* (1987)

Roche and Smith* (1978)

Rotton* (1990)

Smart and McLaughlin* (1978)

Smith and Fiedler* (1971)

Smart and Elton* (1975)

*appears in more than one column 
most important factor. But citation rates and peer or salary prestige measures have both come in for their share of concern. Cartter [1977] ranked the top ten schools in business, law and education on the basis of faculty ratings. Some authors singled out one discipline for study (such as economics, or physics, or even in one case a study of "productive women" in communication studies). The striking facet of all these studies, however, is the attempt to measure in some way. This effort thus becomes quantitative, which intuitively runs contrary to the idea that "worth" and "quality" are qualitative features that defy totally objective numeric measurement.

Only four of the studies in the literature discussed the desirability of establishing a formula whereby "research productivity" can be numerically calculated. These four studies, however, do not question the validity of a mathematical formula for evaluation-they are proponents of such a scheme. Arreola [1979] states that each faculty member decides what criteria he or she will be evaluated on and the percentage weight applied to each role; he then suggests a method of turning these ratings into an algorithm for mathematically computing raises. Saaty [1983] developed a mathematical technique, called analytic hierarchy process, for comparing faculty. This method is a pairwise, stepped, hierarchical process that "can reduce qualitative comparisons to numeric indices." Brooks [1980] echoes the others in suggesting that the ultimate goal is to get values out front and have a consistent method of arriving at rewards and shaping collective goals. Gunn [1982] goes one step further and says that faculty should evaluate their superiors. His system includes peer evaluation, self-assessment, administrative appraisal, arbitration and a yearly mo- 
rale survey (he does not say whether this morale survey should be anonymous)!

Unfortunately, none of these studies have attempted to examine the relationships between department and institution with respect to structure, goals and operation. Lodahl and Gordon [1972] explored differences among disciplines using Kuhn's concept of a paradigm, thus prefiguring Anthony Biglan's work on characteristics of disciplines.

In his study of disciplinary differences at a large midwestern university and a small northwestern college, Biglan [1973A] examined the structure, goals and operations of the various disciplines but touched in only a cursory fashion the relationships to those same factors at the level of the enterprise. By examining what are most "important" characteristics and how each discipline perceived or thought of itself, he derived an eight-cell classification of 35 disciplines based on whether the field is hard or soft, life or nonlife and then further subdivided those four classifications into pure and applied. A few limited studies [Roskens, 1983; Smart and Elton, 1975; Smart and McLaughlin, 1978)] at other institutions strongly supported Biglan's model at both functional and philosophical levels.

Biglan's two seminal studies concentrated on deriving disciplinary characteristics (beginning with the assumption that two primary dimensions are at work-whether a discipline is paradigmatic or not and whether the discipline is concerned with practical application or not). $\mathrm{He}$ paid no attention to how those characteristics might influence or be influenced by the institution in which they existed. Let us note that his study involved faculty at a large state institution and a small liberal arts college [Biglan, 1973A]. He also assumed that disciplinary specialization 
is essentially the same as a departmental unit in the institution, an assumption that today we might hold invalid: an English department may have specialists in Victorian literature, the eighteenth century novel, Romantic poetry, medieval literature; a mathematics department may have specialists in topology, differential equations, number theory, analysis, graph theory; a history department may have faculty who specialize in American history, local history, medieval history, European history; a biochemistry department can have specialists in DNA repair, genetics, immune systems (and a separate department of immunology could also exist), cellular function (which could also belong to the anatomy or toxicology department).

Biglan's paper on subject matter characteristics and structure [1973B] examined disciplinary differences with respect to commitment to teaching, research, administration and service in terms of "liking" and the amount of time spent on these activities, along with some other factors [Biglan, 1973B]. He did not look at promotion and tenure, nor did he examine any relationships to the enterprise itself. Zuckerman's 1970 paper on internal stratification of scientific fields is the only paper that comes close to examining this facet of disciplinary organization. She considers how certain factors can, but do not necessarily, lead to success (meaning honors, awards, grants, recognition by peers, citations). She also commented that "expensive science is not necessarily good science" and said that scientists accept the prevailing system and take the prevailing criteria for evaluation as correct.

In his 1981 book, Burton R. Clark noted that work in a "knowledge-bearing system . . . [reduced] to its primordial elements" has two basic divisions: the discipline and the enterprise (institution, in a geo- 
graphic sense), specialty and geography. [Clark, p.28] Departmental organization brings the two together and strengthens both even though specialization affects the coherence of the enterprise and tends to fragment it rather than unify it. [Clark, p. 36] Thus, "analysis and policy need to take seriously the ways in which universities and colleges are internally differentiated around knowledge." Note that, even at the height of research into various aspects of research and its evaluation, Clark found only two studies that attempted to study these "primordial relationships": Judith Adkinson (1979) and Anthony Biglan, whose work I have already discussed. It is Clark's work that informs the research questions for this study.

One paper (Lincoln, 1983) examined the structure of promotion and tenure decisions, suggesting that the two are different types of decisions, have different goals, and should therefore be made by different groups of people within the institution. Promotion decisions, she suggests, are based on merit and are properly made by peers in the department; tenure decisions, on the other hand, are based on "value," affect the institution, and should be made by administrators who are not in the department.

Pittman and Slate [1989] echoed some of Lincoln's concerns, noting that any effective evaluation system must have a solid conceptual base that results from answering basic questions such as the goals of the evaluation and the areas to be evaluated. They recommended using the university mission statement to create specific evaluation goals and construct a skeletal process. [They did not make it clear how they would construct this process from the institution's mission statement.] The authors said that elementary questions of the purpose and limits of 
evaluation and areas of faculty responsibility must underlie faculty evaluation systems and that having a set of defined values at the core of the process can minimize conflicts. Although the authors discussed the entire faculty evaluation process without specific emphasis on research evaluation, they did tie the discipline or department to the institution-by tying the goals and process of the evaluation to the mission statement.

Two studies by Leo Meltzer (1956 and 1962) tied performance and productivity to organizational structure-specifically in terms of supervision or freedom and funding. These papers are concerned with industrial or corporate research, however, and may not have direct application to higher education. The earlier paper showed a clear relationship of funding and freedom from direct supervision to publications, although Meltzer and his co-author were subsequently unable to demonstrate any relationship of research productivity to organization size or effectiveness. They noted, however, that all relationships were of "trivial magnitude" [Meltzer, 1962].

Prodgers (1980) dealt with the topic of standardizing faculty evaluation. Although he was primarily concerned with teaching and the use and development of student evaluation forms, he did say that faculty must be heavily involved in developing evaluative criteria and processes and that administrative support for systematic change is essential for its success.

A number of researchers compared various measures of "productivity," "efficiency," and "reputation." Productivity for most means papers published-normatively in peer-reviewed journals. This criterion in most studies correlated well with other measures such as awards, citations, 
grant funds (in engineering, biomedical fields, and the hard sciences), and number of PhDs produced. However, results are not consistent, and in one notable study, Roche and Smith [1978] found moderate correlation between citation rankings and peer and productivity rankings. In a study of reputation and productivity in public administration and public affairs programs, the authors [Morgan and Meier, 1974] found only a fair (70 percent) correlation; but more importantly, they found that those in a region tended to rank schools in that region higher. Although correlations in all measures were generally fair to good, even if not highly statistically significant, several authors [notably Smith and Fiedler, 1971] discussed the problems inherent in each and recommended that no one measure be used in isolation.

Since publication is universally considered one measure of productivity, success, research prowess, creativity and scholarship, one paper by Zuckerman and Merton [1971] manages to cover the topic thoroughly from an historic perspective. The authors also examined rejection rates and concluded that, since rejection rates are much higher in the humanities, they reflect the state of consensus in the discipline-namely, that there is little consensus. Also, notably, they found that referees [of one physics journal] showed no preferential pattern of rejection and acceptance of papers submitted by authors with different reputational rankings, which would seem to indicate that concern for the advancement of the discipline is of paramount importance.

A limited volume of literature is available that deals explicitly with tenure and promotion per se-the structures and processes associated with the decision to promote or not to promote. Creswell examined the criteria used for evaluating faculty for promotion and tenure, noting in 
particular that institutional attitudes are especially important as universities seek "world class" faculty. He did note that different institutions approach research and scholarship differently. He also discussed evaluating research performance and reviewing that performance at different levels and indicated the importance of considering "the process for ordering importance and the criteria on which to base the ordering," [Creswell, 1986, p. 95].

Seldin has produced two volumes dealing with the evaluation of research, but he looked at criteria rather than the relationships that exist between department and enterprise. Seldin was more interested in the tools than in the underlying culture and philosophies and did not deal with the relationships between institution and discipline.

Centra [1977] also examined the evaluation of faculty research performance, but again more from the perspective of tools, specific criteria, changing trends in the use of certain information and, in some small sense, disciplinary differences. This is the one study that discussed how the evaluation of research depends on the "the type of department and the level of the institution" [Centra, p. 1].

We see from the above discussion that the literature dealing with issues and the conceptual basis of promotion and tenure is seriously limited. The literature dealing with the relationship of the discipline and department to the encompassing institution in faculty evaluation issues is equally limited. Whereas, as we have already seen, many researchers have conducted studies on the particulars of various evaluation criteria and their relative merits, few have devoted attention to the influence of the institution on the department (or the influence of the department on 
the institution) with respect to the goals, structure and operation of the evaluation of research.

Burton R. Clark's 1983 book, The Higher Education System, calls attention to this gap in the research about higher education. He noted that most writers have concentrated on enterprises and their students, although others have focused on disciplines, the academic profession, the "academic man," and some "small effort has been made to study the national academic associations . .." [Clark, p. 32]. He said further that "analysis and policy need to take seriously the ways in which universities and colleges are internally differentiated around knowledge" [Clark, p. 41]. Although Biglan studied disciplinary differences, Clark evidently is of the opinion that those studies are not taken seriously enough. He also discussed the six "legitimate" authority structures found in higher education (the personal, collegial, guild, and professional being "rooted in the discipline," and the trustee and institutional bureaucracy "belonging to the enterprise." Where do these authority structures meet and how?

David D. Dill [1986] picked up these threads and examined the effects of culture and context on research performance. He noted that three main processes are at work: (1) recruitment — selecting those with a proven commitment to research; (2) communication-support of colleagues within and without the local enterprise; and (3) leadership and structure-leaders and administrators must have values and knowledge and a "competence and commitment to research" in places where research performance is expected.

Daniel Alpert, also in 1986, used Clark's matrix concept to reexamine the university and department relationship at a structural level. 
He noted that faculty often have closer relationships with colleagues in their own fields at other universities than with members of other units on their local campus. He also commented that, where interdisciplinary efforts are involved, the university depends on individual faculty "rather than organizational structure or administrative leadership" [Alpert, p. 90]. He clearly had difficulty placing what he called "interdisciplinary mission organizations" into the matrix model. Alpert also remarked that the evaluation of research, as it is done today, imposes a conformity of values and calls for "new maps of the future university" [Alpert, p. 99]. He suggested that this new map might be a construct of "informal networks" that transcend the governance structure of the institution and the disciplinary or professional communities.

The research reported in the next chapters will attempt to develop some insight into these issues and concepts. In particular, I hope to show how the enterprise and the discipline interact and, in so doing, develop some insights on enhancing the research culture at self-styled research universities. 


\section{Chapter III}

\section{Methodology}

This study is a two-part project which began in the fall of 1995 with a content analysis of the promotion and tenure sections of faculty handbooks from 31 state, land-grant institutions. This analysis reveals that state land-grant universities could be reasonably divided into three governance groups according to how committees and administrators are involved in promotion and tenure decisions. These categories are the bureaucratic, shared governance, and collegial authority structures as defined in Chapter I. This content analysis was used to derive the prospective interviewee enterprises, selecting one as representative of each type of authority structure.

The second part of the study involved interviews with the chair and chair of the personnel or promotion and tenure committee in each of four departments at each of the three selected enterprises. These departments represent four of Biglan's eight disciplinary categories (omitting the four life-nonlife categories). A table of departments to be interviewed was developed according to Biglan's typology: English (basic, soft), psychology

Table 3: Biglan's Disciplinary Categories-An Example

\begin{tabular}{|c|c|c|c|c|}
\hline & \multicolumn{2}{|c|}{ Hard } & \multicolumn{2}{|c|}{ Soft } \\
\hline & Life & Nonlife & Life & Nonlife \\
\hline Basic & Biology & Chemistry & Sociology & English \\
\hline Applied & Plant Science & Engineering & Education & Economics \\
\hline
\end{tabular}


(applied, soft), mechanical engineering (applied, hard) and chemistry (basic, hard). Table 3 illustrates these categories.

The top administrator charged with the oversight of faculty personnel matters and the top academic administrator (chancellor, provost or vice president) were also interviewed. A set of six to eight questions was developed for each category of person to be interviewed-chair, committee chair or upper administration. The chosen universities were then contacted by an initial letter to the chief academic officer, asking permission to interview on that campus.

Beginning in the fall of 1996, I sent e-mail or made telephone calls to set up appointment times for telephone interviews and, over a period of almost a year, interviewed four department chairs, two P\&T committee chairs, the associate provost and provost at the bureaucratic university (which we shall call Bureaucratic University); four department chairs, one P\&T committee chair and the provost and associate provost and the shared governance university (here called Shared-Governance University or S-G U.); and finally three chairs, the associate provost and the chair of the university personnel committee at the collegial university (called Collegial University). P\&T committee chairs as a group were not available because of a policy of confidentiality at Collegial U. Table 4 shows the respondents from each enterprise.

The questions were slightly different depending on the position of the person being interviewed (see Appendix A). As usual with open-ended questions and interviews of this nature, some respondents answered fully but did not precisely direct their answers to the question. Some tried responding with one-word answers. Some went into lengthy explanations that were not particularly germane. One noticeable tendency was 


\section{Table 4: Interviews Conducted}

Department/

Position

\section{English}

Chair

P\&T Committee

Chemistry

Chair

P\&T Committee

Psychology

Chair

P\&T committee

\section{Engineering}

Chair

P\&T Committee

Chief Academic Officer*

Associate Provost

University Committee

\section{Institution}

Bureaucratic U S-G U Collegial U

$\begin{array}{lll}X & X & X \\ X & - & -\end{array}$

$\begin{array}{lll}X & X & 0 \\ - & 0 & -\end{array}$

X $\quad$ X

$\begin{array}{lll}- & - & -\end{array}$

X $\quad X \quad X$

$\mathrm{X} \quad \mathrm{X}-$

$\mathrm{X} \quad \mathrm{X} \quad \mathrm{O}$

X $\quad X \quad X$

$\mathrm{X}$

*The position includes the following titles: provost, chancellor, vice chancellor, chief academic officer, and vice president. I have used here the term I found most common among all institutions originally surveyed.

$\mathrm{X}$ interviewed

- no such position in this department or no incumbent at this time

0 failed contact or incumbent declined to be interviewed 
Table 5: Relationships to Be Investigated

Discipline

\begin{tabular}{l|c|c|c|} 
Institution & Structure & Goals & Operations \\
\hline Structure & 1 & 2 & 3 \\
\hline Goals & 4 & 5 & 6 \\
\hline Operation & 7 & 8 & 9 \\
\hline
\end{tabular}

the desire to discuss teaching and its evaluation instead of a perceived relationship (or lack of one) of research to teaching and their relative weight in the promotion and tenure process. A question to ask in a future study might try to tease out whether this tendency is a result of solid concerns about the function of the academy or a result of "student centered" attitudes and articles critical of the quality of undergraduate instruction in research universities as well as critical of the research itself. Is there a solid appreciation of the fact that the academy, to exist at all, must have both students and professors? And there probably is not an appreciation that faculty-student conflict is as old as the concept of a university [see Morison, Three Centuries...].

Following the guidelines of the Institutional Review Board for the Protection of Human Subjects, each respondent was assured that his or her answers would be strictly confidential and that there would be no identifiers or any other way for either them or their institution to be identified. Each interview was taped and transcribed, except for one interview for which the tape did not function properly so that handwritten notes had to be relied on.

After each interview was transcribed, it was coded using the method recommended in Berg [1989]. Each coded interview was then cut 
according to the coding phrases and taped onto $3 \times 5$ cards (see Appendix B for a complete list of the terms, not all of which proved germane to this study). After an initial arrangement of cards into sections, some topics were collapsed to yield the final groupings used (see Appendix C) and some were eliminated. This part of the research was completed in the early spring of 1998. 


\section{Chapter IV}

\section{Discussion and Analysis}

\section{Preliminary Statistical Analysis}

Prior to beginning any analysis of faculty handbooks, data was collected on all state, land-grant universities with Carnegie classifications of Research I or Research II. With the assistance of Magdalena Bugaj, we attempted to determine if there was any relationship between demographic information about the institution (such as the geographic region, size of surrounding community, size of student body, ratio of faculty to students, books in library, external funding, ratio of graduate to undergraduate students and the number of upper administrators) and its formal authority structure as deduced from the content analysis of faculty handbooks. There was no correlation. Admitting that the total sample size of 31 is very small (and only 25 for Research I universities), we were unable to find any relationship. Then we analyzed these same factors with respect to whether the institution is bureaucratic, sharedgovernance or collegial according to a content analysis of faculty handbooks (see below). Again there was no correlation. Even after adjusting for the extremely small cell size (there are only three universities that can be classified in the collegial category and four in the bureaucratic category). See Appendix E for selected tables. 
Table 4: Graphic Representation of Analysis of Faculty Handbooks

\begin{tabular}{|c|c|c|c|c|c|c|c|c|c|}
\hline \multirow[b]{2}{*}{ University } & \multicolumn{5}{|c|}{ Document Flow } & \multicolumn{4}{|c|}{ Criteria } \\
\hline & 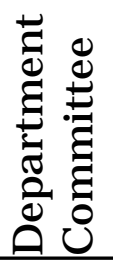 & 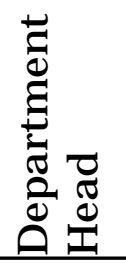 & 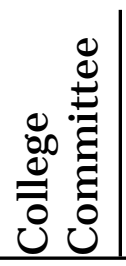 & 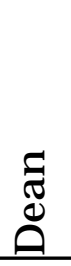 & 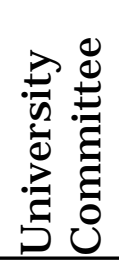 & 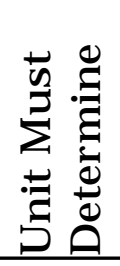 & 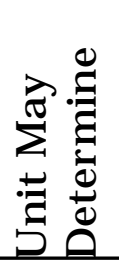 & 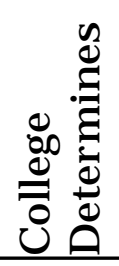 & 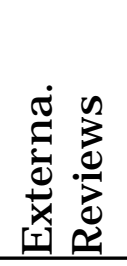 \\
\hline$\# 1$ & $\mathrm{x}$ & & & & $\mathrm{x}$ & $\mathrm{x}$ & & & $\mathrm{x}$ \\
\hline$\# 2$ & $\mathrm{x}$ & & $\mathrm{x}$ & & & & & & $\mathrm{x}$ \\
\hline \#3 & $\mathrm{x}$ & $\mathrm{x}$ & & $\mathrm{x}$ & & $\mathrm{x}$ & & & opt. \\
\hline$\# 4$ & $\mathrm{x}$ & & $\mathrm{x}$ & $\mathrm{x}$ & $\mathrm{x}$ & & & & $3+$ \\
\hline \#5 & $\mathrm{x}$ & $\mathrm{x}$ & $\mathrm{x}$ & $\mathrm{x}$ & $\mathrm{x}$ & & & & 2 \\
\hline \#6 & $\mathrm{x}$ & & $\mathrm{x}$ & $\mathrm{x}$ & & & & & $3-5$ \\
\hline \#7 & $\mathrm{x}$ & $\mathrm{x}$ & & $\mathrm{x}$ & $\mathrm{x}$ & & $\mathrm{x}$ & & 3 \\
\hline$\# 8$ & $\mathrm{x}$ & $\mathrm{x}$ & $\mathrm{x}$ & $\mathrm{x}$ & & & $\mathrm{x}$ & & $\mathrm{x}$ \\
\hline$\# 9$ & & $\mathrm{x}$ & & $\mathrm{x}$ & & & & & \\
\hline \#10 & $\mathrm{x}$ & $\mathrm{x}$ & & $\mathrm{x}$ & & & $\mathrm{x}$ & & $\mathrm{x}$ \\
\hline \#11 & $\mathrm{x}$ & $\mathrm{x}$ & $\mathrm{x}$ & $\mathrm{x}$ & $\mathrm{x}$ & $\mathrm{x}$ & & & 4 \\
\hline \#12 & $\mathrm{x}$ & $\mathrm{x}$ & $\mathrm{x}$ & $\mathrm{x}$ & & & & & \\
\hline$\# 13$ & & $\mathrm{x}$ & & $\mathrm{x}$ & & $\mathrm{x}$ & & & \\
\hline \#14 & $\mathrm{x}$ & $\mathrm{x}$ & & $\mathrm{x}$ & & $\mathrm{x}$ & & & $\mathrm{x}$ \\
\hline \#15 & $x$ & $x$ & $\mathrm{x}$ & & & $\mathrm{x}$ & & & opt. \\
\hline \#16 & $x$ & $x$ & $x$ & $\mathrm{x}$ & $\mathrm{x}$ & & & $x$ & 3 \\
\hline \# 17 & & $x$ & & $\mathrm{x}$ & & $\mathrm{x}$ & & & \\
\hline \#18 & $x$ & $x$ & $x$ & $\mathrm{x}$ & $x$ & $x$ & & & $5-6$ \\
\hline \#19 & $x$ & $x$ & $x$ & $\mathrm{x}$ & $x$ & & $\mathrm{x}$ & & \\
\hline$\# 20$ & $\mathrm{x}$ & $\mathrm{x}$ & $x$ & $\mathrm{x}$ & $\mathrm{x}$ & & $\mathrm{x}$ & & \\
\hline$\# 21$ & $x$ & $x$ & $x$ & $\mathrm{x}$ & & & $\mathrm{x}$ & & $3+$ \\
\hline \#22 & $x$ & $\mathrm{x}$ & $\mathrm{x}$ & $\mathrm{x}$ & & & & $\mathrm{x}$ & $\mathrm{x}$ \\
\hline$\# 23$ & $x$ & $\mathrm{x}$ & $\mathrm{x}$ & & & & & & 4 \\
\hline$\# 24$ & $x$ & $x$ & $x$ & $\mathrm{x}$ & $x$ & & & & $x$ \\
\hline$\# 25$ & $\mathrm{x}$ & $\mathrm{x}$ & & $\mathrm{x}$ & $\mathrm{x}$ & & $x$ & & 3 \\
\hline$\# 26$ & $x$ & $x$ & $x$ & $\mathrm{x}$ & $x$ & & $\mathrm{x}$ & & $x$ \\
\hline$\# 27$ & $x$ & $x$ & $x$ & $\mathrm{x}$ & $\mathrm{x}$ & $\mathrm{x}$ & & & $x$ \\
\hline \#28 & $x$ & & $x$ & & $x$ & $x$ & & & \\
\hline$\# 29$ & $x$ & $x$ & $x$ & & $x$ & $x$ & & & opt. \\
\hline \#30 & $\mathrm{x}$ & $\mathrm{x}$ & & $\mathrm{x}$ & & $\mathrm{x}$ & & & $\mathrm{x}$ \\
\hline
\end{tabular}




\section{Faculty Handbooks}

Every university has some statement about promotion and tenure policies and criteria in its faculty handbook. A content analysis of these documents formed the first phase of this study. But before commencing a discussion and analysis of the interviews with departmental and institutional personnel, we should briefly examine the guidelines and criteria for promotion and tenure provided in the handbooks of the three enterprises under consideration here.

\section{Bureaucratic $U$}

The faculty handbook at Bureaucratic U indicates that chairs and deans make recommendations on promotion and tenure to the university level official. But at the same time, elements of the shared-governance structure are clearly evident in that all major decisions on structure, procedure and specific criteria for the promotion and tenure process are the purview of the department or unit.

Although "each academic unit is charged to establish procedures so that its faculty can provide advice to the academic administrator regarding recommendations for various academic personnel actions," the enterprise has developed "a comprehensive form" for reporting various activities and accomplishments of the candidate. Institutional guidelines do not specify a structure, process or criteria for promotion or tenure, stating simply that "faculty members have a responsibility to conduct research and engage in creative activity in their area(s) or appointment and professional competence."

Dossiers are reviewed in the department, and "each academic unit is charged to establish procedures so that its faculty can provide advice to the academic administrator regarding recommendations for various 
academic personnel actions." Each department is required to have "procedures and criteria that are clearly formulated and relevant on which to evaluate the performance of faculty members." Additionally, chairs are "responsible as an individual for the recommendations made."

Deans review departmental recommendations and may, but are not required to, establish an advisory committee for promotion and tenure actions. Of particular interest is the statement that external peer reviews are encouraged but not required.

The office of the provost reviews all recommendations for promotion and tenure "primarily in terms of the evidence for the effectiveness of each individual in the performance of academic duties." The provost considers the following factors (quoted from the faculty handbook):

* "In each case, solid evidence of consistent and persistent professional improvement and effectiveness . . . sufficient to serve as a basis for predicting continued professional effectiveness and growth for the remainder of the individual's academic career.

* Evidence of actual and/or potential external competition for employment in the Big Ten or institutions of at least comparable quality.

* The history of salary increases awarded the individual relative to others in the unit.

* Evidence of having met the standards of the college and department/school for recommendation of appointment, reappointment, award of tenure, and promotion."

The provost will also consider "progress of the unit toward achievng and maintaining diversity and recognition of diversity in the unit's definition of quality."

\section{Shared-Governance $U$}

Shared-Governance $U$ had, at the time of these interviews, just revised its promotion and tenure guidelines. The striking difference between the old guidelines and the new ones are the absence of any men- 
tion of unit guidelines that may supplement those of the enterprise. The following are statements from the 1995 promotion and tenure guidelines:

* "Candidates for promotion and tenure will be evaluated objectively for evidence of excellence in the performance of assigned duties, in their scholarship or creative activity, and in their professional service.

* "The responsibilities of individual faculty in relation to these fundamental commitments will vary and will be specified in position descriptions developed at the time of initial appointment and revised periodcally, as necessary.

* “. . . [A]ll faculty are expected to be collegial members of their units ...

* "Scholarship and creative activity are understood to be intellectual work whose significance is validated by peers and which is communicated. . . . [S] uch work in its diverse forms is based on a high level of professional expertise; must give evidence of originality; must be documented and validated as through peer review or critique; and must be communicated in appropriate ways so as to have impact on or significance for publics beyond the University, or for the discipline itself."

The guidelines state that faculty involved in joint efforts should clarify their role in that effort and also that the successful application for grants is evidence of "achievement in scholarship."

The new guidelines document outlines procedural guidelines, which include the statement that "the process for earning promotion and tenure begins at the moment of hiring." The candidate's supervisor and "a promotion and tenure review committee formed from among the tenured faculty within the unit (at or above the rank for which the candidate is being considered) will independently evaluate the materials in the dossier, and will recommend either for or against the candidate's promotion or tenure." Of particular interest may be the state board of higher education requirement that "students will be invited to participate in the review of faculty for promotion and tenure" in matters related to teaching. The next step is the college review, the procedures for which are established in each college. "A letter of evaluation from the dean, and 
from the review committee in colleges where one is established for this purpose, are added to the dossier as it is forwarded for review at the University level." At the university level, the Associate Provost for Academic Affairs reviews each dossier, who may confer with others. Dossiers with mixed reviews will be reviewed by "the University Administrative Promotion and Tenure Committee, which is chaired by the Provost and Executive Vice President and consists of the Associate Provost for Academic Affairs, the Vice Provost for Research and International Programs, the Dean of Extended Education, and the Dean of the Graduate School .... The purpose of the University review is to ensure that all faculty are held to common standards, and to resolve disagreements in previous recommendations."

Thus, we see that a promotion and tenure committee is required at the unit or departmental level, although its structure is not specified. The dean reviews the dossier with the advice of a college promotion and tenure committee. The university level committee, surprisingly, is made up entirely of individuals holding administrative positions. The primary requirements for promotion and tenure are the "communication and validation" of scholarly or creative work, meeting the job expectations outlined in the position description, and collegiality.

\section{Collegial U}

At Collegial U, the faculty handbook defines titles and includes numerous policies concerned with tenure and promotion, but few are germaine to this study. The handbook says only that review committees are responsible for maintaining the "quality of the faculty of [Collegial U]" by ascertaining "the present fitness of each candidate and the likelihood 
of the candidate's pursuing a productive career." Of particular note, this paragraph on the responsibilities of the review committees says that "it is appropriate to consider professional integrity as evidenced by performance of duties." These review committees are nominees of the institutional personnel committee and make their reports to that body which, by policy, is composed of faculty and is responsible for "making an unequivocal recommendation." Thus, the committees discussed in this document are subcommittees of the university-level committee and not departmental or college committees.

The faculty handbook leaves the structure and procedures at the department level entirely up to the department, requiring only that the chair's recommendation include documentation of the department's assessment of a candidate. Supporting documentation for the institutional review committees comes from the department chair whose comments should include "comprehensive assessment of the candidate's qualifications together with detailed evidence to support this evaluation." This letter also should include a "report of the department chair's consultation with the members of the department." The chair normally also provides complete biographies, bibliographies, and opinions from colleagues. "Extramural opinions are imperative in cases of proposed appointments to tenure status of persons from outside the university." Opinions of external peers thus seem not to be essential in any other case of promotion or tenure.

There is no mention of departmental committees-only that the chair has consulted with departmental faculty. Neither is there mention of the involvement of the dean or college committee in the process. However, in a flow chart appended to documentation received from the insti- 
tutional review committee, the documentation flow, which appears in Appendix D, includes the dean and college level review committee. Since this flow chart is not indicated in the faculty handbook, which is a policy document for all campuses of the university system, we can only conclude that the document flow chart is an enterprise-level procedure. This committee has also provided a guide for the "advancement and promotion of junior faculty" that serves as a supplement to the faculty handbook.

The handbook of Collegial U, like the others, seeks to maintain the high quality of its faculty. However, it includes some statements (such as the one we have already seen on professional ethics) that are not found in the handbooks of the other institutions in this study:

(1) "Account should be taken of the type and quality of creative activity normally expected in the candidate's field.

(2) Due consideration should be given to variations among fields and specialities and to new genres and fields of inquiry.

(3) Textbooks, reports, circulars, and similar publications normally are considered evidence of teaching ability or public service.

(4) . . .contributions by faculty members to the professional literature or to the advancement of professional practice or professional education should be judged creative work when they present new ideas or original scholarly research."

\section{Mission Statements}

\section{Bureaucratic U}

“. . . holds a unique position in the state's educational system. As a respected research and teaching university, it is committed to intellectual leadership and to excellence in both developing new knowledge and conveying that knowledge to its students and to the public. And as a pioneer land-grant institution, . . . strives to discover practical uses for theoretical knowledge and to speed the diffusion of information to residents of the state, the nation, and the world. In fostering both research 
and its application, this university will continue to be a catalyst for positive intellectual, social, and technological change.

"At . . . excellence is a continuing tradition. . . . is a research intensive, land-grant university where people matter. The University is dedicated to educating tomorrow's leaders and scholars. Innovative and hard-working, ... . creates knowledge and extends learning to actively serve [the state], the nation, and the international community."

In addition, the university promulgates five goal statements:

* Academically outstanding, nationally and globally; preparing tomorrow's scholars and leaders

* A vital resource in creating and applying knowledge to help address the critical problems of the 21 st century; improving economic competitivenss and the quality of life for [the state], the nation, and the world

* A university preferred by students who are diverse, talented, and eager to learn

* One of the most effectively administered, people-oriented institutions in the United States

* Coherent and focused on strengths that create a distinctive and enduring character to assure [the university's] future

To attain these goals, the university has developed a set of "guiding principles":

* Improve access to quality education and expert knowledge

* Achieve more active learning

* Generate new knowledge and scholarship across the mission

* Promote problem solving to address society's needs

* Advance diversity within community

* Make people matter

\section{Shared-Governance U}

“. . . serves the people of . .., the nation and the world through education, research, and service."

"... extends its programs throughout the world, and is committed to providing access and educational opportunities to minorities and to disabled and disadvantaged persons.

". . . has an inherent commitment to provide a comprehensive array of high-quality educational programs in the sciences, liberal arts, and selected professions. The University encourages students, both on and off campus, to develop an enriched awareness of themselves and their global environment. 
"Through research, ... . extends the frontiers of knowledge in the sciences, liberal arts, and in all aspects of natural, human, and economic resources. . . . contributes to the intellectual development and the economic and technological advancement of humankind.

"As a Land Grant and Sea Grant University, . . . has a special responsibility for education and research enabling the people of . . . and the world to develop and utilize human, land, atmospheric, and oceanic resources. Unique programs of public service throughout [the state] supplement campus-based University teaching and research."

\section{Collegial U}

In 1996 Collegial U revamped its mission statement into a "pledge," which reads as follows:

"The [Collegial U] Pledge is designed to fulfill the university's historic promise to maintain diversity while preserving excellence and to provide the best education to all of the state's diverse student populations particularly those whose opportunities are limited because they are financially or educationally disadvantaged.

The [Collegial U] Pledge has five goals:

1. to help strengthen the K-12 schools

2. to enhance campus recruitment efforts through a new campus Recruitment Corps

3. to keep [Collegial U] affordable for all students

4. to enhance campus academic support services for ... . undergraduate and graduate students and,

5. to provide an environment that encourages promising undergraduates to pursue graduate and professional studies."

The enterprise has "pledged one million dollars to realize these goals. In December 1996, two other projects were incorporated into the pledge: the [Collegial U] Academy and the Pledge Volunteer Corps.” Expanding on the five points, the enterprise continues its advertising by explaining

"The [Collegial U] Pledge, launched in 1996, is a program committed to sustaining campus diversity by providing equal opportunity and access to all, particularly those students most disadvantaged and underrepresented in higher education in [the state]. The Pledge has five key components: 
* to strengthen [[Collegial U]'s] partnership with K-12 schools, and attempt a new outreach model that can be replicated in the state and nation

* to enhance [Collegial U's] statewide recruitment activities to attract top performing students, especially those from disadvantaged populations

* to increase scholarship support and employment opportunities so that financial barriers do not prevent students from attending [Collegial U]

* to strengthen campus academic support services to sustain high retention and graduation rates

* to encourage undergraduates to pursue graduate study and professional careers"

\section{Discussion and Analysis of Interviews}

The respondents in this study ran the gamut from reticent and essentially uncooperative to overly talkative. The interviews provided some valuable insights to instruct future studies of the relationship between departmental and institutional promotion and tenure objectives, operation, and structure.

General themes of the interviews include

* Concern with "quality," "high standards" and "status" (goals)

* Looking to the institution for criteria referencing but to the discipline outside the institution for judgment of the quality of scholarship to attain goals (operation).

* The subjectivity inherent in the process of judging another faculty member's work, leading to committees to gather information or to evaluate the candidate or both (structure).

Of particular note is the evidence that structure and operation at the departmental level appear to have no essential relationship to the structure and operations of either the institution or the discipline in either the bureaucratic or shared governance institution. In other words, 
each department appears to have arrived at its functional process and departmental structure in a totally random fashion without reference to the enterprise that houses it or to the discipline that informs its basic standards of research endeavor.

\section{Structure}

Every department in the study, and probably every formally constituted department at any institution of higher educaton, has some variety of a committee or group that either reviews or is charged with collecting the credentials of candidates for tenure or promotion. In some cases it is an ad hoc, informally constituted group that collects information for presentation to the department as a whole, to some subset of the department, to the chair, to the dean or to the university; yet other units have a formally elected or appointed committee or subcommittee that reviews (rather than just collects) the candidate's credentials; some elected committees perform as the ad hoc groups and just collect information.

Table 6 provides a preliminary overview of the structure of departmental promotion and tenure committees. This table, even with the little detail possible in such a graphic, shows immediately that structures are quite dissimilar both within the enterprise and across the discipline. Two departments at Shared-Governance U appear to be constructed alike, and all departments at Collegial $U$ appear to be alike, although from the preceding discussion, we know that there are substantive differences. It appears, then, that the authority structure at the enterprise level-bureaucracy, collegium, or shared governance-has little or no discernible bearing on the structure obtained at the department level in the promo- 
tion and tenure process. The departmental promotion and tenure structure will be discussed in greater detail in the following pages. We will see that no pattern exists either within the enterprise or within the discipline at the national level.

Table 6: Departmental Promotion and Tenure Committees at Three Universities

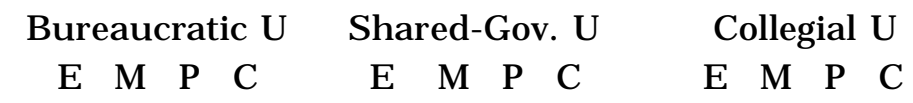

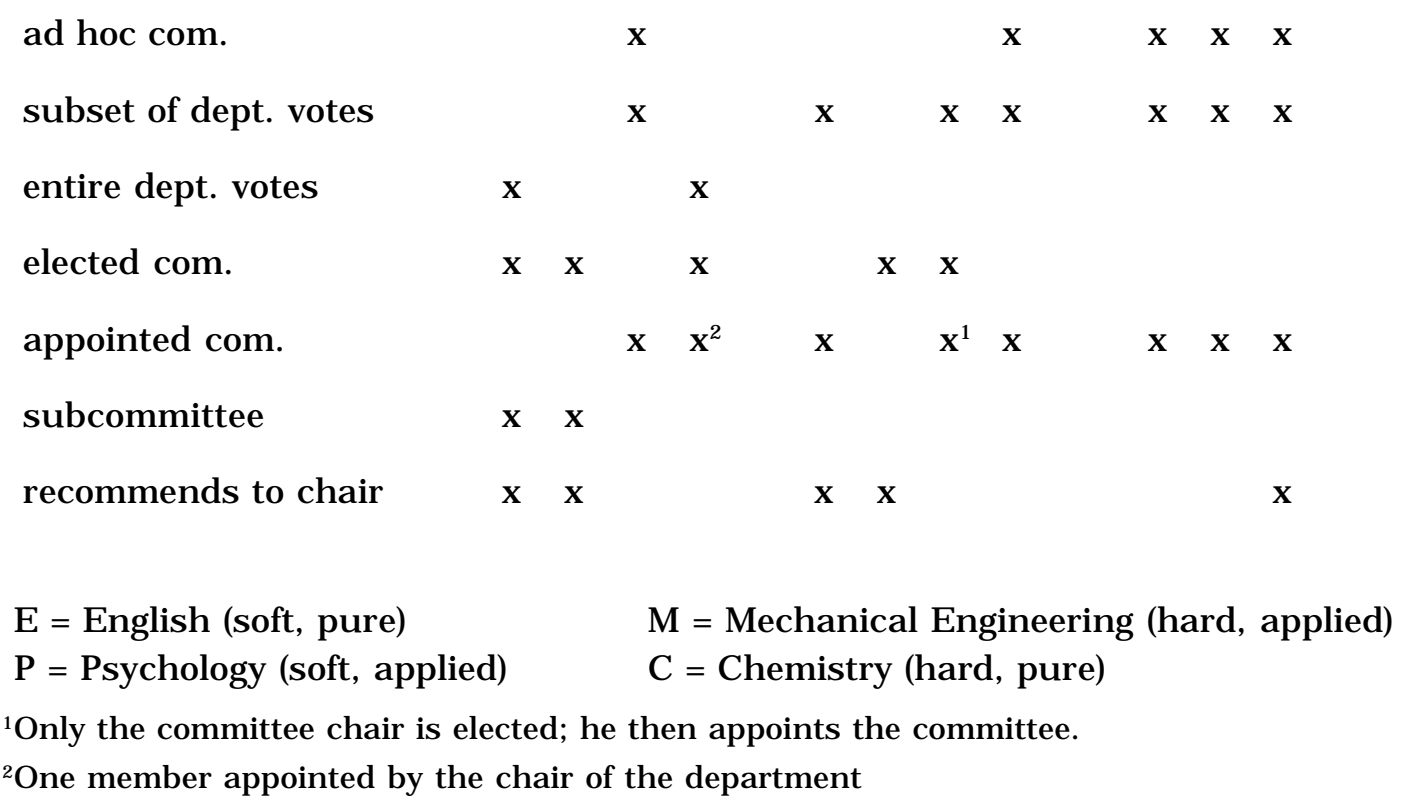

At Bureaucratic U, we find a variety of structures for dealing with promotion and tenure. In engineering, the promotion and tenure committee is departmentally elected, reviews the candidates, writes a report, and passes the "advisory recommendation" on to the department chair. This is much like the English department at Shared-Governance U-except for the fact that the P\&T committee "will take each person to be reviewed carefully and form a three-person subcommittee." These subcommittees 
"must have representation from the promotion committee" - in fact, two members of the subcommittee are from the promotion committee. Additionally, the candidate has the right to replace one member of the subcommittee with a person of his or her choosing. Let us note the fact that the chair said "each person to be reviewed carefully"-we will return to that phrase later. Again, although the P\&T committee is elected by the department as a whole, it forwards its report to the chair without further discussion with the department.

The chemistry department at Bureaucratic U presents yet another structure. Here the P\&T committee is yearly nominated by faculty in each of the primary subfields of chemistry, with a fifth appointed by the department chair to serve as P\&T committee chair. Once constituted, the P\&T committee then polls every faculty member "as to whether they would like to be considered for promotion. That makes contact at the outset between the committee and the person involved and sometimes provides an opportunity for feedback to the individual." The committee does its evaluation and writes a report, which it presents to the entire department in a "full faculty meeting." "There is discussion amongst the faculty, and the faculty then votes on whether to accept or deny the recommendation of the P\&T committee." As the chair said in explanation of this procedure, "A tenure decision I think is regarded in our department as the most important decision that a department makes." This idea found support in his statement "that if a vote is, say, 60 percent in favor and 40 percent against, it is unlikely that that person is going to get tenure." Evidently this department wants strong consensus to award tenure and is similarly concerned with promotion issues. 
As with other departments and other universities, only faculty at or above the rank to which the candidate seeks participate in the evaluation. But unlike some other units, minority and gender representation on the committee are not a concern. However, the chair commented that "The area we try to balance gender roles is in search committees for hiring, but there is no special consideration at the tenure and promotion level."

Communication at each level and at each stage of the process appear to be important in this chemistry department, especially as the chair noted that "[a]t the conclusion of the process, I always sit down with the person involved and review the report of the $[\mathrm{P} \& \mathrm{~T}]$ committee and also give my own views on the progress the person is making." This statement suggests that the chemistry department is using yearly reviews in a constructive manner to help faculty realize their potential and receive the promotions they want.

The psychology department also involves the department in the promotion and tenure decisions, although only those with rank at or above the candidate vote on that candidate. In this department, rather than having a duly appointed or elected P\&T committee, each person up for either action has a "review committee" to help them gather the necessary materials. "That tends to be three or four people. It's four people if there's a critical decision required such as a promotion to associate with tenure or promotion to full."

It is this review committee that appears to be the site of departmental contention at times. This is an "information gathering" group. But, the chair noted that "A problem we've had over the years-and I don't know if it is a problem, perhaps most departments have it-is to 
what extent should that be an evaluative committee or to what extent they should be fact finding, and we go back and forth, frankly. Sometimes they get to the end. . . and become advocates to the point that the rest of the faculty gets a little irritated because they don't think they are getting the really accurate information. And so we go back and forth a little bit. ...If we have conflict, it tends to be in the process that we use. We seem to want to. . .we get tired of a process, and then we want to change it a little bit each year."

Turning to the English department at Bureaucratic U, we find a structure similar to the one in engineering. In English, a "three- or sometimes four-person committee [is] appointed to look specifically at his or her work [the candidate's work], to elicit external evaluations, and so on. That committee, which differs from candidate to candidate, each committee then makes its recommendations about its candidate." These recommendations go to a six-person elected committee called the Policy Committee. One member is always an untenured assistant professor who serves a one-year term, and four members serve two-year staggered terms. This committee then writes a report which it presents to the "voting faculty," which the chair describes as "the faculty in the tenure system. That would be the simplest answer, plus specialists who are appointed in the, let's call it the job security system, which is a category set up for specialists." It is this more "global" group that then votes on the candidate; and, to be sure that everyone gets a chance to vote, the departmental bylaws require a mail ballot.

At Shared-Governance U, we again find a variety of departmental structures. In fact, each department is different. 
The engineering department elects its promotion and tenure committee. As the chair says, "There are four faculty members on it, and two are elected each year for two-year terms. And they have to be . . oh, I don't remember, they have to be associate or full professor, . . . and tenured." This committee makes a recommendation to the department head, who writes his own recommendation and places it in the dossier, which then goes to the college committee. This staggered elective arrangement provides for functional and procedural continuity on the committee. And, since the members are elected by the department as a whole, it is more likely to be representative of departmental attitudes than a committee appointed by the chair (although this is not a certainty).

On the other hand, the chemistry department at Shared-Governance $U$ has no promotion and tenure committee per se. The chemistry chair appoints a subcommittee of three people each year to review a tenure-track candidate's research and teaching. This subcommittee has different people each year so that, in the words of the chair, "as many as fifteen different people look at the candidate and give reports back to the candidate. This means the entire department is plugged into this process. It's just not a few people." The chair noted that "a P\&T subcommittee of three or four people who are always the same people and are always the people who sit in judgment, ... [they] are the gatekeepers.” The subcommittee then writes a report (called a motion) which it discusses with both the chair and the candidate. After all the "amendments" are made to the written report, the report goes to the members of the department who can also make amendments. Once all the amendments have been made to the motion, that statement goes into the candidate's file. The department chair commented that "by the time you have the sub- 
committee chair, and I have talked with the candidate, and the subcommittee chair has talked to the candidate, there usually aren't many mistakes in fact in the situation."

One point that the chair also made was what he termed a "subtle point": the subcommittee is composed of only one person from the person's area and two from outside his or her area. He explained that this prevents the situation in which a "particular group dominates the candidate and can lead to really some hard, rough feelings." So, even though judging a colleague might be a "gut reaction," it is a "gut reaction by the entire promotion and tenure faculty." Additionally, "there's a kind of oral tradition in the department that we should have a 3/4 positive vote before the recommendation can go forward." This implies a desire for departmental consensus for tenuring or promoting a candidate. Only one other department in this study indicated that it sought a particularly high degree of agreement for recommending tenure or promotion (chemistry at Bureaucratic U): “. . . if a vote is, say, 60 percent in favor and 40 percent against, it is unlikely that that person is going to get tenure."

The chemistry chair stated that he is "very concerned about process these days, much more so than I ever was before I became chair. Because I see what happens when the process doesn't work right. The positive aspect of it [the operation in this department] as I see it anyway, having worked with this system, is that the candidate really sees how the whole department feels. Not just how the chair of the department feels. Maybe even how the subcommittee chair, if you just have a P\&T subcommittee that works each year and only maybe at the end, when they come up for review, you've got a real problem at that point because sometimes 
the candidate really didn't realize how some people in the department felt about him or her."

The process just outlined is perhaps the most elaborate of all the P\&T processes described in this study. It appears to be a joint effort among everyone-candidate, subcommittee, department and chair. Moreover, the chair thinks "that the department is happy with it. . . I have never had any complaints about the structure we are using in terms of promotion and tenure."

The English department at Shared-Governance U also has a reasonably convoluted structure. This department has an elected executive committee of eight faculty plus the chair and two students; it ratifies appointments by the chair. The P\&T committee itself has five faculty plus two students serving one-year appointments. This was the only department that reported having students on departmental committees. The chair made a point of it: "Let me add one thing. All of our committees have student representation. . . . We usually have an undergraduate and a graduate student on each of our committees." The chair also makes an effort to "make the committee as diverse as possible ... depending on our hiring in a particular year, we may or may not be able to have minority representation. But when we are able to, we certainly strive for them." But, he notes that "the most important is that the committee be as balanced as possible in terms of gender. .." No other chair or P\&T committee chair stressed the issue of minority status and gender as strongly as this. The chair of the P\&T committee for this year also commented that they "try to have a set of balances in far as are possible-balances in terms of seniority, in terms of gender. For us there is not, unfortunately, much possibility for racial balance. We only have one African-American 
faculty member, and she's about to take a job somewhere else." Let us note here that, although the state board requires students to be involved in evaluating teaching for promotion and tenure, this department chair is the only one who mentioned that fact.

When it comes time for promotion or tenure, the P\&T committee reviews materials and votes by secret ballot on whether to recommend a person for tenure or promotion. This recommendation is made to the chair, not to the department as a whole. It is interesting to note that the chair serves on the executive committee, but he or she also appoints members of the P\&T committee, which appointments are ratified by the committee on which he sits.

To recapitulate, the English department P\&T committee is composed of five faculty and two students appointed by the chair for oneyear terms and ratified by the departmental executive committee, on which the chair sits. The recommendation of the committee goes to the chair of the department. Except for the election of the executive committee members, this is the most bureaucratic of all the structures examined for this study.

The structure of the P\&T process in the psychology department is the simplest of all: The entire department elects a P\&T committee, which then reviews the dossier of the candidate and presents the material to the department as a whole. The entire department votes for tenure or promotion.

The structure of the promotion and tenure committees appears on the surface to be much more homogeneous at Collegial U than at the other enterprises. Each department constructs an ad hoc committee for each person up for review. In each case the ad hoc committee is com- 
posed of two to three members appointed by the chair of the department. This committee compiles the candidate's dossier, reviews the documents, requests reviews from peers, writes reports which are discussed with the candidate and then either made available to or discussed in a meeting with all members of the department at or above the rank to which the candidate will be promoted. What varies from department to department is the structure of the ad hoc committee-how peers are selected to review the candidate's scholarship and how the voting is actually conducted (in one case e-mail voting is desired for faculty who cannot be present in person). And in one department, the committee's formal report goes to the chair rather than to the faculty.

The English department chair appoints five people to review a candidate's work and write a report. Each person doing a review is supposed to work independently of the others and write an individual, evaluative report. These reports are then all presented to the faculty in an open meeting of faculty at or above the candidate's next rank. By this time, the candidate has seen the reports and has had chance to comment or rebut. The voting faculty can also append comments to the reports. Interestingly, the reports "are given to the department, well, in the first instance anonymously, and then it's announced to the department who it was who actually wrote the reports."

In the engineering department, there is an appointed ad hoc committee for the purpose of reviewing each candidate, "probably two persons in their area and one person outside their area." The committee then gathers information and "writes a report with a recommendation, including an evaluation of the research. ... [t]he committee's report would be to me ... And then the entire record of this person's file would 
be available for all faculty above, I mean in the rank that he's going to and above, to review before a faculty meeting is held. And then a faculty meeting would be held and there would be a discussion. And then there would be a secret ballot of the faculty, the question being do you agree with the recommendation of the ad hoc committee or do you disagree with that, or do you abstain, and make comments?"

The ad hoc committee in the psychology department is appointed by the chair, as are the others. "I try and pick one person who is reasonably closely related to the area of research that the person is involved in, that the candidate is involved in. I try to pick a second person to be from a related area to some degree and I try not to put a faculty member on more than one promotion committee a year." The committee writes "an individualized assessment based on the kind of research that person does, the area that they're studying. So we evaluate the person, himself or herself, on what they've accomplished." The formal report is submitted to the chair.

From the information collected in the interviews, there is the suggestion that two factors are at work. First, the structure indicated in the faculty handbook is only minimally carried through to the structure of the promotion and tenure process at the departmental level. Second, despite what faculty handbooks indicate is the institutional structure for promotion and tenure, all institutions essentially follow the shared governance pattern. In fact, the institution with what is apparently the highest level of faculty control and the least amount of administrative involvement thinks of itself as the epitome of shared governance. However, if we consider administrative involvement in promotion and tenure decisions at both the enterprise and departmental levels, and if we consider chairs 
as part of this administration, we can, although with some difficulty, distinguish among the three authority structures; but as noted, that differentiation will not agree with the analysis from faculty handbooks.

Collegial U, with its ad hoc committees and departmental voting structure, epitomizes the collegial structure (even though chairs write their own evaluation of each candidate and forward that recommendation along with the departmental recommendation to the college dean, who then forwards his recommendation and the rest of the dossier to the university committee). With respect to the other two universities, three of the four departments at Shared-Governance U have appointed P\&T committees that serve staggered terms of two to three years; one elects the chair of the P\&T committee, and that person selects the committee. Two of the four recommend to the chair rather than to the department as a whole. The other two present the cases to the entire department; and although everyone can comment on a dossier, only a subset of the department can vote. In one case (chemistry), the structure mirrors that of Collegial U. At Bureaucratic U, three of the four departments have elected P\&T committees. The one department with a different structure has no committee, only an ad hoc review group that reports to the department as a whole, which then votes (this, again, mirrors the situation at Collegial U). In only one case does the P\&T committee recommend to the chair rather than to the department.

One feature of the promotion and tenure process that turned up in different departments across the different universities was the ad hoc committee. But use of the ad hoc committee does not appear to be related to structure-it is appointed and in all cases is only advisory or a data gathering body and thus seems to be the most bureaucratic of de- 
partmental structures; yet it is the only one in evidence at Collegial U. Only one department in Shared-Governance U has an ad hoc committee: chemistry (hard, pure science in Biglan's terminology); two departments in Bureaucratic $\mathrm{U}$, the shared governance institution, use the ad hoc committee structure: psychology (soft, applied science) and English (soft, pure). But all three departments surveyed at Collegial U, the collegial institution, use the ad hoc committee structure.

It is instructive to notice that in all these instances the department chair appoints the committee members, but the functions of the committee tend to be somewhat different. In one instance, the ad hoc committee is purely for information gathering; in fact, the chair noted that the department is constantly "tweaking the process." All ad hoc committees at Collegial U collect information and also write reports and reviews that they then present to the voting members of the department. These committees, however, are only information gatherers and writers of reviews of the candidates' work. The reviewers, rather than writing recommendations, simply report to the department, which votes in meeting after discussing the committee reports and the scholarship of the candidate. This process is also that of the chemistry department at Shared-Governance U.

The most complicated structure is that of the English department at Shared-Governance U. In this case there exists an executive committee which ratifies promotion and tenure committee appointees, who write reviews of the candidates and present those reviews to the chair rather than to the department. This is also the department that has students on the committee to provide review of the candidates' teaching prowess. Again, despite its existence in a shared-governance authority structure, 
this is a more bureaucratic situation with more layers of decision making. The presence of this structure at this enterprise further upholds the notion that the structure of the enterprise really does not affect the structure of the promotion and tenure process at the departmental level.

Thus, we see that Shared-Governance U has more of its departmental committees appointed by the chair; and more of these committees report to the chair, which makes it appear to be, in actual practice, the most bureaucratic of our three enterprises. Bureaucratic U has elected committees in most cases, which are more likely to report to the voting faculty of the department. The ad hoc structure is the common one at Collegial U; yet even here not all is the same. In most cases, the ad hoc committee members can be appointed by the chair but make no recommendations themselves. But in psychology, the ad hoc committee does make a recommendation, and it goes to the chair rather than to the department. This process is much more like the bureaucratic SharedGovernance U than other departments at Collegial U.

Only one factor is the same across all institutions: tenure is tied to promotion to associate professor. It would be convenient to say that those voting for promotion or tenure must be at or above the level to which the candidate will be promoted. Although it is true in several departments that even nontenured faculty can comment on dossiers, in all cases but two, full professors vote on the promotion of associate professors, and associate and full professors vote on the promotion of assistant professors. And both of these exceptions are the same enterprise: in the English and chemistry departments at Bureaucratic U, the entire department votes on promotion and tenure cases. 


\section{Operation}

Turning now to operation, meaning how decisions about promotion and tenure are reached we will examine the different areas of consideration one by one. We will begin by considering criteria for reviewing research: publications, peer reviews, judgments of quality, funding and collegiality.

\section{Criteria}

There are many criteria and many subtle distinctions that departments make in their evaluation, such as the particular journal that a paper might be published in, or the press that publishes a book, or the length of the paper. Other considerations that enter the mix include the number of students a candidate has had (especially PhD students), the number and amount of external awards, the number of citations, special awards, student evaluations, colloquia, offers from other institutions, chapters in books, teaching (which according to almost all chairs and P\&T committee chairs now has a weight equal to or almost equal to research in the tenure and promotion considerations). The basic criteria, however, are the same across disciplines and universities-publications and peer review.

\section{Publications}

We note at the outset that not all publications carry equivalent weight in P\&T evaluations. The value of a particular type of publication (journal article, book, technical report) depends on the discipline. In this respect the research upholds Biglan's findings of disciplinary differences. We also find that there may be some justification in Alpert's opinion that the goal of achieving excellence has led research universities "into a rating game that places far greater rewards on conformity than diversity, measuring performance primarily in terms of original research published 
in scholarly journals. . . A narrow definition of excellence has also served to impose the values of the most powerful disciplines on many of the less prestigious disciplines and professional schools ... [Alpert, 1991, p. 99]

At the time of the interviews (1997), Shared-Governance U had just developed a new set of institutional guidelines for promotion and tenure. The essential concept for this institution is that the work be communicated and "validated"-and they make rather a case of distinguishing between communicating and publishing. The provost of the university described validation: “. . . it may be comment; it may be direct evidence where a new approach, a new technique, a new discovery is being applied and used by others in ways that are helping to shape the discipline or the field, etc., a new teaching technique that is being used widely by others, insofar as that can be documented, that suggests that there is validation of the effectiveness of that technique."

Communication, he adds, is not just publication-"There are a variety of ways that that could be done, and it differs across the disciplines as to how that might be done, and particularly with new electronic kinds of means of information dissemination that there are a variety of ways to communicate information to peers." But of course, the ultimate test is communication-- that "there be documented evidence that indeed it has been communicated and that others have validated the significance of that." The chemistry chair commented that "just doing it themselves in the lab and never getting it out to anyone else probably doesn't really make it." Shared-Governance U was the only institution to make this fine distinction between publication and communication, validation and citation. But it is instructive to quote once again from the chair of 
chemistry: “. . . we have started in the last two or three years asking the candidate to write a statement along with their CV so that we can more fully appreciate what their impact has been in the various areas of teaching, scholarship and service." This is the only department interviewed that is asking candidates to make such a statement for the file, and it is the only one developing a "portfolio" requirement.

On the other hand, the chair of psychology notes that "everyone uses his or her own judgment in each individual case. There is a global perspective. There is an arbitrariness about numerically coding someone's performance. How do you specify quality?" Of course, that is the question that almost everyone in academe is struggling with in much the same way.

The engineering chair says that "things culminate, really, in scholarly publications. And we look at those scholarly publications and a very crucial item in them is 'Is the person publishing in the appropriate vehicles for the work they are doing?' It doesn't have to be in the most prestigious journals in a whole general area if other ones are more appropriate." While the engineers at Shared-Governance U look at appropriateness of the vehicle (and perhaps also its quality level or prestige), the engineers at Bureaucratic U use a formula that gives refereed journals so many points, conference proceedings so many points, book chapters so many points, and so on. This was the only department in the study that uses a formula. But despite the use of a formula in its annual reviews (which are also used for computing raises), the chair said that "there is no single model of any kind, you know, for performance."

The English department at Shared-Governance U makes a point of seeking "intellectual quality”: “. . . it’s the absolute intellectual quality I 
would say is what's spoken to. Usually things like anthologies or teaching material don't count, or collections, edited things don't count very much. What's looked for is a work of original research or original criticism. And this of course isn't true in many other departments, but it happens to be kind of tradition in ours." Clearly he is saying that there are departments at Collegial $U$ that do not require originality in scholarship for promotion and tenure. He continued: "I should have said before on the idea of standards that the usual expectation is that the person will complete and have accepted a book for publication, although that's not always the case. It's usually completed, maybe not accepted. And that's a kind of unspoken requirement. . ."

A candidate in the English department at Bureaucratic $\mathrm{U}$ is expected to have "a substantial set of refereed items-in print-now, we've defined substantial set of refereed items to mean . . . equivalent in aggregate as well as in scope and depth to an individually authored book." It is the publication record that is of paramount importance, and also "the quality of the press that did the publishing," according to the English chair at Bureaucratic U.

At Shared-Governance U, the chair of the English department said that "evidence of distinction and national recognition in scholarship. . ." is necessary for promotion and tenure. The P\&T committee chair was slightly more specific, saying that “. . .we don’t have a set number of publications that are required for promotion to associate and tenure and promotion to full, but we all have some kind of rough sense of what amounts to a substantive, substantial amount of scholarship." He noted further that the department wants to be assured that "the scholarship is contributing importantly within the discipline." However, as we shall see, 
the English department at Shared-Governance U places greatest reliance on external peer reviews.

The chemistry department at Shared-Governance U has similarly fuzzy guidelines. When asked about specific written guidelines or criteria, the chair said, "We don't have anything in writing like that. That is fair to say. At least, I haven't been able to find any P\&T guidelines in our department that says you must have, uh, you know, three grants approved or you must have six papers written or you must have something else, $\mathrm{X}$, Y, or Z. We do not have that." In like fashion, the chemistry department at Bureaucratic $U$ has recently been through "a discussion to specify more closely what the criteria for promotion and tenure [are], and that was a discussion that scored at a low level in the department."

Given the variability in reliance on publications and the expressed differences in types of publications, we see that Biglan's findings about disciplinary differences are upheld in this instance. In the words of the chair of the universitywide faculty personnel committee at Collegial U, "Well, we look at publications. That's a primary indicator, what's the person publishing, where are they publishing. We look at reviews, impact, citations. We look at . . um . . . sometimes there are different . . . you know again, once again, this is a matter that varies by taste and by discipline. In the humanities typically someone will not publish many articles; they'll be writing a book, and it may take six, seven, eight years to publish a book." Disciplinary difference show up again: "Whereas, for example, if that same subject matter is being studied by someone who is from a disciplinary point of view a sociologist in a different unit like a public policy school, a social welfare school, we might look at different criteria. We might not look at, for example, methodological rigor; we'll 
look at policy impact; we'll look at who's reading and using this work; we'll look at its relationship to the practice of social work in a social welfare school or to its policy impact in a public policy school." It is evident, at least at Collegial $\mathrm{U}$, that the university committee recognizes and takes into consideration disciplinary differences in scholarship and other activities.

The provost at Shared-Governance U said that "the important thing is there be documented evidence that indeed it has been communicated and that others have validated the significance of that." It does not necessarily mean publication in the traditional sense. He continued, saying that "there are a variety of ways that that could be done, and it differs across the disciplines as to how that might be done, and particularly with new electronic kinds of means of information dissemination that there are a variety of ways to communicate information to peers." This, of course, is a very broad interpretation, one that some departments or disciplines might be uncomfortable with. Interestingly enough, all the chairs interviewed felt the new guidelines and definitions were appropriate and consonant with their disciplines, that the new guidelines occasioned no major changes in the way things were done or in the type of decisions made.

\section{External Peer Review}

Much more consensus and similarity across both institutions and disciplines is evident when we examine the way departments conduct peer review of scholarship. All require some kind of peer review, which is effectively an evaluation of a candidate's work with respect to its importance to and impact on the discipline. And, as we shall see, Shared- 
Governance $\mathrm{U}$ appears to place the greatest reliance on external peer reviews, Collegial U the least.

The chair of engineering at Shared-Governance U commented that peer reviews "are very, very important. Are they overriding? . . . I think the initial answer is yes. If the external reviews come out generally negative, then there has to be a very preponderance of other information to make the case viable, which is very rarely done." He added that external peer review could "give some additional evaluation, if you will, as to whether a person is publishing in the right areas and whether they are of a reasonable stature or not."

At Collegial U, outside reviewers are asked to "be quite specific in terms of those accomplishments and also in terms of how these stand relative to others in the world who work in that area."

The chair of the promotion and tenure committee of the engineering department at Bureaucratic U said that "[e]xternal reviews are not the only criterion by which people are given tenure or promoted, but it certainly is a strong part of the process. And I think that the reputation of the institution or the record in the institution as well as the record of the individual external reviewer are quite important in how seriously those reviews are taken by the department, college and the university."

Further, the department, at the strong suggestion of the institution, takes a somewhat different approach by seeking reviewers from a certain set of institutions: "Reviews from faculty, and typically these are reviews from faculty members, reviews from faculty members who are either serving at an academic level at or below the faculty member under review or from a non-Big Ten Plus institution tend to be not taken as seriously as those reviews from faculty members serving at a level above 
the candidate under consideration and from a Big Ten Plus institution. . . the ... uh . . the higher . . the academic ranking of the institution and the more well known the person is from which that review is obtained, within the technical area or within the academic area of the person under review, the more likely that that review will be taken strongly."

In psychology, all departments have a similar attitude about outside peer reviews. At Collegial U, the reviewers are asked "for an evaluation of the contribution, of the significance of the research in the field, the impact." But this department also uses "both internal and external [reviews] - that's for cases of promotion from assistant to associate and from associate to full professor. If it's an advancement within rank, say within associate or within full professor, we only use internal review." At Bureaucratic U, again outside reviews are important, although there is balance: “. . . we look for consistency between what the outside people say and what the inside people say. We really have never had a situation where there was a big disagreement between what the outside people were saying and what the inside people were saying, so it has never really come up as an issue. You know, who are we going to go with, the outside people or the inside people? We just haven't had to deal with that problem." At Shared-Governance U, however, the chair noted that "choosing outside reviewers is almost incestuous because everyone is out to protect his own field."

Interviews were conducted in only two chemistry departments, but those again show the same pattern of relying on outside peer reviews. At Shared-Governance U, the chair said that they "let the outside reviewers tell us whether we are right or not" [about the department's evaluation of the impact of a candidate's work]. . . . We had one tenured last year in 
material science, for example. ... We knew we were going to get good letters back because they [departmental faculty] said we were going to get good letters back." He also pointed out a case in which the department had no expertise. "I told the candidate, you know, unless your outside letters come in really, really good, you are out of here; and he said, 'Fine, I am going to have very good outside letters.' And we went to people at Berkeley, Harvard, and MIT; I mean, we hit the absolutely top schools for outside letters, and we got back great letters. So we said, You're in." At Bureaucratic U, the department looks for "experts in the person's field of expertise. And that may take us anywhere."

In English, the picture is much the same. Every department makes use of external peer reviews. The chair of the English committee at Shared-Governance U noted that "the process within the committee differs each time." The emphasis is also similar to what has gone before, although in one case, Collegial U, the chair commented that "we don't always pay very much attention to those. We care more about our own judgment. But superior reviewers in the system, the ones who take. . .consider our recommendation, might very well pay more attention to those than we do." This department permits anonymous, written reviews of the candidate's scholarship, which may all be submitted by peers within the department. One person suggested that Collegial U would naturally not require external peer review because it considers itself in a league by itself to such an extent that it has no peers.

So, we see that, even though the English department at Collegial U requires external reviews, they consider them of little significance. Is this a disciplinary or institutional difference? With so few departments under consideration, it is difficult to determine. But the suggestion is 
that it is not a disciplinary difference, but perhaps a function of the institutional structure since the chair of engineering at this university also suggested that external reviews were only requested for tenure and major promotions and may not carry as much weight as the internal reviewers' comments.

On the other hand, when we look at Shared-Governance U, we see again heavy reliance on external reviews: "In terms of scholarship, that [distinction and national recognition] is primarily determined through external evaluation, and an important part of the promotion and tenure process here is the solicitation of evaluations of the candidate's work from leaders of the field around the country. So we look for high-quality external evaluators and very much rely on their judgments of the significance and quality of the faculty member's work." The chair of the promotion and tenure committee repeated this statement almost verbatim: "We also read the materials, but we do put heavy emphasis on the external reviewers. ... We make sure we know what we are dealing with, but for the evaluation and the quality of the work, we rely heavily on external reviewers."

The English department at Bureaucratic U "gives a lot of weight" to the recommendations of external reviewers; the chair will also "assess the letter of evaluation itself." But in this department, we see a somewhat different emphasis on the external reviews-it prefers to request letters from that institution's "peer institutions, and those are the ones I will tell the chairpersons of the individual search committee to try to get nominations from." In putting together the list of reviewers, consideration is given to "the quality or the level of the institution of the person whose evaluation is being solicited." But even more pointedly, the chair said 
that he "would hate to send up to the dean external evaluations from four faculty, all of whom who [sic] are at schools that Bureaucratic U, rightly or wrongly, does not see as comparable."

The chair of the chemistry department at Bureaucratic U also sought external reviewers from "other research institutions that are regarded as being peer to Bureaucratic U.” Although he did say that "what we are looking for is experts in the person's field of expertise. And that may take us anywhere." In engineering, also, "reviews from big . . . what is referred to as the Big Ten Plus institutions tend to be the most effective reviews in terms of department and college tenure and promotion action." Reviews from faculty at other institutions (the non-Big Ten ones) "tend to not be taken as seriously. .."

While on the subject of the list of external reviewers, we should examine in more detail how that list is constructed. It is not, perhaps, surprising that every department interviewed followed much the same procedures with much the same philosophy. Namely, the candidate provides a list of names of people who can be asked for reviews and the review committee or P\&T committee provides a list of names. In every department, the candidate can provide a list of names of people who should not be asked for evaluations. In some cases, the candidate can work with the committee to develop the list of external evaluators. In each case the department chair or the P\&T committee chair abides by the wishes of the candidate in not asking certain people for reviews.

In this respect, the engineering chair at Collegial U said, "I also ask the candidate to supply me with a name or two if they wish of persons they would not want me to ask. So they, you know, if they have cultivated an enemy so to speak along the way by some sort of run-in they've 
had with someone over some issue or something, and they would not feel comfortable with that person evaluating them, then can make that known to me and I would not do so." Also at Collegial U, the English department chair noted that "the candidate can say, you know, 'I don't think so-and-so likes me, I would appreciate it if that person didn't review. In that case we might not." Let us note here that it appears to be more of an issue at Collegial $U$ that the candidate have an opportunity to provide names of those who should not be asked to provide reviews. Two of three chairs mentioned this issue spontaneously; neither department heads nor P\&T committee chairs at either of the other two institutions brought this topic up [and since Collegial $\mathrm{U}$ was the last one to be interviewed, the question could not be added for all interviewees].

In the English department at Bureaucratic U, the "individual candidate . . gives that committee a list of five names of people who are, in the judgment of the candidate, qualified to be approached for external reviews. All right? The committee then develops a list of its own that includes some of the candidate's nominees but cannot consist only of the candidate's nominees." However, in the engineering department, the review committee may or may not ask the candidate for a list of names. "The review committee certainly is free to do that. In some cases, they do that; I have ... It's not an established part of the protocol for obtaining external reviews." This is the only department at the bureaucratic and shared-governance institutions to have external peer reviews optional.

At Shared-Governance U, the English department develops a list from "the suggestions from the candidate and then from others that the candidate does not propose. . to make sure we have the right people doing this. .." The subcommittee in the chemistry department at Shared- 
Governance U "chooses, . . with the candidate. . the outside reviewers. We ask the candidate to give a list of, say, six to eight names, and we choose usually half the names that we go to from that list. And then the subcommittee chooses a group of another three or four people to send letters to." The engineering department at Bureaucratic U "asks the candidates themselves, and then in addition to that, people on the promotion and tenure committee will take a look at a list of . . . will generate a list of people we think are capable of reviewing this particular candidate. And then the department chairman also has input to that list."

\section{Quality and "High Standards"}

The next question to examine is that of quality and "high standards." This is, of course, the primary concern of tenure and promotion committees and the subject of the review of research. We find that all universities and departments in the study (and probably all universities everywhere) are concerned with maintaining or improving "quality" and "high standards" according to their definition of what that means. And, as it turns out, most departments at most universities openly base that definition on an evaluation of their own faculty's performance and acclaim; but it is an evaluation executed by faculty at other institutions. The chair of the psychology department at Bureaucratic U was typical when he unhesitatingly responded that "We do outside letters" to determine whether someone has outstanding performance-"We use peer judgment, the faculty, you know, make a judgment about tenure faculty." Alpert's comments that the use of published papers in professional journals as a measure of research performance leads to conformity and the imposition of "the values and the mission of the outstanding research 
institutions on most of the other colleges and universities" also applies to the use of external peer reviews. [See Alpert, p. 99].

We also find during this discussion that "quality" is a subjective concept, based on the judgment of a group of people and informed by the judgments of yet other individuals. Those involved appear to recognize the inherent subjectivity of the process, and there is a clear attempt to reduce or eliminate any capriciousness by involving groups of evaluators (rather than individuals) at different stages of the process, and in most instances over a number of years.

To achieve the objective of maintaining quality, as we have already seen, every department makes use of external peer reviews to some extent in the evaluation of research and scholarship. Only two departments rely heavily on their own departmental reviews; the others place great weight on individuals outside the home institution. Some, as at Bureaucratic U, want the preponderance of those reviews to come from their "peer" institutions. Others are satisfied with reviews from the "top" individuals in the area under consideration. The following discussion examines statements about quality and excellence by institution rather than by discipline because it appears that this concept is guided more strongly than any other by institutional norms and structure.

The chair of the university committee at Collegial U noted that "academic standards and expectations vary so much from discipline to discipline. . . . and our expectations of . . . different kinds of work will be different because the missions of the schools are different." When asked about outside letters, this person said that "you can get a file where you have recommenders from institutions which are not on a level with Collegial U. And you might view that with some suspicion. But it could be that 
these institutions have first-rate departments in the area in which the candidate is working; or it could be that the very best people in the candidate's field don't work at first-rate institutions but at other kinds of institutions. So you have to understand the nature of the persons, the department and the institutions from which the letters come. . . the general theory is that you want a candidate reviewed by the best people in the field in which the candidate works." There is, from this response, clearly an understanding that some of the best people may work at less prestigious places.

Along these lines, the chair of engineering stated, "And every case has to be based specifically on research, teaching and service-university service and professional service. And honors and awards. So every case that's made has an analysis of those aspects of a person's professorship. And so then you'd say, well how do you evaluate their research? Well, we look at first of all their list of publications in the refereed archival journals and/or refereed papers in conference proceedings. And the first thing we do I guess is count them. If they are zero, then there's not much to say. But we count the number and then we, the people who are on these ad hoc committees who are supposed to be knowledgeable in their area would review these papers and pass judgment on their quality. And then we also, in these promotion steps, we ask outside reviewers in this person's area of expertise to give a written evaluation of the person's research accomplishments. And we request that they be quite specific in terms of those accomplishments and also in terms of how these stand relative to others in the world who work in that area."

The chair of the universitywide committee at Collegial U said, "You know, the sense of what, what is necessary ... for promotion to tenure 
or what. . . You know, these are standards that one can articulate, but in actuality, their meaning lies in their implementation. And one is always trying to calibrate them with the way one has implemented them in the past, to be equitable about it. So, yes, it's constantly the case that we are cross-checking and comparing." This statement may be viewed as a note of caution and a statement that those involved in making decisions are aware of the inherent subjectivity of the endeavor and so are continually trying to make it less so. At the same time, he noted that "what we do as scholars all the time is make these judgments, don't we? So we do what you would do as a scholar in your own field-say this work is good, this work is bad."

But there is also an undertone of what a few of the chairs at $\mathrm{Bu}$ reaucratic U said-there is clearly a desire to have letters from the most prestigious universities. The English department seeks "a clear publication record in first rate cases, in the particular area or field of specialization ..." This department also looks at "the quality of the press that did the publishing" and puts candidates through a "stringent examination." In the words of the chair, "The reports themselves [of the departmental review committee] are of very high quality. It's often said that the work of the candidate doesn't get any better reviews than it gets inside those walls at the review meetings. It's simply the originality and the worth of the scholarship, of the writing, and its quality. It's based on its intellectual quality as perceived by the reviewers."

With respect to standards of quality and excellence, the chair of the English department at Bureaucratic U said, "And that [a memorandum from the associate provost] sets out some criteria for promotion consideration, which includes such things as improving the quality of the 
faculty, which frankly I read as saying that the standards today cannot be the same as we had twenty years ago. That they should be higher. That the university is asking more, rather than the same or less than it once had."

The chair of psychology said his department was always tweaking the process. This appears to indicate a desire to eliminate as much subjectivity as possible and to make the promotion and tenure decisions as equitable as possible. "We like to evaluate the candidate against some kind of impersonal standard rather than against the others that are coming out. But of course in practical fact, that is impossible. I mean, you can't be unaware of the relative strengths of two candidates that come up together, but we attempt to evaluate the candidates individually on their own terms. .."

In engineering at Bureaucratic $\mathrm{U}$, the department examines several factors to determine quality: "Well, the major ones that we look at are published journal articles, archival journal articles, published conference proceedings that are reviewed, contributions to books or research monographs and things like that, published that is, and production of $\mathrm{PhD}$ students, production of master's students, primarily with thesis is what we're most interested in although we have some students. . .we don't have a lot of students who go through without doing a thesis but some do, and they don't count very much in our scheme. A master's student who completes a thesis counts a fractional part of a $\mathrm{PhD}$ student in some measurable way. Research expenditures,. . .those are the main things." But, he also added that he discusses with the candidates "some rough idea of norms. But I point out that there is no single model of any kind you know, for performance." 
In the chemistry department at Shared-Governance $\mathrm{U}$, there is a clear intent that the candidate should be "excellent" in his or her area: "We have typically hired people and evaluated, tried to pick the very best in our judgment in terms of fitting into our system early on and then see if they have met the criteria that we have for promotion and tenure. . . . The people in the department who are in the area under consideration have their own sense as to whether [the candidate is meeting expectations of 'significant scholarship and uniformly high standards']. And then hopefully we make good choices with respect to the outside reviewers, and we let the outside reviewers tell us whether we are right or not."

\section{Other Concerns}

Interviewees mentioned several additional factors that contribute to a determination of excellence, other than publications, validation and peer evaluation. The most prominent of these were external funding, hiring practices, annual reviews, and, interestingly, collegiality.

At two universities, the concept of "fitting in" and "collegiality" were important, at one because the university guidelines require "collegiality." But what does this mean and how do departments interpret it? The concept of "fitting in" meshes well with this university's requirement of collegiality in its guidelines. When asked about this provision, department chairs and P\&T committee chairs all agreed that it had not been an issue to date but they would not want to either hire or tenure a faculty member who was highly divisive or disruptive in the department.

In the words of the English P\&T committee chair: "You know, that's one of those sort of tricky areas where you've got to find some kind of middle ground between one extreme using this as sort of a hammer to 
force everyone to conform to some kind of party line but at the other extreme to have faculty who simply are not cooperative, who don't contribute to the department. So, the term collegiality there is meant to provide an opportunity to require and expect your faculty to be contributing members of the department." He further said that the statement "is meant to guarantee the faculty that you choose to tenure and keep as your colleagues indefinitely are going to be contributing members of the department who serve on committees when asked and are people who get along with other people."

The English chair said, "it would weigh heavily if it was determined that someone could not work effectively with colleagues and could not work effectively toward common departmental interests, then that would be, I would say, a problem." The psychology chair said, "Collegiality is important. I don't mind people who disagree, but there should be respect for the department—departmental citizenship."

The chemistry chair had a somewhat different view of collegiality. His interpretation was to involve a number of people in the promotion and tenure process to avoid hurt feelings: The process the department uses "gives more collegiality because more people are involved." Further, he commented that "if feelings get damaged in promotion and tenure, that kind of hurt can continue for years. I mean, it can continue for a whole lifetime, and people won't work that well together for ten years, for God's sake; and all you've done is decrease the capability of your department to be effective."

Only one other chair mentioned collegiality, or in his terms, citizenship. The chair of psychology at Bureaucratic U came very close to mirroring the statement of the psychology chair at Shared-Governance 
U: “. . .for promotion to full professor . . . we look a little bit more at departmental citizenship, as I said before, for going to full professor than we do for tenure and promotion to associate. But basically it is the same. We want people to do it all. We are very selfish about that, or greedy."

\section{Dissension in the Ranks}

Comments from several interviewees point to what some would consider an anomaly-namely, there appears to be remarkably little dissension within departments and also between faculty and upper administration when it comes to promotion and tenure, despite the fact that received wisdom and anecdotal evidence point to just the opposite. The first indication of this was the statement from several chairs that, during their tenure as chair, the faculty their departments "send up" for tenure have always succeeded (although this was not always the case for promotion from associate professor to full professor). The second indication was the statement from provosts and associate provosts that they listen to what the departments tell them and only in extremely rare cases decide contrary to departmental recommendations. The third indication was the fact that, with only one exception, all the chairs said that deans and provosts thought highly of their departmental promotion and tenure practices and the direction their departments were taking. Even within departments, there was no indication (except in one instance) of divisive differences among the faculty or the faculty and chair-disagreement, yes, definitely, but no real dissension. A large measure of consensus was in evidence in every department.

Let us examine each of these three indicators more fully, institution by institution: 


\section{Tenure Success}

At Shared-Governance U, the English department has, in the words of the chair, a "fairly high" success rate-he could only think of "a couple of cases" of people "who have been denied tenure who have put themselves forward over the years." But he noted that several factors enter into the equation: "There have been faculty who have declined to put themselves forward or who have withdrawn before the conclusion of the process . . . The ones that are most likely to succeed are the faculty who go through the process." Of the four cases this chair has supervised, all were successful in their bids for either promotion or tenure.

The same picture holds true in the psychology department, where all departmental recommendations for tenure in the past several years have been upheld. The chair of psychology at Shared-Governance U said that "it would be unusual for the college or university to overturn a departmental P\&T decision. In the past eight years, there have been five tenure decisions and no decisions not to tenure." The only indication of major disagreement was the case of a minority candidate "who we had hired on a very affirmative action program a few years back who turned out not to be satisfactory - a very poor teacher and did no research. If that individual hadn't have left, I'm sure the department would have turned him down for promotion and tenure. And I'm equally sure the university would have awarded it. But other than that circumstance, I think that the department's opinion would be listened to."

In chemistry, the chair said "my concern is if the department and the chair and everybody pulling as hard as the candidate is to make this whole thing work." He believes his department has an 80 percent success rate. 
In engineering, the success rate is also high. Of the cases [and the number is undetermined], the chair noted, ". . . and I think all of these, my memory is a little bit fuzzy on one, all of these men. . people who. . .uh, who the decision was negative, once it got essentially up to the dean's level with negative connotations decided to resign rather than be terminated." He commented further that the department has "typically hired people and evaluated, tried to pick the very best in our judgment in terms of fitting into our system early on and then see if they have met the criteria that we have for promotion and tenure." The chair said that one person the department had given a lukewarm recommendation for promotion (this was not a tenure case) was turned down by the administration. But, it was a "judgment call. . . . I have no problem with it coming down saying, well, you know, these guys are right and he needs to develop his outside reputation a little better before we push this one through." This person "won't go up this year, I know that. He might go up next year again." In that same department, a candidate that the chair thought "might not make it" did so "on the strength of his outside letters. Everyone that we wrote to, which were the best people we could find in the field, said "Man, you've got to tenure this guy. He solved a problem that people have been working on for years and have been unable to solve. So we tenured him, and I think we've been happy with that-even though he did not have very many publications. And he had had only a few grants at that point."

In all of the cases in which a candidate failed to be tenured, "it was a combination of the teaching and the research/scholarship which were the issues." So, the tenure process in this situation is possibly viewed as a validation of how will the department picks its beginning assistant 
professors. If this is the case, the department has a vested interest in tenuring those it has hired in the first place. Is it perhaps a question of resources, time and internal reputation?

Turning to Bureaucratic $\mathrm{U}$, the engineering chair said that he did not "think that the department in the last ten or 12 years at least has ever recommended for tenure that it hasn't gone through.” There are good reasons for that to occur, he explained. First, the department has "a tenure track position for each person we hire. So, if we make good judgments and then bring a person along effectively, we could in principle, with confidence, tenure everybody that we hire." But, since they "don't always get it right . . . and sometimes a person's changed his or her own mind," not everyone gets tenured. Second, "promotion doesn't come up as a major departure from our way of doing things. It's more of an intensification and a focus." Third, the chair said, "We're hard on ourselves, feeling it's better to be hard on ourselves and then be able to argue effectively than sort of cast it out there and hope." The chair of the P\&T committee noted that "candidates self-select themselves not to be reviewed." He also commented that "the department has historically appointed quite strong candidates at the beginning assistant and associate professor levels. We've done a good job searching. . ." In the 16 years he has been in the department, there have only been four negative departmental reviews, and the college and institutional have upheld all departmental decisions.

In the psychology department, the incumbent has been chair for 16 years; in that time, "I haven't had any recommendation refused," and only one person got as far as the penultimate year prior to the tenure decision when it became evident he would not be tenured, and he re- 
signed. The department currently has "one person who is sort of on the fence ... but that person is two years away from a decision." Again, the tenure success rate is very high because of strong hiring practices, yearly reviews and discussions with candidates "because we don't want surprises." The chair added quite positively that "we want to send up very strong cases. And frankly we want those cases to be, if you like, a notch or so above the other units that are in the college. And I think it has served us well over the years.; and I think it has helped to promote the effort to increase the reputation of the department of psychology in terms of the productivity of the faculty . . . And I haven't had any recommendation refused in the 16 years that I've been chair." Additionally, if there is a somewhat weaker case that the department wants to promote, the record of strong candidates allows him "to put more muscle behind that argument. So, it's worked very well, I think."

The chair of the English department, which has a somewhat complicated committee structure, presented a slightly less homogeneous picture of the promotion and tenure process. Even though he has never recommended contrary to the Policy Committee recommendations, that committee has recommended differently from the individual P\&T committees. Additionally, none of his recommendations on tenure or promotion have been overturned at a higher level. He did stress that the dean and the university had the right to do so, but never have.

The chemistry department at Bureaucratic U was the only one interviewed that had denied tenure to a candidate (four years prior to this study), and this on the grounds of lack of originality in research. In addition, the chair said that his recommendation was different from that of the P\&T committee. There "was a heated discussion which was just 
fine. In the end, I think there was consensus, in the sense that we were going in the right direction." Notably, he commented that "if a vote is, say, 60 percent in favor and 40 percent against, it is unlikely that that person is going to get tenure. . . if there was that much concern on the part of the faculty, then that is not a strong show of support." Since 1996, the department had denied promotion to only one person.

At the level of the institution, the associate provost said, "If you do a cohort analysis, which if you start, you know, with a set of folks coming in and then said how many of those would be promoted and tenured after the six-year review period, you'd have about an 80 percent rate. But that includes people who are not renewed in the first term, or unfortunately die, or change jobs, or are counseled out, and so on. But when we actually come to the set of folks on the list who come up at the end for the six-year period, uh, the tenure rate is about 90 percent."

Collegial U, the collegial structure, presents much the same picture. In English, "You have a chance clear through to tenure. You have a clear shot at tenure. You have to lose it not to get it." At the same time, however, the chair said that when he first came to the university, "about one of every two candidates failed. But now the percentage is much higher, probably nine out of ten make it, or maybe even more. So that shows a shift in the way things are done." He commented that one departmental consensus against tenuring a candidate was reversed by the administration; although when presented with additional arguments, the administration subsequently reversed its own decision. In psychology, every "everyone who came in as an assistant professor with the exception of one person ... has gotten tenure" since the early 70s. Moreover, only one person in the past few years who has "come up for an advancement 
within rank . . was turned down." In engineering, "We have promoted every junior faculty person to tenure that, on schedule, plus or minus a year or so, as we had hoped we would and planned to do."

\section{Administrative and Departmental Agreement}

While the departments and chairs say they are being so successful with tenure and promotion candidates (and, as we have seen, the primary goal of some chairs is to be the advocate for the department and candidate), what are the associate provosts saying about their agreement or disagreement with departmental recommendations? At each university, the chief administrator in charge of promotion and tenure decisions was interviewed. Each of them said that they agreed with departmental recommendations an average of 85 percent of the time (both negative and positive promotion recommendations). In fact, all associate provosts and provosts interviewed stated categorically that they would not normally turn aside the decision of the department and college and would never do so unilaterally-in fact, in the past two years only one positive recommendation from both department and college was overturned at the institutional level at all three universities. (Exact comparative numbers for promotion and tenure decisions are unavailable because associate provosts and provosts were uncertain about how many cases they actually review.) Positive departmental recommendations with negative or lukewarm college recommendations tend to be overturned more oftenon the order of $2-5$ percent. It is thus clear that most disagreements between department and institutional administration occur in departments other than those interviewed. But even these are few in number. Let us examine the comments of the top academic administrators. 
The associate provost at Shared-Governance U said that "of the 105 dossiers that came up, 12 were denied promotion and five were denied tenure. Now some of the promotion and tenure were similar so. . . [meaning that these were cases in which the candidate was going for both tenure and promotion to associate professor, which is the norm at every institution]." But, he noted he was "not sure from the summary how many of the denials agreed with the college and the department." He believes that he disagreed with the department and college recommendations that year in about 5 percent of the cases. Structurally, the decision-making committee at Shared-Governance $U$ is composed of all administrators, and they depend heavily on comments in the outside letters and dean, college and department recommendations, "so it is only when it is an unusual case that we overturn what's done in the college or department. Our goal is to, you know, to concur with all of the recommendations, although there are times when it appears to us that something is amiss and we call it. ... So it's not that our charge is only to look at procedural things." He said the role of the university committee "is primarily to be sure that the process is working properly, that there are not misinterpretations of the guidelines. .." They seek "equity between the different units."

The provost commented that the role at the university level is "to see whether units have adequately considered all of the factors as they have made their recommendations." He explained one case two years previous in which the department had recommended a candidate for tenure but the college had not: “. . . and it was clear that the college committee and the dean both used a very narrow and traditional definition of scholarly expectations and did not adequately consider two factors 
in my view. One is it was a minority faculty member, one of the first ones, actually THE first one in that department and one of the very few in that college, and in that case I posed a whole series of questions back to the dean about to what extent had the department and the college made efforts to provide the kind of support that was necessary to allow this person to be successful in their assignment. I also asked to what extent they had considered the kinds of special demands on this person's time created by the fact that a whole parade of students and others were immediately interested in having access to this person and that ... that . . . indeed the person had made significant contributions in both teaching and particularly advising of students, and in some cases faculty colleagues, but there seemed to be no recognition or acknowledgment of that as an important contribution in the evaluations that were made at the college level. And so in that case I posed a whole series of questions as to how they had dealt with a number of these things. After receiving their answers, then I considered the case and their responses, and I made the decision that indeed this person had accomplished what was necessary to be awarded tenure."

So here we have an explicit explanation of how one case was decided in favor of the candidate at the highest level. Both associate provost and provost agreed that their primary roles at the institutional level were to examine the dossier as a complete document.

The provost further said that the cases that failed in their bids for promotion or tenure did so for one of two reasons: "This past year, I think in every case, it had to do with a failure to document satisfactorily that indeed there were original contributions that met the definition of scholarship - that is it had been communicated with peers and had been 
validated by others, and actually the definition was very useful in being able to distinguish some cases where the evidence simply wasn't there. If it had occurred, the dossier was not adequately prepared in a way that made it clear that that had happened. . . .

"The other category is not related to scholarship but related to the basic performance of assigned responsibilities. Inadequate performance in teaching or in outreach functions in particular or where there was evidence in the evaluations of those performances that had come forward and suggested some real questions about effectiveness in outreach functions where there were serious problems with clientele relationships or with the reactions of clients, particularly principle clients who expected to be served by that individual. So those would be the two categories, either a failure to document scholarship satisfactorily or a failure or deficiencies in the basic performance of assigned responsibilities."

We see here a much looser definition of scholarship than might be expected at a Carnegie Research I institution (or than is evident at other institutions) as well as an administrative structure that appears traditionally bureaucratic and quite attuned to concerns other than traditional scholarship.

At Bureaucratic U, the associate provost said there was a time when "deans would come with a very large set of promotional recommendations. What they wanted to do was to be told that the people were not strong and then they could go back and tell the chair, 'Well, I'd like to have done it, but the provost turned it back.' The situation is different now, he said, so much so that he turns back recommendations very seldom-"a couple a year on the average." These are the mandatory cases, he explains, and are only "a couple a year because we've worked 
very hard to make sure that we don't get very many cases that departments and deans endorse but we have to turn back. And that flows from this on-going set of interactions about expectations, so people know the kind of people, the kind of records that they really need to sustain. But there are always cases for which there's disagreement on a variety of issues ....”

Concerning the nonmandatory cases of promotion from associate to full professor, Bureaucratic $\mathrm{U}$ has a somewhat unusual slant on the process. The deans compile a list of candidates for promotion and gather the dossiers. The associate provost reviews the dossiers and then meets with the deans. On questionable cases, the associate provost "raises a bunch of questions, and the dean talks about them, and you raise more questions and issues, and then this meeting always precedes the final formal recommendation that comes forward, so they are preliminary in that sense. In a number of cases, these names never reappear again. Now, we never really say, we are not going to endorse Jones or Green or Brown, but we raised a series of questions about the dossier and the case, and you know, the dean considers all of this and in most instances, those folks will disappear and return at a later date when they've had their record enhanced." When asked what the primary reasons might be for turning down a tenure bid, he said the major one is "lack of either evidence or predicted evidence about an effective research and scholarly base. . . but each of these cases is particularistic, and as I said, I want to communicate, they are very, very few."

The provost reviews all "material at the margin, even though the recommendation is positive and everything that is a negative recommendation." What the provost does is ask for further commentary, outside 
the institution if necessary, "and most often I do." Disagreements with recommendations occur "infrequently." This low level of disagreement is a result, in part, of the institution's practice of reviewing "everyone who has not been tenured annually prior to reappointment. And in the process of that annual review of everyone in the system, our concerns are usually expressed in that context. ... So when we get to the end of the process, it's highly unusual that there is a major disagreement because we've raised the concerns as we go along."

Like other institutions, Bureaucratic U tries "very hard to reach an accommodation of different views early so that the faculty member is not surprised by the judgment. . . . and has an opportunity to try to meet those expectations so those are clarified." And again, the desire is to "have some assurance that there is a trajectory of scholarly activity. Again, not always that they are going to be the Nobel laureate of the future, but a solid record of scholarship. .." But the provost also stressed the importance of teaching: “The word here is 'and,' not 'or.' . . . in good conscience we cannot tenure individuals who have shown that they are not effective in the classroom." She said that the "most significant disagreements come when an individual has a marginal teaching record but a very good record of scholarship. And that is simply unacceptable."

The general picture of upper administration agreement with departmental recommendations is similar at Collegial U, but with a somewhat different slant. The associate provost there commented that "I virtually never would disagree with a recommendation that was uniform up to the point where it reaches my desk. Um,, the, um, the . . a very small percentage of the cases, maybe, you know, 5 percent of the cases maybe, 
that there is a difference from the departmental recommendation, but it's ,. . . it would never be that I would say no if the department recommendation were yes; there would be a set of no's up the line that would lead to a negative decision. I would say that I virtually never would disagree with a recommendation that was uniform up to the point where it reaches my desk. What I'm judging is the sufficiency of the argumentation, the kind of weighing of the evidence for tenure or against tenure. . . so I'm judging the weight of the evidence that's presented and the arguments that are made on the basis of that evidence." What reasons would the provost at Collegial $U$ have for disagreeing with a departmental and college recommendation? Again, the same as we have seen at the other institutions: a "lack of distinction of research [as well as] . . . the whole range of factors, um, that the campus considers when deciding whether to tenure someone or not." This provost also noted that a candidate could be denied tenure or promotion for poor teaching, indicating the same philosophy of the importance of teaching as did Bureaucratic and Shared-Governance universities. But at the same time, she was absolutely adamant about never making a judgment about the quality and value of the work itself.

\section{Role of the Chair of the Department or Division}

Now that we have heard chairs discuss the promotion and tenure process, we must ask what they themselves consider to be their special or particular roles in this process. If we look carefully, we see that the chair, at the bureaucratic as well as at the collegial enterprise, has a fair amount of power, even if he or she does not, in effect, "control" the process. The chair appoints the ad hoc committees in every case where this 
type of committee exists. In other cases, the chair appoints the chair of the P\&T committee, or even serves on the P\&T committee. In almost all cases, the committee or committees write a report on each candidate and, in most instances, the department discusses the report and votes on whether or not to tenure or promote the candidate. In only two instances does the process bypass the department and involve only the chair. But even when the department is responsible for voting, the chair is responsible for writing a letter of recommendation that will accompany the candidate's dossier to the dean and college committee and subsequently to the associate provost and college committee. Although there are universities at which the dean and college do not necessarily review and approve departmental recommendations, that was not the case at any of the universities in this study - in each of the universities in this study, the dean and college committees receive dossiers or "books" from the departments and pass them on to the university-level committee with their own recommendations. The flow of influence can most logically be represented by the following diagram with the boxes representing the relative influence of each component:

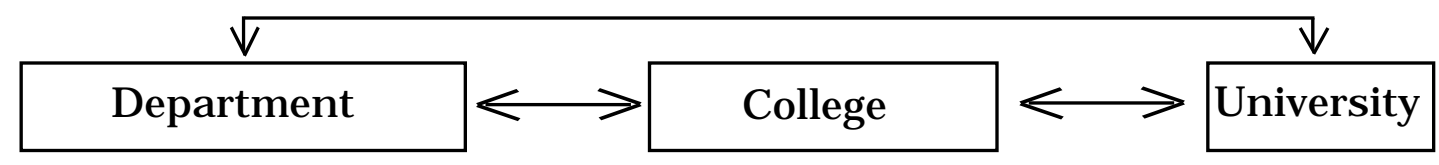

So, given their position, their responsibilities, and ultimately their power, how do they see themselves in this position? We will examine chair roles by institution rather than by discipline because, as several mentioned, they do pay attention to what the institution says and tend to guide their actions accordingly. 
At Shared-Governance U, the engineering chair says that "the department here at Shared-Governance $\mathrm{U}$ in engineering can play a significant role in the makeup of the faculty and in this promotion and tenure process." Thus, he holds discussions with faculty, organizes candidates for promotion and tenure each year, and talks with the P\&T committee. But "first and foremost, when I make a hire, I review the promotion and tenure criteria both on my own mind in evaluating the candidates and then with the candidates as they are considering their role here." Thus, the tenure and promotion wheels begin to turn before a person is even hired. This practice is not unusual.

The chair of chemistry is responsible for writing a recommendation to the dean and college. But even more than that, he appoints the ad hoc subcommittees that review the candidate's work each year. Although he was of the opinion that there is no real gatekeeper, said that his recommendation, "the chair's recommendation, carries more weight probably with the dean and with the upper administration. . . . And in that respect I can be the gatekeeper.”

The English department chair sees himself in a similar light: "On one level I am a gatherer of evidence. It is my responsibility to determine who will be contacted to provide expert testimony on the quality of faculty work, and it is my responsibility to gather accurate records of the faculty member's performance. . . . And I see it as my responsibility to guarantee that peer review is done and that regular ... reviews are done. And at the same time, I need to be making my own judgments about the quality of an individual faculty member's contributions to the institution because I see the faculty member's evaluations. I also end up dealing with any students who might come in to maybe praise the faculty mem- 
ber, to complain about the faculty member. ... And so I see myself being able to add to the procedures a fair amount of information . . .." Recall that this chair appoints the P\&T committee members, appointments which are ratified by the departmental executive committee on which he serves.

In psychology, we see a much more egalitarian attitude. This chair considers himself "as first among equals rather than an administrator per se or an oligarch." He notes that he is responsible for yearly reviews, which faculty have the opportunity to read and rebut if they are so inclined. He also selects outside reviewers different from those named by the candidate. He says he also is "an advocate for the department in judging whether one coming up for promotion and tenure should be promoted or tenured." He commented that one person in the college had said the "role of the chair is to promote the careers of people who hate you. I don't take that viewpoint." Echoing the comment of the engineering chair, he said that "the letter from the chair is the most important document in the dossier; it is critical." So again, we have a chair who wields tremendous power.

The engineering chair at Bureaucratic $U$ takes a somewhat different approach. Although he is responsible for writing a letter of recommendation that becomes part of the candidate's "book," he considers his primary responsibility "to make sure that the procedures are followed carefully. . . . A second thing is to try to make sure that the faculty, especially the younger faculty . . . understand their rights." He placed his review of the data and recommendation letter third in order.

The chemistry chair again has a different concept of his role, that being "to make sure that the department is improving, that the vector is 
up in terms of quality." This chair is not at all reluctant to use his power: So it is not uncommon at all for there to be a majority positive vote on a tenure decision and still have it turned down by the chair. In other words, at the end of the day, the tenure and promotion committee and also the full faculty are advisory to the chair." Although it does not happen frequently that he would counter a promotion and tenure recommendation of the committee, "it certainly happens and it certainly has happened."

The psychology chair also feels it is his responsibility "to develop a strong faculty." The faculty recommends to him, "so the bottom line is that I have to make the decision about whether to recommend tenure and promotion or not," but the "ultimate responsibility" is his. Additionally, he commented that he had not "had any recommendation refused in the 16 years that I've been chair. So it serves . . it also increases the credibility of the chair. So, if there is ever a case where it's, you know, I have not the strongest case in the world, I can put more muscle behind the argument." He also said that "the history is pretty much that the chair listens to the faculty," but the suggestion is that the chair always has the right not to listen to the faculty.

As for the chair of English, he has several points that he considers his special role in the P\&T process. First is assuring consistency, both as applied to candidates for promotion to the same rank and "between this year's recommendations and those of previous years." He cautioned, "I am not using the word uniform, by the way." And, since the recommendations are not uniform, "standards today cannot be the same as we had 20 years ago. . . . The university is asking more, rather than the same or less than it once had." He also, as the chair of psychology noted, is not 
bound by the recommendations of the faculty committee; but the chair "is responsible as an individual [for recommendations either pro or con]" for recommendations which he must put in writing. As he explained, if a faculty member files a grievance, it is against him, not the university.

At Collegial U, the chair of English felt his special role in the promotion and tenure process was essentially being an advocate for the department to the upper level decision-makers: "he would try to make the best case he can for the candidate based on the reports that are .. . the best case he can for the department's decision so that, you know, given those reports that were given, and the department then finally votes in favor, the chair will, trying to be honest of course, will present the materials in such a way as to justify that decision." If the chair "feels very strongly against the vote [of the department], "she is asked . . not asked but invited, to write a separate letter of her or his own opinion."

In the engineering department, the chair's role is to "essentially just orchestrate the thing through until the faculty votes." He also considers himself a mentor, even though the department formally appoints "a specific faculty member mentor for every junior faculty member. . . . But of course they often come to me and ask for my advice on those things in addition to that mentor. You know, I have an open door for that." Then, after the department votes, the chair prepares the departmental recommendation for the dean: "And then actually, uh, sit down and write up the case for the department, the recommendation, which has in it ... which I choose exactly what level will be recommended for the person based on my assessment of the strength of the case."

The chair of psychology says his primary role is "to make an honest evaluation and to support that evaluation. If I think that person war- 
rants an advancement or promotion, then it's my obligation as the chair of the department to make the best case possible as to why the university should reward that individual." Once again, we see the idea that the chair is an advocate for the department's decision or wishes while also constructing and justifying an independent evaluation.

\section{Role of Chief Academic Officer}

It is clear that some provosts and associate provosts, vice presidents, chancellors and presidents consider themselves leaders and trendsetters. At the same time, they place responsibility for promotion and tenure decisions in the department. It is instructive to examine how they view their role in the institution and how they view their responsibilities in the promotion and tenure process. It is equally clear that the two roles are related, although this study was not designed to examine that relationship.

Associate provosts and provosts also consider themselves guides, guardians, and informants. They hold orientations, "go very carefully through what the cases should look like for merit advancement and for promotion, and hold meetings with assistant professors (Collegial U). As for the kind of leadership role they play, "it is a very important one. Um, but it's not that it is not influenced by faculty. I don't think anyone could be in either my position or the [provost's] and decide on a set of institutional goals that weren't ones that the faculty was . . f fully saw the kind of urgency and value of. . . .with my knowledge of the institution, trying to decide what is most important for it to pursue and then persuade faculty that that is the most important thing to pursue." It thus appears that the provost and associate provost believe they have wide and com- 
prehensive knowledge of the institution and where it should be going and try to set those objectives. But it is equally clear that no one is going anywhere without the knowledge and concurrence of the faculty.

At Bureaucratic U, the associate provost sees himself as "playing a very active role with the provost and the president and our legal affairs staff on issues of policy and procedures." But like the associate provost at Collegial U, he conducts meetings "with faculty about particular issues, policies, problems, ..." and "works with chairs and directors who have issues and concerns about faculty behavior or particular policies and procedures they're going to develop. .." But of greatest importance seems to be the "enormous amount of effort in say the last five to eight years on really getting a very strong base of support in the faculty development arena, teaching improvement and effectiveness being a major dimension there." He also sees himself as "a major questioner, um, a commentator in dialogue with the dean ..." The provost was even more positive about the necessity of being a leader with support from the faculty: “. . . I work very hard not to be out there by myself. . . because my ability to implement it at department X when I can't look at all the vitas and sit in on their discussions depends on my getting some buy-in. So it does require me to lay out ... to use a different analogy, you know, I've got to lay out the parade route because that is what people believe that provosts should do." Her "special role is to try to be out in front of the process talking to faculty, deans and others and trying to get for the community a level of expectation that narrows the gap between our rhetoric and what actually happens." She stressed the importance of not just helping to "frame the parade route," but making "sure that the gap between the front of the parade and the rest of it is very small." 
At Shared-Governance $U$ on the other hand, we can perceive much more of a top-down approach. The associate provost's special role is to make the promotion and tenure process "more equitable across campus . .. So we are more interested in interpretation-how the guidelines are implemented and kind of making sure there is equity between the different units and that the same guidelines are being used and interpreted the same way." He thinks the institution "is characterized by relatively low walls between units in terms of many of our academic units. ... In other areas, I think there are a lot of turf issues and walls, people working in their own silos."

He says faculty are involved in all decisions, academic policies "are run by the academic deans. ... . Work groups that deal with different issues . . . usually have faculty representation." Note that he said "usually," which suggests that faculty are not always involved. Although "programs are initiated by faculty or units that come up with good ideas as opposed from a lot of top-down kinds of stuff," the administration has "identified areas that we would like some initiative." When this occurs, the administration makes funds available and "kind of go with an RFP process where people will send in proposals and define initiative areas and compete for some of the funds to do these things. But this way we define essentially what areas we need help in or would like initiative in and some of the ground work in that exact program and how it may be accomplished."

In the past, he said that the administration essentially decided what programs to initiate but now is requesting more action from the faculty. But, it is noteworthy that he said, "Not every program can be operated that way. In some cases, that is not an effective way." When 
asked how it was decided to revise the university promotion and tenure guidelines, he said that it "was primarily a faculty-led initiative."

The provost corroborated this idea that the faculty initiate changes in curricular matters: "Certainly faculty have been key and have driven changes like the development of the baccalaureate core. .." Changes in academic programs are also originated "by and large" by faculty. Yet other changes have been "driven by the initiative of the president appointing one person to do a study and bring the results back and the president making a series of decisions." This president is "very much a change activist in identifying a whole series of things he would like to see the university respond to and some changes in directions." Although the faculty "ultimately become involved in the discussion and consideration and obviously any implementation, ... the initiation of those certainly is not in the faculty." So, although Shared-Governance U does involve the faculty in the construction and implementation of new programs and does make some effort to create Shared-Governance U's "buy-in" situation, it appears that the administration here is much more apt to make decisions on its own.

\section{Goals}

Considering what the chairs say is their role in the promotion and tenure process, we have an emerging picture of the department that is much more concerned with itself as an individual and separate entity than we might have presumed. It is part of the institution and in many cases looks to the institution for guidance in the criteria for promotion and tenure. It is part of the national and international discipline and 
looks to peers outside of the institution for evaluation and judgment. But it appears to be undertaking these actions with a view to self-aggrandizement and within-institution, individual power. The most prominent goal of each department seems to be reputation and scholastic excellence, but it is reputation that gives it power. Can we interpret this to mean that departments are participating in a zero-sum game to the extent that whichever department has the greatest reputation will gain for itself more institutional funds and more positions-to the exclusion of other departments? Or is it a simple matter of horizontal competition for recognition without regard for competition for resources? Or is it a need to justify its programs and positions to just maintain them? These are questions that need answers-especially with respect to how much a department's reputation benefits it within the institution.

At Collegial U, the English department clearly seeks people who "are among the most extraordinary people in the country ... who are going to be leaders in the profession. . . . one thing that does count is that notion of superior intellectual attainment." The engineering department also says, "And, um, what we look for is the best. . . .we hope that we're hiring the best. And we are, we do feel fortunate in that we almost always get our person. I mean the top person that we in our search, the person that we go after, we almost always get that person." The psychology department hedged, but he also said the department sought faculty who are "outstanding in the areas of research, teaching and university and professional service." Because of the way this chair hedged his answers and in one instance even backpedaled, his statement here has the ring of a canned speech and is much less believable as a valid opinion than the other two. 
The chair of engineering at Bureaucratic U noted that some changes had occurred over the past few years, bringing "our standards into a good alignment in the college as a whole, and so it's become a more serious decision [tenure]." He adds that the department is "hard on ourselves, feeling it's better to be hard on ourselves and then be able to argue effectively than sort of cast it out there and hope." So here is a department that holds itself to some "higher" standard so that it can put itself in a position to get what it wants when that is necessary.

The chemistry chair says his department has "consensus in terms of what we are looking for." And what they are looking for is "originality, . . . recognition, . . . evidence of peer review, . . . funding." The P\&T committee chair added that another "issue is whether the research that's being done is of a form that is likely to be. . .continue to be successful in the future."

In the psychology department, the chair said rather straightforwardly that one issue in making very strong recommendations that "are a notch or so above the other units that are in the college" is "to increase the reputation of the department." This department is specifically seeking "somebody who is going to be a solid teacher of undergraduates and graduate students, ... somebody who is going to contribute to the discipline, . . . [and] a colleague who is carrying their weight in terms of other departmental responsibilities. . ."-the teaching, research and service triumvirate? Is this department, therefore, looking around at other disciplines to see what other fields are doing and guiding its promotion and tenure criteria accordingly?

This picture is very different from that described by either Biglan or Alpert. And, although this is a single instance, there is a suggestion, 
however tenuous, that other departments at other universities are looking around to see what other departments are doing about tenure and promotion-either to see what they can get by with or to see what they have to do to be that "one notch or so above." The English department chair admitted that "As a whole, to be candid, we are a department that, over the 30 years I have been here, has tended to ask too little rather than too much." But despite this failing, he says, "we are always looking for breakthrough stuff, all right, and on the assumption that one can recognize breakthrough stuff when one sees it, yes."

At Shared-Governance $\mathrm{U}$, the engineering chair provided the sweeping statement that his department's goals are to tenure and promote individuals with "solid contributions in essentially all of the areas and excellence in teaching or research and scholarship." The P\&T committee chair said that "the objective here is to make sure that the department increases its stature and the quality of the student increases." Although he was the only one to mention student quality, it is a response that indicates acknowledgment (if only a philosophical acknowledgment) of the relationship of research to instruction and students at every level.

The chemistry chair also says, "We want to have someone who makes a solid contribution to the department in certainly in the areas of teaching and research.... We would like to have someone who can really help make our reputation in the area of scholarship. I think that is very important to us, and that's why the outside letters make such a difference." Again, "solid contribution," but more, a concern over reputation. And one gets the impression it is not just the national reputation, but the national reputation as it increases the departmental reputation within the institution. 
The English department seeks "effective teachers . . . and productive scholars who are producing work that is of high quality and that they are participating in and making contributions to the profession." The P\&T committee chair was somewhat more specific, noting "we want evidence of good teaching. We want evidence of reasonable contributions with the promise of significant contributions in scholarship. We do not expect our people to be leading, brilliant scolars in the fields just in order to get tenure." This was a rather refreshing comment-admitting that not everyone can be "the best in their field."

The psychology chair was even more forthright in his recognition that "officially, the expectation for research is the same as elsewhere, but in practice we can get by with somewhat weaker credentials [because the department is an undergraduate unit only and faculty have higher teaching loads]." His goals for tenure are also realistic: "competence and a clear indication they are going to continue to perform competently. I want people who will be scholars for the rest of their lives. I want people who like what they do." Again, a refreshing departure from the standard mantra of "excellence," "best in their field" and "superior quality."

Note that, in my own interpretation of the interviews, the two most candid interviewees were at Shared-Governance U, which is the only institution for which there appeared to be hidden conflicts between the administration and the departments. This may be further validation that, indeed, some major conflicts exist there. 


\section{Teaching, Research and Service}

A similarity across all departments at all universities was the relationship of teaching to research in the tenure and promotion evaluation and their relative weight with respect to the third leg of the higher education triumvirate-service. In each case, research and teaching were ranked equal or within a few percentage points (15 was the maximum) of each other with service, variously defined, of much lower importance (ranging from 5 to 15 percent of total effort). Collegial U defined two distinct realms of service-service to the community and service to the profession, and, except for this dual definition, the nature of service appears to be everywhere rather amorphous, ranging from serving on departmental committees to serving on advisory and review boards to giving talks at the local high school. A broad spectrum of activities appear to fit in the service category—in fact, everything that cannot be comfortably classified as either scholarship or teaching drops into the service basket.

The chemistry chair at Shared-Governance U says that "teaching has certainly become much more important in the last . . certainly since I have been chair. I've been chair since 1984, and teaching has increased in importance I would say nearly every year. . . . [I]f there are problems in the teaching area, then it's not so certain that everything is going to go well." He said that "good teaching can tip the balance" in promotion from associate to full professor, although "where tenure is involved, that becomes more problematic. . . . but . . . we even had really outstanding teaching make a difference." He says teaching "may be 40 percent-45 percent-and scholarship about the same," but "service [is] much less." The English department chair said essentially the same thing: “. . . a faculty member who was not teaching effectively would have 
trouble being tenured ... and a problematic record in teaching would be something that would be problematic for promotion and tenure." The P\&T committee chair was of the opinion that "teaching and scholarship are equally important, both of them more important than service." The P\&T committee chair in engineering thought that "people realized they were losing some excellent teachers, and I think people started to realize that, if you're a land-grant college, a land-grant university, perhaps the main emphasis should be on educating a large mass of undergraduate students instead of spending an awful lot of time and funds and attention on the graduate programs." But, despite the attention to teaching undergraduates, he was of the opinion that "research is important, and research, if properly pursued, makes a better teacher out of a person." In psychology, the chair was of a similar opinion: "Research and teaching are about equal weight in actual practice." However, since his personal opinion was somewhat at variance with that assessment, he "would give research a 4, teaching a 3 and 1 or less for service. . . We have a higher research expectation than other schools with the same teaching loads."

Only two chairs answered the question of the relative importance or weight of teaching and research at Bureaucratic U, but these are similar to what we have seen at Shared-Governance U. In fact, not only mechanical engineering, but all of the engineering college "allocate[s] effort at the level of 45 percent for teaching, 45 percent for research and 10 percent for service unless specific arrangements are made to do something different from that." The P\&T committee chair noted, as did the engineering P\&T chair and the chemistry chair at Shared-Governance U, that the weighting between teaching and research "has moved in the direction of becoming co-equal. . .equal." He also commented that the 
college has a student-initiated teaching award which "has been won every year for the last 16 by research-active faculty. . . . Faculty members with . . the poorest teaching records tend to also have the poorest research records. . . . I think the feeling amongst the faculty members in the department is that the two really do go hand in hand and are mutually supportive."

The psychology chair also noted that a "contribution to knowledge is very important to keep the discipline moving forward, and if you like, to improve the quality of our teaching. If we stop doing that, I think we're in big trouble. . . . Teaching is kind of a necessary but not sufficient condition for tenure or promotion." Even at the "high status," Collegial $\mathrm{U}$, teaching is an essential adjunct to research: "[the university] probably wouldn't promote a brilliant teacher who had a weak research record, but it certainly might not promote a person with a good research record who wasn't a good teacher," said the English chair. He was of the opinion that "teaching is very close to it [research]. But I would say, let's see, um, put it 55, 40 and 5 for that."

The chair of engineering said the relative importance of teaching and research is "different than it was 20 years ago, but this is what I believe is the case right now-I believe that teaching and research are just about equal in weight. . . . One would not be able to promote to tenure a faculty member who was not getting good teaching evaluations." He added that "it used to be possible to advance with horrible teaching, but now I would say that the only cases that I put forward, the only cases that I can recall that I put forward that were not successful as I had recommended them were due to perceived shortfalls in the teaching component." If he "had to put a percentage on things," he would place it 
"about 45 percent teaching and about 45 percent research and about 10 percent service." And although he admitted that there "are some problems with that [evaluatng teaching], of course, a person absolutely cannot advance now without good teaching." Making an even stronger statement, he was of the definite opinion that there is an "entirely overwhelming relationship" between teaching and research: "I mean, we don't have people who don't do research and we don't have people who don't teach." He added that, "except possibly in introductory courses, there's not a real clear line between them."

When asked the question about the relative importance of research and teaching, the psychology chair stated that research, teaching and service "are all important, all equally important." But when asked about the relationship of teaching to research for the university as a whole, he said, "Yes, I would say research and teaching, I'm not sure about the service. And I would also back off in my department."

University-level administrators were also all of the opinion (or so they all said) that research is important to teaching but that good teaching is an essential component for tenure and promotion.

At Shared-Governance U, the provost said that "those involved . . . in research and discovery bring those insights and the cutting-edge kind of understanding of a field into the classroom, into the teaching." Interestingly enough, this university has just revised its general promotion and tenure guidelines, in the process of which there was evidently a concerted effort to "try to reduce the emphasis on only original research as what would be acknowledged or credited." The associate provost said "it varies a lot on who you talk to, I guess," but he did think that scholarship "does in fact make a faculty member a more well rounded and a 
better. . to better function in other assignments like in teaching or in extended education, conference consulting, whatever." He also said that with the new guidelines the university is "moving away from" the attitude "that if you are not a researcher, you are a second-class or that kind of issue."

The same philosophy of the connection between research and teaching is in evidence at Bureaucratic U. The provost was firm in saying that "it is important as we look at who is an effective faculty member, we recognize that not everyone is going to do. . .to do uh. . . sort of original work throughout his or her career, But it is important to synthesize and to put new spin on the work of others and to transmit that into teaching so we are teaching cutting-edge concepts and are using in [sic] cutting edge concepts even in Arts and Humanities to be sure that we using the most recent critiques, the most recent ways of thinking about canon so that students are exposed to the intellectual creativity of various scholars."

Additionally, "I think that there is a strong sort of symbiotic relationship between research and teaching. And what we have talked about here is an expectation that all of our faculty are research active and student centered. Emphasizing the 'and,' not the 'or." When asked what student centered means, she explained that "It means, in our sense, being concerned about not only being a good teacher in a technical sense, but being concerned about the student as a learner and a partner in learning." The associate provost was of the same bent, believing that "the scholarly activity is the stock of knowledge that one imparts to students and that the vitality and quality of the instructional process are not going to be animated in terms of new ideas, new perspectives, unless 
there is an active scholarly base that is very closely connected with the teaching activity." He did note that there are "different perspectives [and] ... some variable opinion" concerning the relationship of the two activities. He also noted that a question of time commitment often arises, which promotes the idea that "the research and scholarly activity is competitive with time and effort devoted to teaching and outreach. So in that sense there would be some argument about whether these are close coupling or whether as a time dimension they are competitive." The other question that frequently arises is one of rewards and, "although changing, I think fairly rapidly in recent years, that the research and scholarly record . . . is the coin of the realm, the only thing that really counts. And so in that sense, that reinforces those activities at the expense of others." The associate provost at Collegial $U$ said that the people at that institution feel "that excellent research leads to excellent teaching, that one's research informs one's teaching and that it's a way of bringing both graduate and undergraduate students into the research community." This is so much more of the same in words that we have seen elsewhere. The only person who expressed a quite different view was the chair of the university level, faculty review committee at Collegial U. He was of the personal opinion that research and teaching are not related: "I view the teaching as independent." But then he said that "there's a skill in teaching in which you are engaged with cutting-edge material because of your research that you couldn't if you weren't doing cutting-edge research." In the final analysis, he thought that "there probably is a relationship, although I imagine it's a weak one." 


\section{Summary of Findings}

With respect to the initial research questions, we have some answers to the eight research questions of phases I and II:

\section{Phase I}

1. To what extent does structure vary with respect to size, geographic location, history, cultural milieu, stated goals, level of operational control, and external funding in different institutions?

2. To what extent do goals vary with respect to size, geographic location, history, cultural milieu, and external funding in different institutions?

3. To what extent do operations and level of centralized control vary with respect to size, geographic location, history, cultural milieu, mission and goals, and external funding in different institutions?

Because of the nature of the findings, we will answer all three of these questions at one time. According to the statistical analysis of demographic data for all 31 state, land-grant enterprises for which usable data exists, there is no significant relationship either among the demographics or between various demographic data and goals, structure or operations. As we can see from examining the charts of mean values (see Appendix E), the means are all quite close. There is no significant difference, so no significant, meaningful correlation between or among these data. Structure, goals and operations do not depend on and are not statistically significantly related to, size, cultural milieu, history (founding date), external funding, administrative hierarchy or level of operational control, geographic location (size of local town, commuting popula- 
tion, region of the country), or student body make-up (numbers of graduates and undergraduates).

\section{Phase II}

There are five questions in Phase II. I will discuss the major findings related to each one.

\section{To what extent are the enterprise and departmental authority} structures congruent?

Discussion of promotion and tenure (or review) committee structures (see Table 6, page 44) indicates little, if any, relationship to the authority structure as indicated by content analysis of faculty handbooks. Committees in all departments interviewed at Collegial $\mathrm{U}$ are ad hoc, appointed by the chair. Committees at the other two enterprises are constituted in a number of ways. Committees may be appointed or elected, with variations within that structure such as an elected chair who appoints the committee, or an elected committee with one member appointed by the department chair. What is most striking in these arrangements is the lack of pattern. Even at Collegial U, where all committees are ad hoc, two report to a subset of the department while one reports to the chair and the department. We might conclude that the structure adopted by any given department is randomly chosen. As discussed earlier, however, it would be logical that faculty coming from other enterprises would bring their own experiences with them and infuse their new department with new ideas and new ways of conducting departmental duties and responsibilities. 
2. To what extent are the operations of the enterprise and the department congruent?

With respect to the operation of promotion and tenure committees, most report, for decisions on recommendations for tenure or promotion, to a subset of the department, while one (psychology at Shared-Governance U) reports to the department as a whole, including nontenured assistant professors. Review committees at Collegial U generally report to the departmental faculty who are at or above the rank the candidate is applying for; although, in one case the review committee sends separate reports to both the chair and the faculty.

Voting also has many formats, none of which depend on either the departmental operations or the enterprise. In some cases the faculty making the recommendation decision vote by secret ballot, but most vote openly in a meeting. In one case faculty vote by e-mail if they are not on campus. As we have seen, some departments have "an oral tradition" of requiring a two-thirds or three-fourths vote of approval for a recommendation to pass beyond the department to the next level of review. But, that chair noted that university requirements stipulate that if a candidate wants the dossier "to go forward," the department must send it on (Shared-Governance U).

The English chair at Collegial U noted that a two-thirds majority vote is necessary in that department, but not in others on campus, for a recommendation to carry. "If there is a discrepancy of one vote either way, there's an immediate re-vote, and that vote is final." This department also does not allow e-mail voting, although letters are accepted and read to the tenure staff-"You can't vote if you're not at the discussion." 
We have also seen that at least one department requires external funding for award of tenure; and, as we have also seen, this stipulation apparently is a direct contradiction of institutional "policy." Thus, we might now say that the operation of the enterprise has little bearing on the operation at the departmental level. There simply is too much variation and a decided lack of pattern, much as we saw when we examined the congruence of structure at the enterprise and departmental levels.

One universal factor in the operations of the review of research is the reliance on external peer reviews. Without exception, such reviews are required for tenure, though not always for promotion. The enterprise here often stipulates a minimum number of outside letters (see Table 5, page 33). The department, however, is at liberty to request much more (one chair said that they normally send out ten letters requesting external review and often get six or seven back). The important thing here, however, is that peer review is a universal requirement, and so is unrelated to the classification of the enterprise.

3. To what extent are the goals of the enterprise and the department congruent?

Totally at variance with the lack of congruence between enterprise and department with respect to structure and operation is the rather complete match between the two levels with respect to goals. But, note that all enterprises and all departments are similar in this respect. All say they want the best, the most outstanding, the most recognized, the ones with "sustainable research programs," excellence in research and teaching. Goals, thus, are universal, with no discernable differences at any enterprise or within any department. 
4. What are the most important relationships and interactions between the enterprise and the department with respect to structure, goals and operations?

Examining the relationships and interactions between enterprise and department, we find, as noted above, that the most important is the requirement of external peer review and the desire to promote and tenure the absolute best (and it is normally stated in terms of promoting and tenuring only the "best," not the "best available." The relationship between enterprise and department or department is almost nonexistent with respect to structure and so universal with respect to goals that it becomes an almost meaningless comparison. It is only with respect to operation that there appears to be an important relationship. This is particularly noticeable at Bureaucratic U, where the enterprise wants to see peer reviews from scholars at its "peer institutions." Department chairs here were unanimous in their adherence to this stricture-one chair noting that he would not want to send up a dossier that did not have at least one letter from someone at an institution on the list of desired peer institutions.

5. How do the actors in this process perceive their relationship to the discipline? to the institution? [The interview question was intended to elicit information on the clash of values, authority structures, even goals within the departments themselves; it was only partially successful, although it did yield some interesting suggestions.]

Of special interest is how some of the actors in the review of promotion perceive their relationships to the enterprise, to the department, and to the discipline. Some are wholly independent actors who see little 
relationship between what they want in their department and what the enterprise wants. One department at Shared-Governance U appears to follow its own path quietly, while another at that same enterprise railed against the restrictions placed on it. But, most chairs said they and their departments were looked upon favorably by the enterprise and had little or no conflict with it. Hints of conflict with respect to affirmative action appointments appeared when one chair noted that a departed faculty member would have been awarded tenure by the enterprise against the wishes of the department.

Noteworthy was the statement by all chairs, even the ones who hinted at conflict, that almost all recommendations of the department during the past five or six years have been approved by the enterprise. Chief academic officers mirrored this level of agreement when they said they overturn departmental recommendations in only about 5 percent of the cases sent to them, and those only when there was disagreement between departmental and college recommendations.

Knowledge of how and under what guidelines other disciplines evaluate research within the same enterprise appear to be almost wholly lacking. That was not a concern of the chairs and committee chairs interviewed. What was a concern was how they and their faculty are perceived by members of their own disciplinary members at other institutions. They pay attention to what others, outside of the local enterprise, are saying and doing. It might be logical to presume that this is so because of the general assumption that the opinions of members of their own profession are those opinions that establish the national and international reputations of their department and thus have a direct bearing on their own professional lives. 
As we shall see in Chapter V, this apparent clash of values within the enterprise has implications for understanding the nature of the enterprise. 
Table 7: $\quad$ Outline of Promotion and Tenure Committee Structure and Function at Bureaucratic U

Mechanical Engineering

1. elected promotion committee (six members)

2. appointed three-person subcommittee reviews candidate

3. promotion committee report sent to chair

4. candidate can replace on member of review subcommittee

5. candidate can make statement

English

1. Policy committee of six members (one untenured serving one-year term and five tenured serving staggered two-year terms) elected by department

2. P\&T subcommittee for each candidate

3. P\&T subcommittee recommends to Policy Committee

4. Policy Committee recommends to chair

Chemistry

1. P\&T committee elected, one person from each of four areas of chemistry

2. only tenured faculty on committee

3. chair of department appoints committee chair

4. recommendations brought to entire department in "full faculty meeting"

Psychology

1. three to four member subcommittee (only fact gatherers)

2. conflict in department over time spent discussing candidates

3. voting faculty (rank at or above) discuss and vote

4. secret ballot 
Table 8: Outline of Promotion and Tenure Committee Structure and Function at Shared-Governance U

Mechanical Engineering

1. elected committee

2. committee recommends to chair concerning whether or not to send candidate forward

3. chair involved in committee discussions

4. candidate decides to proceed

5. chair usually agrees with committee

6. candidate meets with committee

English

1. appointed committee

2. recommends to chair

3. students on committee to recommend on teaching

4. executive committee (nine members, department chair plus two from each rank, one elected at large and one elected from within rank) ratifies chair appointments to P\&T committee

5. secret ballot in committee

6. candidate can respond to committee and chair in writing (response goes in dossier)

Chemistry

1. ad hoc committee, different each year

2. appointed by chair

3. subcommittee sends review to voting members of department

4. document goes to candidate for review and discussion

5. voting department members can amend subcommittee report

Psychology

1. committee chair elected

2. committee chair appoints committee members

3. voting members of department

4. anyone can comment 
Table 9: Outline of Promotion and Tenure Committee Structure and Function at Collegial U

Mechanical Engineering

1. appointed ad hoc committee

2. related to person's area (two person in, one outside)

3. report in faculty meeting

4. faculty votes (secret ballot)

5. final report written for university-level committee

English

1. appointed ad hoc committee

2. five substantive internal evaluations which are initially anonymous and then revealed

3. report to tenure staff

4. candidate may comment or rebut

5. tenure staff votes

Chemistry

declined to be interviewed

Psychology

1. ad hoc appointed committee (two people)

2. one person in area, one in related area

3. formal written evaluation submitted to chair 


\section{Chapter V}

\section{Conclusions}

\section{Background}

As noted in the introduction, promotion and tenure decisions represent a major investment and have far-reaching repercussions for individual departments and for the entire enterprise. Because of the general assumption that academic reputations hinge on the reputations of individual faculty, it is important to examine how and why those decisions are made. Clearly, as Burton Clark said, departments and enterprise are intertwined in making those decisions, and this dissertation has answered Clark's challenge to begin to examine those relationships-in authority structures, operations and goals at both institutional and departmental levels. Alpert and Keohane began to answer Clark's questions, but both attempted to develop a useful and functional model of the enterprise based on overarching perceptions rather than by examining the characteristics of structures, operations and goals of the enterprise and of the departments and how they are congruent and interact at those two levels.

Since the primary goal of most enterprises is to tenure and promote the "best" faculty, this dissertation set out to develop an understanding of the factors that enter into the decisions to promote and tenure and how the enterprise and department interact in making those decisions. The set of questions developed for this research were aimed at increasing our understanding of the characteristics of the review of research in the tenure and promotion process and an understanding of the congruency between the enterprise and its departments. 


\section{Phase I}

To begin this characterization, a content analysis of the faculty handbooks from 31 state, land-grant, Research I and Research II enterprises (six of which are Carnegie Research II and 25 Research I) was completed. On the basis of the involvement of committees and chairs at the departmental, college, and institutional levels, each enterprise was categorized into one of three authority structures: bureaucratic, shared-governance or collegial.

Of the 25 Research I enterprises, four are bureaucratic, three collegial and 18 shared-governance.

This phase of the study also required the collection of demographic data about each enterprise. This data included the size of the student body and its mix of undergraduate and graduate students, student-faculty ratios, the number of upper administrators (deans and vice presidents), number of volumes in the library, library budgets, research expenditures, date of founding, geographic region (North, South, Midwest, Mid-Atlantic, etc.), population of surrounding community and commuting population, number of faculty, tenure densities, and full-time vs. part-time faculty. Statistical analysis of these data was conducted to answer the three questions below. Statistical consulting ws provided by Magdalena Bugaj of the Department of Statistics.

1. To what extent does structure vary with respect to size, geographic location, history, cultural milieu, stated goals, level of operational control, and external funding in different institutions?

2. To what extent do goals vary with respect to size, geographic location, history, cultural milieu, and external funding in different institutions? 
3. To what extent do operations and level of centralized control vary with respect to size, geographic location, history, cultural milieu, mission and goals, and external funding in different institutions?

The results of this analysis show no statistically significant relationships at any level in any category. We corrected for the extremely small cell size to tease out relationships between demographic information and the authority structure, operations and goals and still found no correlation. A visual inspection of the graphs of means in the demographic categories with the most complete data (see Appendix E), we saw that the means are all quite close, which is the reason we can show no statistically significant relationships.

\section{Phase II}

This phase of the research comprised interviews with department chairs, chairs of promotion and tenure or personnel committees, chief academic officers and the administrator in charge of personnel matters. Interviews at the department level were conducted in departments representing Biglan's four major disciplinary divisions: basic-hard (chemistry), basic soft (English), applied hard (engineering), and applied soft (psychology), omitting his life-nonlife categories.

The interview questions were aimed at developing enough understanding to answer the following five questions:

1. To what extent are the enterprise and departmental authority structures congruent?

2. To what extent are the goals of the enterprise and the department congruent? 
3. To what extent are the operating procedures of the enterprise and department congruent?

4. What are the most important relationships and interactions between the enterprise and the department with respect to structure, goals and operations?

5. How do the actors in this process perceive their relationship to the enterprise? to the discipline outside of the enterprise? [This was intended to elicit information on the clash of values, authority structures, even goals within the departments themselves.]

\section{Structure}

Having examined the structure of the departmental promotion and tenure committees (where such exist) and how departments arrive at the recommendations submitted to the university's upper administration, what can we say about the relationship of these structures and operations to those of the university itself? What can we say about their relationships to those of other departments in the same discipline at other institutions and to other departments within the same institution? Is there congruence at any level?

As we have seen, the structure of the departmental P\&T committees is highly variable, both within each enterprise and within each discipline, regardless of university. It is perhaps noteworthy to realize that all ad hoc committees are appointed by the chair, whereas most standing committees, whether constituted yearly or not, are elected-in whole or in part-by the members of the department. Note that the ad hoc structure is most com- 
mon at Collegial U (see Table 3); yet because ad hoc committee members are appointed by the chair, we might construe this to be the most bureaucratic of structures.

Additionally, although most committees, whether ad hoc or elected, report to the department (eight of the 11 for which I have interviews), some report to the chair (and in one case to the chair and to the department). Except in that one case (the engineering department at Collegial U), reporting to the chair or reporting to the department are mutually exclusive. In most cases, also, the committees are essentially "fact-finding" committees; it is the department members (who are at or above the rank the candidate is going to) who examine the "facts in the case" and actually recommend whether or not to promote the candidate. Thus, the decision to recommend a candidate for promotion or tenure appears to be truly a collegial one, not dependent on either enterprise or discipline but rather appears to be a function of the concept of professionalism (variously defined in the literature, but always including the idea that members of the profession determine its own membership and criteria for membership).

But what is "full membership" in the profession? Even that varies, with a subset of faculty voting on promotion and tenure in all departments except one, and this one, in which all faculty in the department have a vote on promotion and tenure, is at Shared-Governance U. Interestingly enough, the collegial institution allows only the subset, not the entire department, to vote on these personnel issues. So, we can conclude that collegiality as a departmental organizational structure is circumscribed under certain conditions. As to what those conditions might be, there appears to be no pattern, either within institutions or within disciplinary areas. This finding does not seem to fit any established organizational 
theory, including Biglan's theory of disciplinary differences, and directly contradicts Alpert's matrix model.

In addition, let us note that some departmental structures, even though the department members have a voice in elections, are so construed as to leave, on close examination, a great deal of power in the hands of the department chair. This phenomenon is particularly evident in the English department at Shared-Governance U. Recall that here the chair appoints the P\&T committee, which appointments are ratified by an elected departmental "policy committee." But, and this is an important point, the department chair serves on the Policy Committee. The P\&T committee then sends its recommendations to the chair. Also at Shared-Governance U, the engineering department committee forwards its recommendations to the chair; but here the committee is elected. We find that same pattern at Bureaucratic $U$ in both the English and engineering departments.

What does this tell us about the relationship of the institutional structure to the departmental P\&T structure? It suggests that the institutional structure does not really have an impact on how the department structures its internal affairs. Additionally, given the fact that the departments we are dealing with here are English (soft, pure) and engineering (hard, applied), we would be hard pressed to find two more philosophically disparate disciplines. Yet they use the same structural arrangement. Further, this surprising discovery suggests that the efforts to construct a model that will "describe" institutions of higher education are doomed to failure. All of the models have some validity, but they all fail to provide a complete snapshot of the organization called higher education. Pieces of each model hold for portions of different institutions. 
Perhaps, rather than seeking $a$ single model, we should be seeking traits that can help us determine which parts of which model to use in certain situations, or characteristics of universities that can help us determine what these institutions do best or how they behave academically. But even there, the variability we are seeing both within institutions and within disciplines across institutions suggests that (at least for promotion and tenure issues), we are going to fail to find one model that will hold everywhere.

Before leaving discussion of structure behind, let us look at the one concept that appeared to be a unifying idea: shared governance. We have seen that university administrations are loathe to go counter to the wishes of the department in academic matters (or they say they are). This is part and parcel of the idea of shared governance in which the department handles academic matters and the university administration takes care of nonacademic matters.

Evidence of the value of shared governance is particularly prominent when we look at the collegial institution in this study. This institution is one of only three land-grant universities in the initial set of 35 institutions with what appears to be faculty control over promotion and tenure decisions-in which the faculty handbook states that decisions "may" involve members of the upper administration (provost and president). This is also an institution in which all upper administrators are active members of their disciplinary departments. Although the chief academic officer recommends personnel actions to the president of the university, there is a universitywide committee of faculty who evaluate promotion dossiers and recommend action to the chief academic officer. When asked, this officer said that there would have to be a truly compelling reason to abrogate the 
recommendation of the university committee. Yet, despite this evidence of faculty control of the institution, two interviewees noted that their institution was the epitome of shared governance in higher education.

The only other facet of the structure of P\&T committees that is truly congruent across all systems is the ad hoc vs. standing committee structure: ad hoc committees in this study were uniformly appointed, while standing committees all have elected members (in only one case was only one member elected.).

Thus, we find that Biglan's disciplinary differences do not carry into the P\&T structure. Additionally, Alpert's matrix model does not seem to have validity in this situation either.

\section{Operation}

The interviews suggested that the more active the faculty are in the institutional decision-making process and the more active they are as scholars in their own field, the stronger the institution appears to be academically and the higher its academic standards and reputational ranking. (In the last two U.S. News \& World Report issues dealing with university rankings, both Collegial $\mathrm{U}$ and Bureaucratic $\mathrm{U}$ were in the top 100 of the first tier; Shared-Governance U was in the middle of the pack in the second tier.) The relationship of faculty involvement in institutional governance with reputational rankings and the individual faculty record of scholarship needs to be tested.

The corollary to this is the weaker the faculty are as academics, the more powerful is the central administration and the more prominent are factors other than scholarship in promotion and tenure decisions. Associ- 
ated with this dichotomy is the level of dissatisfaction and unhappiness, which appears to be highest at the bureaucratic institution and lowest at the collegial one. At the enterprise categorized in this study as shared-governance, one chair expressed clear unhappiness at the level of control by the state and administration over academic matters such as curriculum.

At that same university, one chair said that an unwritten rule in his department was that faculty would not be tenured unless they had external funding for their research. When asked about the importance of external funding, the provost stated categorically that external funding was not an essential element for either tenure or promotion. This suggests not only a level of unhappiness, but a sense of disenfranchisement which, if continued, could lead to apathy and a continuing spiral of faculty relinquishing control of academic matters to the administrative bureaucracy. This again needs to be tested to see if there is any essential relationship between faculty disenchantment and disenfranchisement to institutional structure and reputational rankings. Although all reputational rankings are flawed in some sense, they do provide a reference point.

In addition, let us emphasize that departments appear to operate idiosyncratically, regardless of what might be occurring at the level of the enterprise or even at the cross-enterprise level of the discipline. As already noted, however, this finding is not so surprising in light of the fact that departmental members come from many different enterprises, many different backgrounds, many different programs and have many different goals and agendas.

It is noteworthy to mention again that, even though these enterprises were classified according to statements in the faculty handbooks, they all 
function in much the same way-i.e., they all operate in a shared-governance fashion, with faculty making recommendations at the disciplinary level and those recommendations traveling up the bureaucratic ladder to the top spot where the final decision is made to approve or not approve the recommendations. Also noteworthy is the fact that only administrators, not rank and file faculty, serve on the university committee at Shared-Governance U; whereas at Collegial U only faculty serve on the universitywide committee.

In an interesting comment, the chair of the universitywide committee at Collegial U stated that "you have to learn who to trust and who not to trust in the system. These are repeat players, so you see what, you know, you get effective comparison.... And so one of the first things one does as one learns the system is understand who one is dealing with." This implies that things do not operate as smoothly as one would like and that the process involves power plays, politics and personalities. This statement upholds rather clearly Bachrach's political model of the university.

\section{Goals}

Goals and objectives are the one really unifying aspect of this study. Every institution appeared to be concerned with both "equity" (not "equality,' but 'fairness') and reputation. In turn, departments were uniformly concerned with fairness and reputation, but most of all with reputation.

As we have already seen, every department makes use of external peer reviews of the "quality" of the work of candidates for promotion and tenure. Although, as the associate provost at Bureaucratic U said, "What has happened over the past 15 years increasingly, pretty much everyone 
uses it [peer review]. It started predominantly in the sciences and then spread out in terms of the other disciplines." This is one example of how practices in the sciences have spread to other disciplines; another is the dependence on published work in evaluating "productivity" and "value."

In only one department does it appear that internal reviews may be as important as external ones in the evaluation of an individual's scholarship. This clearly extends the findings of research conducted at Stanford University that found that faculty perceive their colleagues to wield more influence and power in evaluations [Hind et al., 1974]. These findings clearly uphold Alpert's matrix model as it pertains to connections and influence among different units and individuals in the discipline, but this is a result of the reliance on external reviews-and external reviews necessarily come from faculty in the same discipline at other institutions (whether university or business).

However, as Alpert pointed out, the "rating game" tends to produce conformity, and the units with the greatest prestige rating wield power over those less fortunate, as we have seen at Bureaucratic U. Additionally, this is true among disciplines, as Alpert stated: A narrow definition of excellence has also served to impose the values of the most powerful disciplines on the less prestigious disciplines and professional schools and, in the process, has denigrated their intended purposes." Perhaps, though, Shared-Governance U's attempts to define scholarship more broadly is an attempt to break this pattern of dominance.

Another almost universal occurrence is the attempt to counsel into leaving those who are not likely to make the grade. Is the attempt to counsel faculty out before the "up-or-out" decision has to be made an effort to 
"save face?" to increase the internal reputation-and thus the internal power-of the department? or to avoid possibly acrimonious grievance situations and lawsuits? In support of both the saving face theory and the theory of internal power is the comment of the chair of psychology at Bureaucratic U: "Many years ago, we used to try to get somebody up as soon as possible, and we'd think it was somewhat of an insult if the university turned that person down. I've argued over the years that was foolish and what we should do is wait and send up strong cases. ... [W]e like to send a message to the college about the department when we send somebody up for reappointment and promotion. We want to send up very strong cases. And frankly, we want those cases to be, if you like, a notch or so above the other units that are in the college."

Another goal is to tenure faculty who will be "productive members of the department." Now, that phrase clearly has multiple meanings, as the guidelines at Shared-Governance $U$ indicate that the requirement for "collegiality" is part of the concept of productive. For some, productive means producing published work-either abstracts in conference proceedings, or books, or papers in refereed journals. But productive also means getting external funds, being cited (although it is not clear if being cited in a negative sense is looked upon as a plus in the productivity column), producing master's and doctoral students, giving invited lectures, winning awards. And, for those concerned with collegiality, it means serving on departmental committees (as well as university and professional committees) and "working well" with colleagues.

The desire for a professor to be "collegial" is much more widespread than we might have imagined, with the goal of "working well with others" 
and the avoidance of undue conflict appearing in eight of the eleven departments interviewed. But let us note that collegiality does not mean agreement. As the chair of English at Bureaucratic U said, "I think we all agree it's Tuesday, but beyond that, I'm not betting." What collegiality does mean is lack of severe conflict, as the chair of psychology at Bureaucratic $\mathrm{U}$ noted, "I may want to go back and be a professor once again, and I want to be listened to, too. ... So I tend to listen to my colleagues." Does this mean toeing the proverbial line? Not necessarily, although the danger is there. And in academically weak departments the danger is much greater-note that interviewees at the collegial Collegial U did not mention collegiality as being an important factor. The importance of collegiality and what it means for promotion and tenure warrants further exploration as this study was able only to uncover its presence and prevalence.

Another goal, heavily tied to operation, is the desire-rather necessity - that a candidate be an excellent teacher and be involved with students. As the provost at Bureaucratic U said, it is the "and," not "or." As we have seen, there are different views of how research informs teaching-and only one person said he thought that there was only a weak connection, if any. But even if there is no connection, the statement that good to excellent teaching is required is universal. Its relationship to research is also almost a consistent one, with most department chairs of the opinion that the relative importance of research to teaching is $45-45$ or $40-45$. Only one department chair thought the spread was as much as 15 percentage points (55-40, which leaves only 5 percent for service). There is no difference among disciplines or among institutions on this topic-it is universal and representative of a growing national concern and trend, perhaps a backlash against concept of the concept of the "ivory tower professor" who 
spends all his time on his own research and never touches down to contact students. Or perhaps in some instances it is indicative of a growing recognition that to have a real university there need to be both students and faculty who teach those students while conducting their own research and scholarship.

Along this same line, we can find more than one university using the term "student centered" in its mission statement, Bureaucratic U among them. As one chair said, "It is our mantra-we are a research-intensive, student-centered, learning community."

What does this analysis finally tell us? First, we see that disciplines look to themselves for a definition of value. The departmental attention to the institutional requirements and goals is primarily one of knowing how the land lies so that they can go through the appropriate motions to get what they want. In this sense, we are seeing the university in light of Bachrach's political model.

Second, some level of discordance is evident in the more bureaucratic university. Administrators talked about a "buy-in" on the part of faculty at both Bureaucratic and Collegial universities. Is there some way to tease out the characteristics of a university that produce the greater harmony? The suggestion is perhaps that internal harmony is a product of the congruence of institutional and departmental goals and is perhaps related to Cameron's theory of effectiveness. This would certainly follow logically from a large number of studies but has been outside the scope of this research.

Third, Biglan's findings of disciplinary differences are clearly in evidence in the operation of evaluating research but appear to have no bearing on the structure the department uses for its P\&T process. Fourth, the 
institutional structure, according to the analysis in this study, bears no relationship to the departmental structure in the P\&T process. And, fifth, since goals and the peer review requirement are almost universally the same (excellence, national and international recognition, high quality, etc.), we cannot relate them to any other aspect of the study in a meaningful way. What is needed is a definition and understanding of how these subjective qualifications are derived-do they really mean conformity across institutions, where, as Alpert suggested, the most prestigious departments at the most prestigious institutions determine what is acceptable everywhere else? It would seem that this is strongly upheld by the simple fact of the general reliance on external peer reviews for promotion and tenure. But the English department at Collegial U injects a note of optimism here. They seek free thinkers and are willing to take risks on new and controversial ideas. The chair pointed out that they have hired people like . . . and . . . "who were picked out early on . . . [as] people who are going to be leaders in the profession." This department is both willing and able to "take chances on somebody who looks a little experimental, a little ahead of his time ..."

\section{Recapitulation of Conclusions with Respect to Research Questions}

With respect to the initial research questions, we now have some answers to the eight research questions of phases I and II:

\section{Phase I}

1. To what extent does structure vary with respect to size, geographic location, history, cultural milieu, stated goals, level of operational control, and external funding in different institutions? 
2. To what extent do goals vary with respect to size, geographic location, history, cultural milieu, and external funding in different institutions?

3. To what extent do operations and level of centralized control vary with respect to size, geographic location, history, cultural milieu, mission and goals, and external funding in different institutions?

Because of the nature of the findings, I will answer these three questions together. According to the statistical analysis of demographic data for all 31 state, land-grant enterprises for which I had usable data, there is no significant relationship either among the demographics or between various demographic data and goals, structure or operations. As we can see from examining the charts of mean values (see Appendix E), the means are all quite close. There is no significant difference, so no significant, meaningful correlation between or among these data. Structure, goals and operations do not depend on and are not statistically significantly related to, size, cultural milieu, history (founding date), external funding, administrative hierarchy or level of operational control, geographic location (size of local town, commuting population, region of the country), or student body make-up (numbers of graduates and undergraduates).

\section{Phase II}

There are five questions in Phase II, the interview phase of the research. I will discuss the major findings and conclusions related to each one:

Discussion of promotion and tenure (or review) committee structures (see Table 6, page 44) indicates little, if any, relationship to the authority structure as indicated by content analysis of faculty handbooks. Committees in all departments interviewed at Collegial $U$ are ad hoc, appointed by 
the chair. Committees at the other two enterprises are constituted in a number of ways. Committees may be appointed or elected, with variations within that structure such as an elected chair who appoints the committee, or an elected committee with one member appointed by the department chair. What is most striking in these arrangements is the lack of pattern. Even at Collegial U, where all committees are ad hoc, two report to a subset of the department while one reports to the chair and the department. We have now seen that departmental authority structures at both bureaucratic and shared-governance enterprises are largely collegial in nature, and departmental authority structures at the collegial enterprise are constituted in a more bureaucratic fashion. We can thus conclude that the authority structure of the enterprise is not related to the authority structure of the department.

With respect to the operation of promotion and tenure committees, most report, for decisions on recommendations for tenure or promotion, to a subset of the department, while one (psychology at Shared-Governance $\mathrm{U})$ reports to the department as a whole, including nontenured assistant professors. Review committees at Collegial U generally report to the departmental faculty who are at or above the rank the candidate is applying for; although, in one case the review committee sends separate reports to both the chair and the faculty.

Voting is another aspect of the operations that has no pattern and does not depend on the authority structure of the enterprise or of the departmental committee. In some cases the faculty making the recommendation decision vote by secret ballot, but most vote openly in a meeting. In one case faculty vote by e-mail if they are not on campus. As we have seen, some departments have "an oral tradition" of requiring a two-thirds or 
three-fourths vote of approval for a recommendation to pass beyond the department to the next level of review. But, that chair noted that university requirements stipulate that if a candidate wants the dossier "to go forward," the department must send it on (Shared-Governance U). The English chair at Collegial U noted that a two-thirds majority vote is necessary in that department, but not in others on campus, for a recommendation to carry. "If there is a discrepancy of one vote either way, there's an immediate re-vote, and that vote is final." This department also does not allow email voting, although letters are accepted and read to the tenure staff"You can't vote if you're not at the discussion." We have also seen that at least one department requires external funding for award of tenure; and, as we have also seen, this stipulation apparently is a direct contradiction of institutional "policy." Thus, we might now say that the operation of the enterprise has little bearing on the operation at the departmental level; neither does the authority structure of the enterprise have an effect on departmental operations. There simply is too much variation and a decided lack of pattern, much as we saw when we examined the congruence of structure at the enterprise and departmental levels.

One universal factor in the review of research is the reliance on external peer reviews. Without exception, such reviews are required for tenure, though not always for promotion. The enterprise here often stipulates a minimum number of outside letters (see Table 5, page 33). The department, however, is at liberty to request much more (one chair said that they normally send out ten letters requesting external review and often get six or seven back). But, since the requirement of peer review is univer- 
sal, we can make no distinction either among or between enterprise or department.

Totally at variance with the lack of congruence between enterprise and department with respect to structure and operation is the rather complete match between the two levels with respect to goals. But, let us note that all enterprises and all departments are similar in this respect. All say they want the best, the most outstanding, the most recognized, the ones with "sustainable research programs," excellence in research and teaching. Goals, thus, are universal, with no discernable differences between an enterprise and its departments or among equivalent departments at different enterprises.

When we examine the relationships and interactions between enterprise and department, we find, as noted above, that the most important is the requirement of external peer review and the desire to promote and tenure the absolute best (and it is normally stated in terms of promoting and tenuring only the "best," not the "best available." The relationship between enterprise and department or discipline is almost nonexistent with respect to structure and so universal with respect to goals that it becomes an almost meaningless comparison. It is only with respect to operation that there appears to be an important relationship. This is particularly noticeable at Bureaucratic U, where the enterprise wants to see peer reviews from scholars at its "peer institutions." Department chairs here were unanimous in their adherence to this stricture-one chair noting that he would not want to send up a dossier that did not have at least one letter from someone at an institution on the list of desired peer institutions.

We cannot conclude, however, that the differences in interactions we see are due to the authority structure at the enterprise, especially in light 
of the fact that all departments at Bureaucratic $U$ have their own by-laws and promotion and tenure statements while none of the departments at Shared-Governance U have such a document.

Of special interest is how some of the actors in the review of promotion perceive their relationships to the enterprise and to the discipline. Some are wholly independent actors who see little relationship between what they want in their department and what the enterprise wants. One department at Shared-Governance U appears to follow its own path quietly, while another at that same enterprise railed against the restrictions placed on it. But, most chairs said they and their departments were looked upon favorably by the enterprise and had little or no conflict with it. Hints of conflict with respect to affirmative action appointments appeared when one chair noted that a departed faculty member would have been awarded tenure by the enterprise against the wishes of the department. Noteworthy in this respect was the statement by all chairs, even the ones who hinted at conflict, that almost all recommendations of the department during the past five or six years have been approved by the enterprise. Chief academic officers mirrored this level of agreement when they said they overturn departmental recommendations in only about 5 percent of the cases sent to them, and those only when there was disagreement between departmental and college recommendations.

Knowledge of how and under what guidelines other disciplines evaluate research within the same enterprise are almost wholly lacking. That was not a concern of the chairs and committee chairs I interviewed. What was a concern was how they and their faculty are perceived by members of their own disciplinary members at other institutions. They pay attention to what others, outside of the local enterprise, are saying and doing. We might 
conclude that this is so because of the general assumption that the opinions of members of their own profession are those opinions that establish the national and international reputations of their department and thus have a direct bearing on their own professional lives. The suggestion that a small number of "stars" set standards and criteria can be construed to uphold Alpert's contention that the peer review system is "a rating game that places far greater rewards on conformity than diversity" and imposes the values of the more powerful on the less powerful. Although Alpert was talking about interdisciplinary influence, his remark would also hold for intradisciplinary, interenterprise influence.

\section{Future Studies}

We have determined some interesting aspects of the evaluation of research for promotion and tenure. Many of these-such as collegiality; levels of satisfaction and contention; the relationship of satisfaction to goals, operation and structure; and definitions of scholarship-require further investigation. These are some of the ways the work begun in this paper might be extended.

Another area that this study was not designed to examine in any depth is the relationship of the roles of administrators in personnel matters and their perception of their roles in the institution (they see themselves as trendsetters and guides). Since this study was not designed to examine upper administrators and their perceptions, actions and roles in any depth, this would be a fruitful topic of investigation in the future.

Future studies should involve faculty in the different ranks rather than the chairs of personnel/promotion committees. Chairs and other 
departmental administrators can provide one view of a departmental process. But to really understand this evaluation process, researchers need to ask faculty (both tenured and nontenured) about their roles, their perceptions, their relationships with colleagues and with the administration of the enterprise, their personal goals and how those relate to departmental and institutional goals.

Along these same lines, and given the apparent popularity of the ad hoc, chair-appointed structure for departmental personnel committees, it seems worthwhile to investigate how the personality of the chair affects the department and the promotion and tenure process. The potential for control and manipulation is clear. Is there a separation of personality from departmental governance structure?

It has also been suggested that, as universities develop partnerships with industry and government, and as legislatures demand and obtain more and more control over the institution, the faculty is losing its involvement in setting standards in both curriculum and research. Also, as more faculty resort to the courts to settle disputes about tenure, the courts are rewriting faculty handbooks. Balch's overview of the legal system's involvement in higher education thus warrants another look.

Despite some drawbacks and the fact that this study has been able to develop only tentative suggestions rather than solid conclusions, it has pointed the way to fruitful and informative future research-research that will help us understand the characteristics of promotion and tenure evaluations, how they develop, how and why they differ within the enterprise and within the discipline. 


\section{Bibliography}

Adkinson, Judith, "The Structure of Knowledge and Departmental Social Organization," Higher Education, Vol. 8 (1979): 41-53.

Allison, Paul D., "Inequality and Scientific Productivity," Social Studies of Science, Vol. 10 (1980): 163-179.

, Processes of Stratification in Science (New York: Arno Press), 1980, Ph.D. Dissertation, University of Wisconsin, 1976. and Stewart, John A., "Productivity Differences among Scientists,” American Sociological Review, Vol. 39 (1974): 596-606.

Alpert, Daniel, "Performance and Paralysis: The Organizational Context of the American Research University," in Organization and Governance in Higher Education (Marvin W. Peterson, Ellen E. Chaffee and Theodore H. White, editors), ASHE Reader Series, Ginn Press (Needham Heights, Massachusetts), 1991: 76-102.

Anckar, Dag and Ramstedt-Silen, Viveca, "Relating Preferences to Policy: Three Problem Areas," in Advances in Content Analysis, Karl Erik Rosengren (ed.), Sage Annual Review of Communication Research (Beverly Hills, California: Sage Publications), 1981: 89-108.

Anderson, R. C., Narin, F. and McAllister, P., "Publication Ratings versus Peer Ratings at Universities," Journal of the American Society for Information Science, Vol. 29 (1978): 90-103.

Andren, Gunnar, "Reliability and Content Analysis," in Advances in Content Analysis, Karl Erik Rosengren (ed.), Sage Annual Review of Communication Research (Beverly Hills, California: Sage Publications), 1981: 43-67.

Archambault, "Evaluation and Funding of University Research," International Journal of Institutional Management in Higher Education, Vol. 9, No. 3 (November 1985): 254-160.

Arieti, Silvano, Creativity: The Magic Synthesis (New York: Basic Books, Inc., Publishers), 1976.

Arreola, Raoul A., "Strategy for Developing a Comprehensive Faculty Evaluation System," Journal of Engineering Education, December 1979: 239-244.

Babchuk, Nicholas and Bates, A. P., "Professor or Producer," Social Forces, Vol. 40 (1962): 341-348. 
Balch, Pamela M., "Faculty Evaluation in Higher Education: A Review of Court Cases and Implications for the 1980's," 1980, EDRS/ERIC ED 187285.

Baldridge, Victor J., Academic Governance, Berkeley, California, McCutchan Publishing Corporation), 1971.

Barron's Profiles of American Colleges, 20th edition (Hauppauge, New York: Barron's Educational Series), 1994.

Bayer, Alan E. and Dutton, Jeffrey E., "Career Age and ResearchProfessional Activities of Academic Scientists," Journal of Higher Education, Vol. 48 (May/June 1977): 259-282.

Bayer, A. E. and Folger, J., "Some C•correlates of a Citation Measure of Productivity in Science," Sociology of Education, Vol. 39 (Fall 1966): 381-190.

Bell, J. G. and Seater, J. J., "Publishing Performance," Economic Inquiry, Vol. 16 (October 1978): 599-615.

Bentley, Richard and Robert Blackburn, "Changes in Academic Research Performance over Time: A Study of Institutional Accumulative Advantage," Research in Higher Education, Vol. 31, No. 4 (1990): 327-345.

Ben-Zion, Uri and Eliezer, Aviva, “A Simple Test of a Screening Procedure $\mathrm{f}$ or Economics," Journal of Economic Education, Vol. 11 (1979): 48-50.

Berg, Bruce L., Qualitative Research Methods for the Social Sciences (Boston: Allyn and Bacon), 1989.

Berk, Ronald, A., "The Construction of Rating Instruments for Faculty Evaluation," Journal of Higher Education, Vol. 50 (September/October 1979): 650-669.

Beyer, Janice M. and Stevens, John M., "Factors Associated with Changes in Prestige of University Departments," Research in Higher Education, Vol. 7 (1977): 229-

Biglan, Anthony, "Characteristics of Subject Matter in Different Disciplines, "Journal of Applied Psychology, Vol. 57 (1973): 195-203 [A].

"Relationships between Subject Matter Characteristics and the Structure and Output of University Departments," Journal of Applied Psychology, Vol. 57 (1973): 204-213 [B].

Blackburn, Robert T. and Bentley, Richard J., "Faculty Research Productivity: Some Moderators of Associated Stressors," Research in Higher Education, Vol. 34, No. 6 (1993): 725-745. 
Blackburn, Robert T. and Clark, Mary Jo, "Faculty Performance," Sociology of Education, Vol. 48 (Spring 1975): 242-156.

Blau, Judith R., "Scientific Recognition: Academic Context and Professional Role," Social Studies of Science, Vol. 6 (1976): 533-545.

Blau, P. M. and Margulies, R. Z., "The Reputations of American Professional Schools," Change, Vol. 6, No. 10 (1975): 42-47.

Blume, S. S. and Sinclair, Ruth, "Chemists in British Universities," American Sociological Review, Vol. 38 (1973): 126-138.

Boyd, James E. and Schietinger, E. F., Faculty Evaluation Procedures in Southern Colleges and Universities, Atlanta: Southern Regional Education Board, 1976.

Box, Steven and Cotgrove, Stephen, "The Productivity of Scientists in Modern Industrial Research Laboratories," Sociology, Vol. 2 (May 1968): 163-172.

Braxton, John M., "Department Colleagues and Individual Faculty Publicaton Productivity," Research in Higher Education, Vol. 16 (1982): 265-282.

Braxton, John M. and Bayer, Alan E., "Assessing Faculty Scholarly Performance," in Measuring Faculty Research Performance, J. W. Crewsell, Editor, New Directions for Institutional Research, San Francisco: Jossey-Bass, No. 50, (June 1986): 25-42.

Broad, William J., “The Publishing Game," Science, Vol. 211 (1981): 1137-1139.

Brooks, "Faculty Evaluation by Formula," Journal of Chemical Education, Vol. 57 (April 1980): 295-296.

Bryden, Tom, "Actor-Reliability: Some Methodological Problems," in Advances in Content Analysis, Karl Erik Rosengren (ed.), Sage Annual Review of Communication Research (Beverly Hills, California: Sage Publications), 1981: 69-88.

Buffardi, Louis, C. and Nichols, Julia A., "Citation Impact, Acceptance Rate, and APA Journals," American Psychologist, Vol. 36 (November 1981): $1453-1456$.

Caplow, Theodore and McGee, Reece J., The Academic Marketplace (New York: Basic Books, Inc.), 1958.

"The Carrter Report on the Leading Schools of Education, Law, and Business," Change, Vol. 9, No. 2 (1977): 44-48. 
Centra, John A., "How Universities Evaluate Faculty Performance: A Survey of Department Heads," GRE Board Research Report GREB No. 75-56R (Princeton, New Jersey: Graduate Record Examinastions Program, Educational Testing Service), 1977: ED 157445 (26 pages).

Chase, Janet, "Normative Criteria for Scientific Publication," American Sociologist, Vol. 5 (August 1970): 262-265.

Christensen, Kip W. and Jansen, Duane G., "Correlates of Research Productivity for Industrial Education Faculty," Journal of Industrial Teacher Education, Vol. 29, No. 4 (1992): 23-40.

Clark, Burton R., The Higher Education System: Academic Organization in Cross-National Perspective, Berkeley, California: University of California Press), 1983. , "The Importance of Being Comparative," Review of Higher Education, Vol. 4, No. 1 (Fall 1980):

Clemente, Frank, "Measuring Sociological Productivity," American Sociologist, Vol. 7 (1972): 7-8.

Cole, Jonathan R. and Cole, Stephen, "Measuring the Quality of Sociological Research: Problems in the Use of the Science Citation Index," American Sociologist, Vol. 6 (1971): 23-29.

, "Scientific Output and Recognition: A Study in the Operation of the Reward System in Science," American Sociological Review, Vol. 32 (1967): 377-390.

Cole, Stephen; Cole, Jonathan; and Dietrich, Lorraine, " "Measuring the Cognitive State of Scientific Disciplines," in Toward a Metric of Science: The Advent of Science Indicators (Y. Elkana, J. Lederberg, R. K. Merton, A. Thackray, Eds.), (New York: John Wiley \& Sons), 1978.

Cole, Stephen, “Age and Scientific Performance," American Journal of Sociology, Vol. 84 (January 1979): 958-977.

Collins, Randall, "Competition and Social Control in Science: An Essay in Theory Construction, Sociology of Education, Vol. 41 (1968): 123-140.

Coltrin, Sally and Glueck, William F., "The Effect of Leadership Roles on the Satisfaction and Productivity of University Research Professors, Academy of Management Journal, Vol. 20, No. 1 (1977): 101-116.

Cox, Lawrence M., "Scientific Productivity: A Critical Test of Several Hypotheses,” Ph.D. Dissertation, Southern Illinois University, 1979. 
Crane, Diane, "The Gatekeepers of Science: Some Factors Affecting the Selection of Articles for Scientific Journals," American Sociologist, Vol. 32 (1967): 195-201.

, "Scientists at Major and Minor Universities: A Study of Productivity and Recognition," American Sociological Review, Vol. 30 (October 1965): 699-714.

Creswell, John W., Faculty Research Performance: Lessons from the Sciences and the Social Sciences, Washington, D.C.: Association for the Study of Higher Education, 1985.

Measuring Faculty Research Performance, J. W. Creswell, Editor, New Directions for Institutional Research, No. 50, San Francisco: Jossey-Bass (June 1986).

Creswell, John W. and Bean, J. P., "Research Output, Socialization and the Biglan Model,” Research in Higher Education, Vol. 15 (1981): 69-92.

Creswell, John, W. and Roskens, Ronald W.,, "The Biglan Studies of Differences among Academic Areas," Review of Higher Education, Vol. 4, No. 3 (Spring 1981):

Cropley, A. J. and Field, T. W., "Achievement in science and intellectual style," Journal of Applied Psychology, Vol. 53 (1969): 132-135.

Dean, J. W., "An alternative rating system for university economics departments," Economic Inquiry, Vol. 14 (March 1976): 146-153.

DeVries, David, "The Relationship of Role Expectations to Faculty Behavior," Research in Higher Education, Vol. 3 No. 2 (1975): 111-129.

Dill, David D., "Research as a Scholarly Activity: Context and Culture," in Measuring Faculty Research Performance, J. W. Crewsell, Editor, New Directions for Institutional Research, San Francisco: Jossey-Bass, No. 50 (June 1986): 7-23.

Drucker, Peter, "The New Productivity Challenge," Harvard Business Review, Vol. 69 (1991): 69-79.

Duryea, E. D., "Evolution of University Organization," in Organization and Governance in Higher Education, Marvin W. Peterson, Editor, ASHE Reader Series, Needham Heights, Massachusetts: Ginn Press (1991), reprinted from "The University as an Organization," edited by James A. Perkins, McGraw-Hill Book Company (1973), pp. 15-37.

Ellwein, "Assessing Research Productivity," Academic Medicine, Vol. 64, No. 6 (June 1989): 319-325. 
Elton, Charles F. and Rose, Harriett A., "What Are the Ratings Rating?" American Psychologist, Vol. 27 (1972): 197

Fagan, William T., "To Accept or Reject," Journal of Educational Thought, Vol. 24, No. 2 (August 1990): 103-113.

Ferber, M. A., "Professors, Performance, and Rewards," Industrial Relations, Vol. 13 (1974): 69-77.

Foster, Julian F. S., "Political mMdel of the University," Educational Record, Vol. 49 (1968): 435-443.

Fowler, Aubrey R., Jr.; Bushardt, Stephen; and Brooking, Stanley A., “An Analysis of Authorship in Management-Oriented Journals: The Relationship between School Status, Article Type, Publication Outlet, and Author Academic Position," Journal of Business Communication, Vol. 22, No. 3 (1985): 25-36.

Fox, Mary Frank, "Publication Productivity among Scientists," Social Studies of Science, Vol. 13 (1983): 285-305.

Fulton, Oliver and Trow, Martin, "Research Ativity in American Higher Education,” Sociology of Education, Vol. 47 (1974): 29-73.

Gamble, "The Relationship between Teaching and Research," Journal of Educational Thought, Vol. 19 (1985): 95-103.

Garfield, E. "Citation Analysis as a Tool in Journal Evaluation," Science, Vol, 178, No. 4060 (3 November 1972): 471-479.

Gaston, Jerry C., "The Reward System in British Science," American Sociological Review, Vol. 35 (1970): 718-732.

; Lanz, Herman R.; and Snyder, Charles R., "Publication Criteria for Promotion in Ph.D. Graduate Departments," American Sociologist, Vol. 10 (November 1975): 239-242.

Gerrity, D. M. and McKenzie, "The Ranking of Southern Economics Departments: New Criterion and Further Evidence," Southern Economic Journal, Vol. 45 (October 1978): 608-614.

Gilley, "A Ranking of the Top U.S. Economics Departments by Research Productivity of Graduates: Comment," Journal of Economic Education, Vol. 17, No. 4 (Fall 1986): 308-309.

Glenn, Norval and Villemez, W., "The Productivity of Sociologists at 45 American Universities," American Sociologist, Vol. 5, No. 2 (1978): 244-251. 
Golden, John and Fred V. Carstensen, "Academic Research Productivity, Department Size and Organization: Further Results, Comment," Economics of Education Review, Vol. 11, No. 2 (1992): 153-160.

"Academic Research Productivity, Department Size and Organization: Further Results, Rejoinder," Economics of Education Review, Vol. 11, No. 2 (1992): 169-171.

Gottfredson, S. D., "Evaluating Psychological Research Reports," American Psychologist, Vol. 33, No. 10 (1978): 920-934.

Graves, Marchand and Thompson, "Economics Department Rankings: Research Incentives, Constraints and Efficiency," American Economic Review, Vol. 12 (1982): 1131-1141.

Gray, P. H., "Using Science Citation Analysis to Evaluate Administrative Accountability for Salary Variance," American Psychologist, Vol. 38 (1983): 116-117.

"Economics Department Rankings: Reply and Errata," American Economic Review, Vol. 74, No. 4 (1984): 834-836.

Guba, Egon G. and Lincoln, Yvonna, Effective Evaluation (San Francisco: Jossey-Bass), 1981.

Gunn, "Evaluating faculty performance: A Holistic Approach," Journal of the College and University Personnel Association, Vol. 34 (Winter 1982): 23-30.

Gustin, B. H., "Charisma, Recognition and Motivation of Scientists," American Journal of Sociology, Vol. 78 (1973): 1119+1134.

Hagstrom, Warron O., "Inputs, Outputs and the Prestige of University Science Departments," Sociology of Education, Vol. 44, No. 4 (1971): 375-397.

Hancock, Terence; Lane, Jula; Russ, Ray; and Glennon, Dennis, "The Ombudsman: Factors Influencing Academic Research," Interfaces, Vol. 22 (September-October 1992): 26-38.

Hickson, et al., "Active Prolific Scholars," Communication Education, Vol. 42 (1993): 224-233.

"Active Prolific Female Scholars," Communication Quarterly, Vol. 40 (Fall 1992): 350-356.

Hind, Robert R.; Dornbusch, Sandord M.; and Scott, Richard W., "A Theory of Evaluation Applied to a University Faculty," Sociology of Education, Vol. 47 (Winter 1974): 114-128. 
Hirsch, et al., "Economics Department Rankings: Comment," American Economic Review, Vol. 74 (1984): 822-826.

Hobbs, Walter C. and Anderson, G. Lester, "The Operation of Academic Departments," Management Science, Vol. 18, No. 4, Part I (December 1971): B-134-B-144.

Hobbs, Walter C. and Francis, John Bruce, "On the Scholarly Activities of Higher Educationists," Journal of Higher Education, Vol. 44 (1973): 51-60.

Hoke, Franklin, "Top Academic Research Centers Boast Variety of Strengths, Strategies," The Scientist, Vol. 7, No. 5 (March 8, 1993): $1,4,8-9$.

"Intangible Factors Are Crucial in Research Universities' Quest for High Achievement in Science," The Scientist, Vol. 7, No. 6 (March $22,1993): 1,3,5$.

"Holdings of Research Libraries in U.S. and Canada," The Chronicle of Higher Education, 3 May 1996: A18.

Humphreys, L. G., “NSF Peer Review,” Science, Vol. 215 (1982): 344.

Jauch, Lawrence R. and Glueck, William F., "Evaluation of University Professors' Research Performance,” Management Science, Vol. 22 (1975): 66-75.

Karger, Delmar W. and Robert G. Murdick, Managing Engineering and Research, New York: Industrial Press, 1969.

Katz, D. A., "Faculty Salaries, Promotions and Productivity at a Large University,” American Economic Review, Vol. 63 (1973): 469-477.

Keohane, Nannerl O., "The Mission of the University," Daedalus, Vol. 122, No. 4 (Fall 1993): 101-125.

King, Suzanne and Wolfe, Lee M., "A Latent-Variable Causal Model of Faculty Reputational Ratings," Research in Higher Education, Vol. 27, No. 2 (1987): 99-106.

Krippendorff, Klaus, Content Analysis: An Introduction to Its Methodology (London: Sage Publications), 1980.

Kroc, Richard J., "Measuring Scholarly Productivity,” PhD. Dissertation, University of Colorado, 1983. , "Using Citation Analysis," Educational Researcher, Vol. 13, No. 6, (June/July 1984): 17-22. 
Laband, David N., "An evaluation of 50 ranked economics departments," Southern Economic Journal, Vol. 52 (July 1985): 216-240. 173-180.

, “Article Popularity,” Economic Inquiry, Vol. 24, No. 1 (1976):

, "A Ranking of the Top U.S. Economics Departments by Research Productivity of Graduates," Journal of Economic Education, Vol. 17, No. 1 (Winter 1986): 70-76.

, "Is There Value-Added from the Review Process in Economics?" Quarterly Journal of Economics, Vol. 105, No. 421 (May 1990): 341-352.

, "Revealed Preference for Economics Journals," Public Choice, Vol. 46, No. 3 (1985): 317-323.

, "Reply to Gilley, Journal of Economic Education," Journal of Economic Education, Vol. 17, No. 4 (Fall 1986): 311-314.

Larson, "Competing Paradigms for Research and Evaluation," Research in the Teaching of English, Vol. 27 (October 1993): 283-292.

Lehman, Harvey C., "The Age Decrement in Scientific Creativity," American Psychologist, Vol. 15 (1960): 128-134.

, “The Chemist's Most Creative Years," Science, Vol. 127 (23 May 1958): 1213-1222.

Levin, Sharon G. and Stephan, Paula E., "Research Productivity over the Life-Cycle,” American Economic Review, Vol. 81 (1991): 114-132.

Levitan, Alan S. and Ray, Russ, "Personal and Institutional Characteristics Affecting Research Productivity of Academic Accountants," Journal of Education for Business, Vol. 67 (July-August 1992): 335-241.

Lewis, Lionel S., Scaling the Ivory Tower (Baltimore: Johns Hopkins University Press), 1975.

Light, Donald W., Jr., "Introduction: The Structure of the Academic Profession,” Sociology of Education, Vol 47 (1974): 29-73.

Lightfield, Timothy E., "Output recognition of sociologists," The American Sociologist, Vol. 6 (1971): 128-133.

Lincoln, Yvonna, "Structure of Promotion and Tenure Decisions, Review of Higher Education, Vol. 6 (Spring 1983): 217-231. 
Lincoln, Yvonna S. and Guba, E. G., "Merit and Worth in Educational Evaluation," Educational Evaluation and Policy Analysis, Vol. 2 (1980): 61-71.

Lindsey, "Production and Citation Measures," Social Studies of Science, Vol. 10 (1980): 145-162.

Lodahl, Janice Beyer and Gordon, Gerald, "Differences between Physical and Social Sciences in University Graduate Departments," Research in Higher Education, Vol. 1, No. 3 (1973): 191-213.

, "The Structure of Scientific Fields and the Functioning of University Graduate Departments," American Sociological Review, Vol. 37 (1972): 57-72.

Long, J. Scott, "Productivity and Academic Position in the Scientific Career," American Sociological Review, Vol. 43 (1978): 889-908.

; Allison, Paul D.; and McGinnis, Robert, "Entrance into the Academic Career," American Sociological Review, Vol. 44 (October 1979): 816-830.

; McGinnis, Robert; and Allison, Paul D., "The Problem of JuniorAuthored Papers in Constructing Citation Counts," Social Studies of Science, Vol. 10 (1980): 127-143.

and McGinnis, Robert, "Organizational Context and Scientific Productivity,” American Sociological Review, Vol. 46 (1981): 422-442.

Luce, T. S. and Johnson, D. M., "Rating of Educational and Psychological Journals," Educational Researcher, Vol. 7, No. 10 (1978): 8-10.

MacRoberts, Michael H. and MacRoberts, Barbara R., "A Re-evaluation of Lotka's Law of Scientific Productivity," Social Studies of Science, Vol. 12, No. 3 (1982): 443-450.

Mahoney, M. J., "Scientific Publication and Knowledge Politics," Journal of Social Behavior and Personality, Vol. 2, No. 2 (1987): 165-176.

Manis, Jerome G., "Some Academic Influences upon Publication Productivity," Social Forces, Vol. 29, No. 3 (1951): 267-272.

Margolis, J., "Citation Indexing and the Evaluation of Scientific Papers," Science, Vol. 155 (March 1967): 1213-1219.

McDowell, J. M., "Obsolescence of Knowledge," American Economic Review, Vol. 72 (1982): 752-768. 
Meador, Mark, Stephen J. K. Walters and John M. Jordan, "Academic Research Productivity: Reply, Still Further Results," Economics of Education Review, Vol. 11, No. 2 (1992): pp. 161-167.

Meltzer, Leo, "The Productivity of Social Scientists," American Journal of Sociology, Vol. 55, No. 1 (1949): 25-59.

, "Scientific Productivity in Organizational Settings," Journal of Social Issues, Vol. 12, No. 2 (1956): 32-40.

, "Organizational Structure and Performance and Job

Satisfaction," American Sociological Review, Vol. 7 (1926): 351+362.

and Salter, James, "Organizational Structure and the Performance and Job Satisfaction of Physiologists," American Sociological Review, Vol 27 (June 1962): 351-362.

Merton, Robert K., "The Matthew Effect in Science," Science, Vol. 159 (January 1968): 59-63.

Michalak, Stanley J. and Friederich, Robert J., "Research Productivity and Teaching Effectiveness at a Small Liberal Arts College," Journal of Higher Education, Vol. 52 (November/December 1981): 578-597.

Miles, Matthew B. and Huberman, A. Michael, Qualitative Data Analysis (Beverly Hills, California: Sage Publications), 1984.

Miller, "Hubris in the Academy," Change, September/October 1990: 9-11.

Millett, John, The Academic Community [New York, McGraw Hill], 1962.

Morgan, D. R., Meier, K. J., Kearney, R. C., Hays, S. W. and Birch, H. B., "Reputation and Productivity among U.S. Public Administration and Public Affairs Programs," Public Administration Review, Vol. 41 (1981): 666-673.

Moravcsik, M. J. and Murgesan, P., "Some Results on the Function and Quality of Citations,” Social Studies of Science, Vol. 5 (1975): 86-92.

Muffo, John A., "Relationships bewteen Colleague Ratings and Faculty Compensation," Research in Higher Education, Vol. 10, No. 2 (1979): 25-36.

, Mead, Susan V, and Bayer, Alan E., "Using Faculty Publication Rates for Comparting 'Peer' Institutions," Research in Higher Education, Vol. 27, No. 2 (1987): 163-175.

Myers, "Journal Citations and Scientific Eminence," American Psychologist, Vol. 25 (November 1970): 1041-1048. 
Oral, Muhittin, Kettani, Ossama and Lang, Pascal, "Methodology for Collective Evaluation and Selection of Industrial R\&D," Management Science, Vol. 37 (July 1991): 871-885.

Parmerter, S. M. and Garber, J. D., "Creative Scientists Rate Creativity Factors,” Research Management, Vol. 14 (1971): 65-70.

Parsons, Talcott and Platt, Gerald M., "Considerations of the American Academic System,” Minerva, Vol. 6, No. 4 (Summer 1968): 497-523.

Pascarella, "Student-Faculty Informal Contact and College Outcomes," Review of Educational Research, Vol. 50 (1980): 545-595.

Pelz, Donald C., "Some Social Factors Related to Performance in a Research Organization,” Administrative Science Quarterly, Vol. 1 (1956): 310-325.

Pelz, Donald C. and Andrews, Frank M., "Organizational Atmosphere, Motivation and Research Contribution," American Behavioral Scientist, Vol. 6, No. 4 (1962): 43-47.

Pittman, Robert B. and Slate, John R., "Faculty Evaluation," Journal of Personnel Evaluation in Education, Vol. 3 (1989): 39-51.

Pfeffer, Jeffrey and Nancy Langton, "The Effect of Wage Disperson in Satisfaction, Productivity, and Working Collaboratively: Evidence from College and University Faculty," Administrative Science Quarterly, Vol. 38 (September 1993): 382-407.

Prewitt, Kenneth, "America's Research Universities Under Public Scrutiny," Daedalus, Vol. 122, No. 4 (Fall 1994): 85-99.

Prodgers, Stephen B., "Toward Systematic Faculty Evaluation,” Regional Spotlight, Vol. 13, No. 2 (January 1980): 1-7.

Rand McNally 1996 Commercial Atlas and Marketing Guide, 127th Edition, Rand McNally \& Company, 1996.

Rasmussen, "Case Study of the Evaluation of Research at the Technical University of Denmark," International Journal of Institutional Management in Higher Education, Vol. 9, No. 1 (March 1985): 58-66.

Rau, and Leonard, "Evaluating Ph.D. Sociology Programs," American Sociologist, Vol. 21, No. 3 (Fall 1990): 232-256.

Reskin, Barbara, “Academic Sponsorhips and Scientists' Careers,” Sociology of Education, Vol. 52, No. 3 (July 1979): 129-146. , "Scientific Productivity, Sex, and the Reward Structure of Science,” American Sociological Review, Vol. 42, No. 3 (1977): 491-504. 
, "Sex Differentiation and the Social Organization of Science," Sociological Inquiry, Vol. 48 (1978): 6-37.

Roach, S. S., "Services under Siege: The Restructuring Imperative," Harvard Business Review, Vol. 69 (1991): 82-91.

Roche, T. and Smith, D. L., "Frequency of Citations as Criterion for the Ranking of Departments, Journals and Individuals," Sociological Inquiry, Vol. 48 (1978): 49-57.

Rosengren, Karl Erik (editor), Advances in Contentn Analysis, Sage Annual Review of Communication Research, Vol. 9 (Beverly Hills, California: Sage Publications), 1981.

Roskens, Ronald W., "Implications of the Biglan Model," Research in Higher Education, Vol. 18 (1983): 285-297.

Rotton, James, "Research Productivity, Course Load and Ratings," Perceptual and Motor Skills, Vol. 72, Part 2 (Cecember 1990): 1388.

Rushton, J. Philippe and Roediger, Henry L., "An Evaluation of 80 Psychology Journals Based on the Science Citation Index," American Psychologist, Vol. 33, No. 5 (May 1978): 520-523.

Saaty, Thomas L. and Ramanujam, Vasudevan, “Objective Approach to Faculty Promotion and Tenure," Research in Higher Education, Vol. 18 (1983): 311-331.

Schmidt, Peter, "Governors Want Fundamental Changes in Colleges, Question Place of Tenure," Chronicle of Higher Education, 19 June 1998: A38.

Schwartz, "Research Productivity and Publication Output," College and Research Libraries, Vol. 52 (September 1991): 414-424.

Seashore, Stanley et al., "Relationships among Criteria of Job Performance," Journal of Applied Psychology, Vol. 44 (1960): 195-202.

Seldin, Peter, "Faculty Evaluation,” Change, Vol. 16 (1984): 28-33. , Changing Practices in Faculty Evaluation: A Critical Assessment and Recommendations for Improvement (San Francisco: Jossey-Bass), 1984.

Sestrup, Preben, "Methodological Developments in Content Analysis, "in Advances in Content Analysis, Karl Erik Rosengren (ed.), Sage Annual Review of Communication Research (Beverly Hills, California: Sage Publications), 1981: 133-158. 
Shils, E. A., "Intellectuals, Traditions and the Tradition of Intellectuals," Daedalus, Vol. 101 (Spring 1972): 21-30.

Smart, John C. and Elton, Charles F., "Goal Orientations of Academic Departments: A Test of Biglan's Model," Journal of Applied Psychology, Vol. 60 (1975): 580-588.

, "Structural Characteristics and Citation Rates of Education Journals," American Educational Research Journal, Vol 18 (1981): 399-413.

Smart, John C. and McLaughlin, Gerald W., "Reward Structure of Academic Disciplines," Research in Higher Education, Vol. 8 (1978): 39-55.

Smith, Richard and Fiedler, Fred E., "The Measurement of Scholarly Work: A Critical Review of the Literature," Educational Record, Vol. 52 (1971): 225-232.

Stamps, L. E. and Fehr, L., "Journal Ratings Revisited: A Closer Scrutiny of Impact Factors,” American Psychologist, Vol. 35 (1980): 1048-1049.

Stigler, and Friedland, "Citation Practices of Doctorates in Economics," Journal of Political Economy, Vol. 83 (1975): 477-507.

Stotsky, Sandra, "Viewpoints: A Dialogue on Paradigms for Research and Program Evaluation," Research in the Teaching of English, Vol, 27, No. 3 (October 1993): 282-292.

Strauss, Anselm and Corbin, Juliet, Basis of Qualitative Research: Grounded Theory Procedures and Techniques (London: Sage Publications): 1990.

Taylor, Calvin W. and Barron, Frank, Scientific Creativity: Its Recognition and Development (New York: John Wiley \& Sons, Inc.), 1963.

Tollison, Robert D. and Goff, Brian L., "Citation Practices in Economics and Physics,” Journal of Institutional and Theoretical Economics, Vol. 142 (1986): 581-587.

Tuckman, Howard P. and Hagemans, Robert P., "Analysis of the Reward Structure in Two Disciplines," Journal of Higher Education, Vol. 47 ( 1976): 447-464.

Von Range, Eugene K., Professional Creativity (Englewood Cliffs, New Jersey: Prentice-Hall, Inc.), 1959.

Walbert, H. J., Mantel, Harvey, and Rasher, Sue P., "Eminence and Citations in Educational Psychology," Educational Researcher, Vol. 6, No. 3 (1977): 12-13. 
Wanner, "Research Productivity in Academia," Sociology of Education, Vol. 54 (1981): 239-253.

Webster, "Institutional Effectiveness Using Scholarly Peer Assessments," Review of Higher Education, Vol. 9, No. 1 (1985): 67-82.

White, Murray J. and White, K. Geoffrey, "Citation Analysis of Psychology Journals,” American Psychologist, Vol. 32 (May 1977): 301-305.

Wilson, Logan, The Academic Man: Sociology of a Profession (London: Oxford University Press), 1942.

Woodburne, Lloyd S., Faculty Personnel Policies in Higher Education (New York: Harper and Brothers), 1950.

The World of Learning (London: Europa Publications Limited), 1996.

Yoels, William C., "On 'Publishing or Perishing': Fact or Fable?" The American Sociologist, Vol. 8 (1973): 128-134.

Zamarippa, E. J., "Research Productivity: A Definition," Mental Retardation, Vol. 31 (1993): 320-325.

Zivney, Terry L. and Bertin, William J., "Publish or Perish: What the Competition is Really Doing," Journal of Finance, Vol. 47, No. 1 (March 1992): 295-329.

Zuckerman, Harriet, "Stratification in American Science," Sociological Inquiry, Vol. 40 (Spring 1970): 235-257.

and Merton, Robert K., "Patterns of Evaluation in Science: Institutionalization, Structure and Functions of the Referee System," Minerva, Vol. 9, No. 1 (1971): 66-100. 


\section{Appendix A}

\section{Interview Questions}

\section{Questions for chairs of departments:}

1. What criteria does your department use in evaluating research for promotion? for tenure? (i.e., what are the contents of a P\&T file or dossier?)

2. Are the criteria and standards used for evaluating research in your department different from those used at the institutional level? Defined differently?

3. Are the criteria weighted? If so, how was this weighting scheme determined and what is it?

4. What are your departmental objectives for promotion? for tenure?

5. Does your department control its promotion and tenure decisions?

6. What is the relationship of research to teaching? to service?

7. Describe the P\&T committee (selection, qualifications, term of service, responsibilities).

8. Have you had any lawsuits or grievances resulting from the promotion and tenure process in the past two years? how many? how were they settled? 


\section{Questions for chairs of P\&T committees:}

1. What processes do you use in evaluating research for promotion? for tenure? Do you rank order candidates?

2. What is the importance of research in your department and why is it important? What is its relationship to teaching?

3. What indicators of creative activity do you use (papers, presentations, grants, students, peer reviews) and do you weight them? How was the weighting scheme derived?

4. Can you describe how the committee functions? Do other members of the unit have a voice in the process? What about the candidate's role?

5. What are the objectives of the committee in evaluating research?

6. How do you operationalize 'highest quality', 'excellence', national reputation, etc.?

\section{Questions for provosts and associate provosts:}

1. What is the importance of research and scholarship at your university and why should it be important? What is its perceived relationship to teaching?

2. How often do you disagree with departmental recommendations for promotion and tenure? What are some of the reasons?

3. Is your approval of promotion and tenure recommendations essentially a rubber stamp?

4. Does the university make a distinction between applied and pure research? How? Why? 
5. How would you describe the structure of your university (bureaucracy, collegium, professional, oligarchy) and why?

6. How much do faculty affect the goals, operation and standards of the university? 


\title{
Appendix B
}

\section{Complete List of Terms Derived from Coding of Interviews}

\author{
abuse of guidelines \\ balance/integration \\ interrelationship of faculty functions \\ between teaching and research \\ environment \\ budget committee \\ buy-in \\ candidate screening \\ candidate statement for dossier \\ chair functions/responsibilities \\ collaboration \\ college guidelines/criteria \\ college review/decision \\ collegiality \\ comparisons/weighting \\ criteria \\ culture \\ demographics \\ department agreement \\ department decision/reputation \\ department objectives/standards \\ department satisfaction \\ department statement/by-laws \\ disagreement \\ equity/interpretation \\ evaluate research \\ expectations \\ faculty initiatives \\ flexibility
}




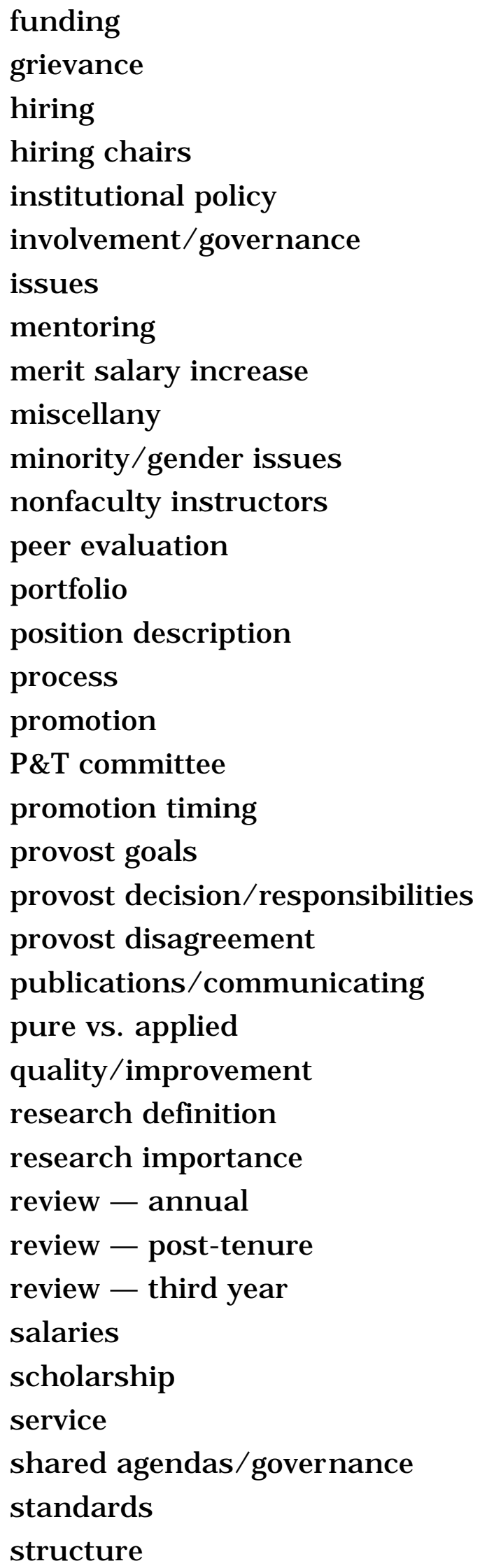


students

teaching vs. research

teaching

tenure timing

trust

unit differences

university goals/principles

university guidelines

university-level decisions/agreement-disagreement/etc.

validation

voting 


\section{Appendix C \\ Final List of Terms}

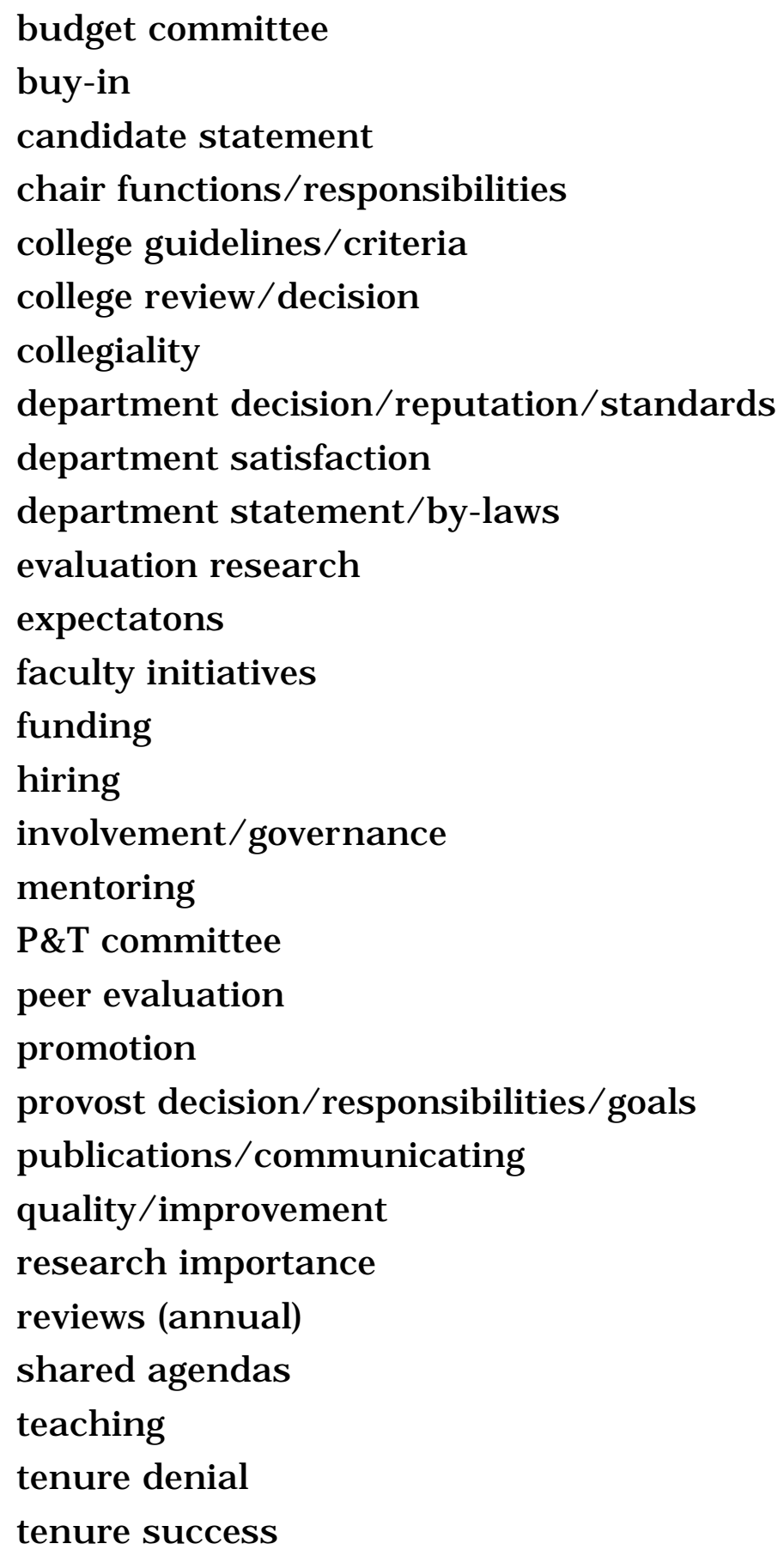


university goals/principles

unit differences

university level decisions/review 


\section{Appendix D \\ Document Flow at for Promotion and Tenure Dossiers at Collegial $U$}

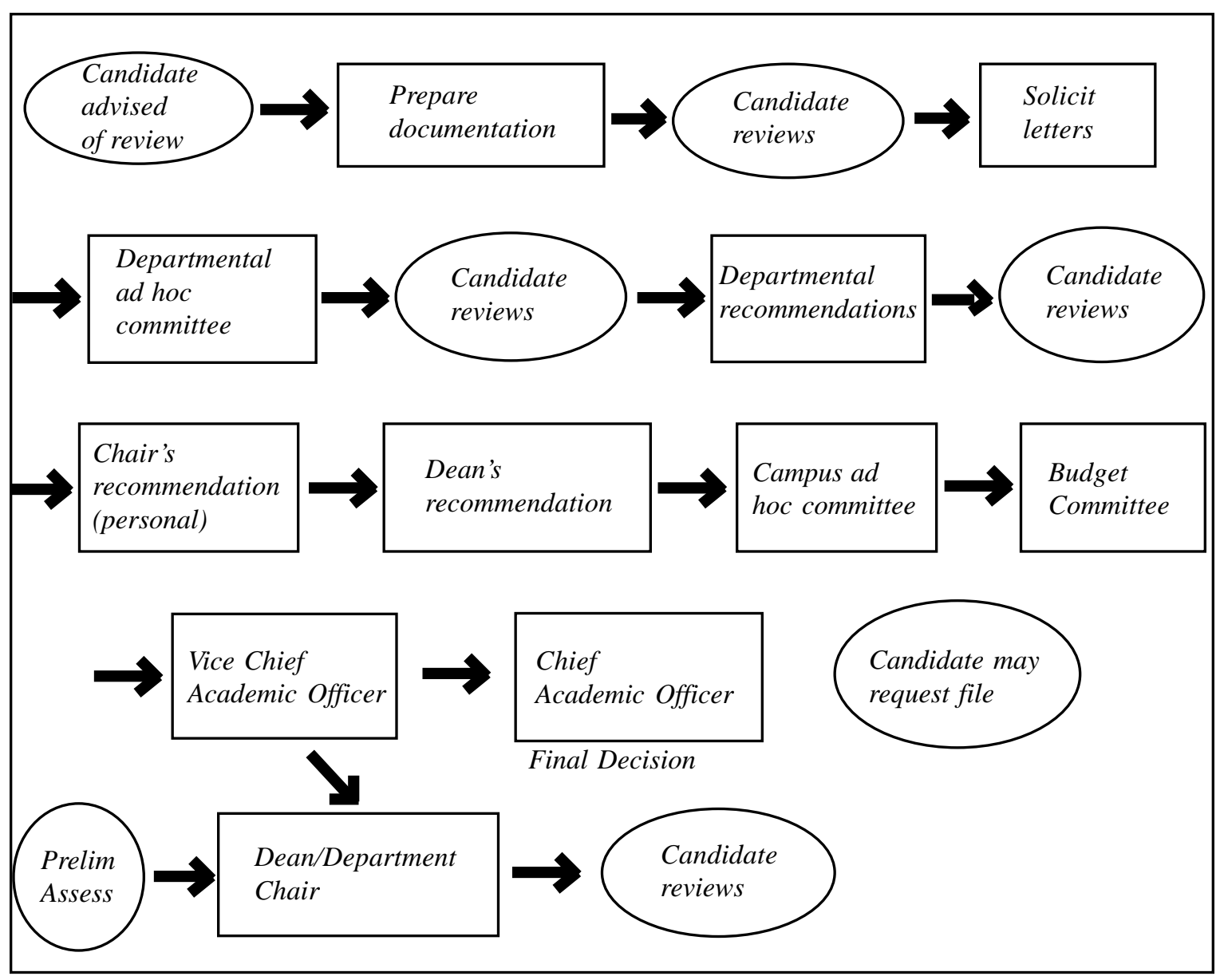




\section{Appendix E \\ Results of Statistical Analysis}

\section{Figure E.1: Chi Square Analysis}

Response: gov. type Iteration History

Converged by Gradient

\begin{tabular}{|lrrrrr|}
\hline Whole-Model & Test & & & \\
Model & -LogLikelihood & DF & ChiSquare & Prob $>$ ChiSq \\
Difference & 6.883612 & 12 & 13.76722 & 0.315819 \\
Full & 10.431516 & & & \\
Reduced & 17.315128 & & & \\
& & 0.3975 & & \\
RSquare (U) & & 24 & & \\
Observations (or Sum Wgts) & 24 & \\
\hline
\end{tabular}

Lack of Fit

\section{Parameter Estimates}

\section{Effect Test}

Source Nparm

adm

lib books

B-pr

res/\#fac

res/grad st

$\mathrm{fac} / \mathrm{st}$
2

2

2

2

2

2

2

$\begin{aligned} \text { DF } & \text { Wald } \\ 2 & \\ 2 & \\ 2 & \\ 2 & \\ 2 & \\ 2 & \end{aligned}$

\section{ChiSquare}

1.8860185

1.1000230

0.6382255

2.6593910

1.6592670

0.5069867
Prob>Chisq

0.3895

0.5769

0.7268

0.2646

0.4362

0.7761

Analysis of data shows no statistically significant relationship. Even though the cells are extremely small, if there were a significant relationship between any of the variables, there would be at least a suggestion of a fit.

It is worth noting here that the various reference books noted in the caption under Figure E.2 all contain different data for the same variable. I selected data for this analysis based on a comparison of a publication's data for WVU with actual WVU data-e.g., I used the data from the volume that contained WVU data closest to what I knew was correct. 


\section{Figure E.2: Calculations of Means}

\begin{tabular}{|r|r|r|r|r|r|r|}
\hline Rows & gov. type & N Rows & Mean(V-p) & Mean(adm) & Mean(acad deans) & Mean(RD/gr st) \\
\hline 1 & 1 & 4 & 6.00 & 21.00 & 15.00 & 19.06 \\
\hline 2 & 2 & 18 & 5.44 & 19.39 & 13.94 & 35.11 \\
\hline 3 & 3 & 3 & 4.67 & 19.00 & 15.50 & 28.36 \\
\hline
\end{tabular}

\begin{tabular}{|r|rr|r|r|r|}
\hline Rows & Mean(lib books) & Mean(lib budget) & Mean(res/grad st) & Mean(res/\#fac) \\
\hline 1 & 5.25 & 10.20 & 0.02 & 0.11 \\
\hline 2 & 2.66 & 6.93 & 0.04 & 0.11 \\
\hline 3 & 2.53 & 7.63 & 0.03 & 0.12 \\
\hline
\end{tabular}

\begin{tabular}{|r|r|r|r|r|r|}
\hline Rows & Mean(st/fac) & Mean(B-\%) & Mean(M-\%) & Mean(D-\%) & Mean(st/fac)2 \\
\hline 1 & 11.00 & 0.36 & 0.37 & 0.27 & 11.00 \\
\hline 2 & 13.17 & 0.43 & 0.34 & 0.24 & 13.17 \\
\hline 3 & 12.67 & 0.38 & 0.35 & 0.28 & 12.67 \\
\hline
\end{tabular}

Legend: 1 = Bureaucratic $\quad 2$ Shared-Governance $\quad 3$ Collegial

Figures 1, 2 and 3 show calculations of the means of the values for the number of vice presidents (V-p), deans (acad deans) and all administrators (adm); $R \& D$ funding per graduate student (RD/grad st), research expenditures per graduate student (res/grad st) and per faculty (res/\#fac); number of volumes in the library (lib books) and library budget (lib budget); student-faculty ratio (st/fac); and the percentage of baccalaureate (B-\%), master's (M-\%) and doctoral (D$\%)$ degrees awarded. All financial information is for the 1992-93 fiscal year. All other data is for the 1993-94 fiscal year from several reference volumes on higher education.(Barron's, Peterson's, the Blue Book, the World of Learning, Statistical Abstracts). It is clear that the means are very close in all categories. 
Figure E.3: Graph of Means
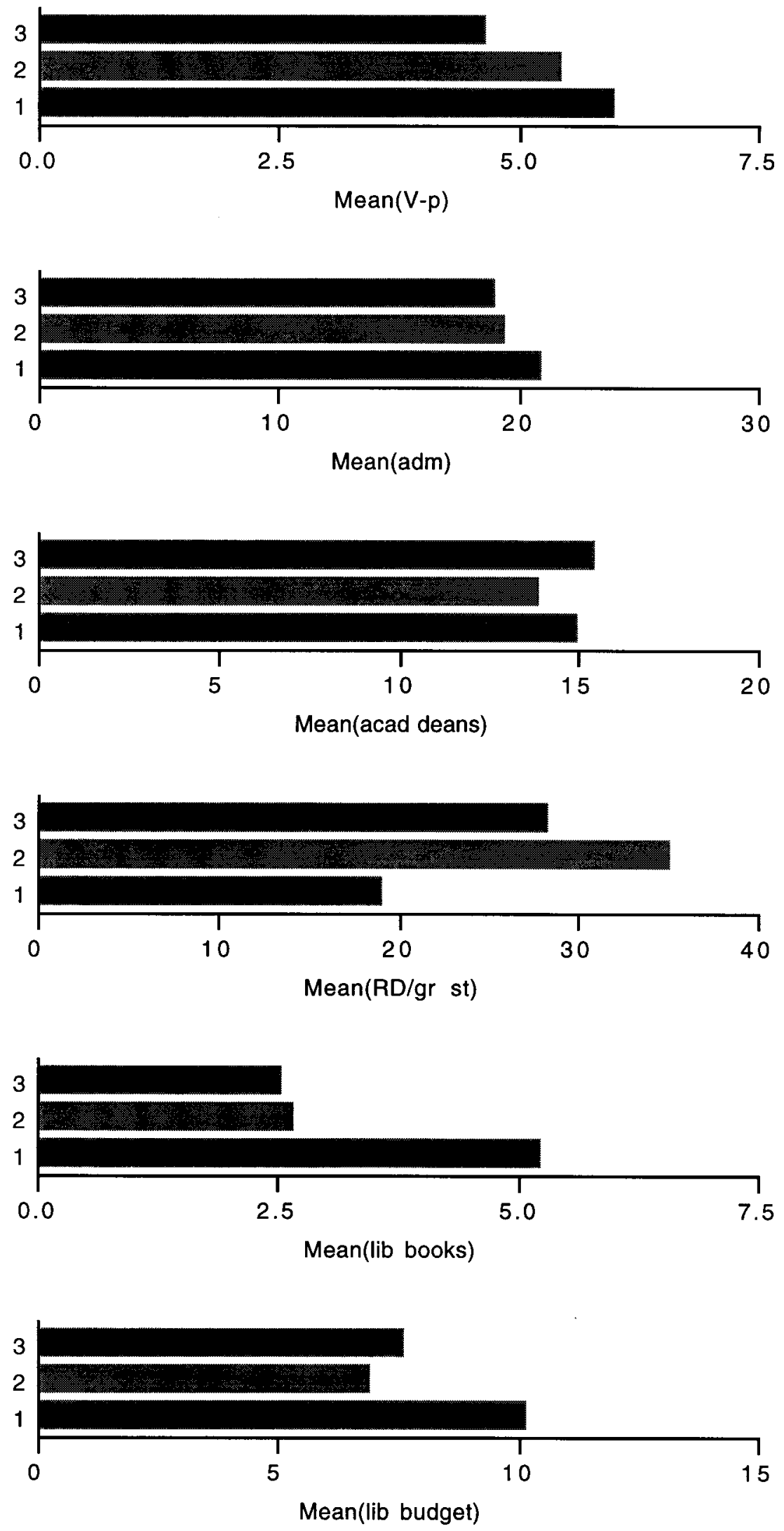
Figure E.3 (continued)
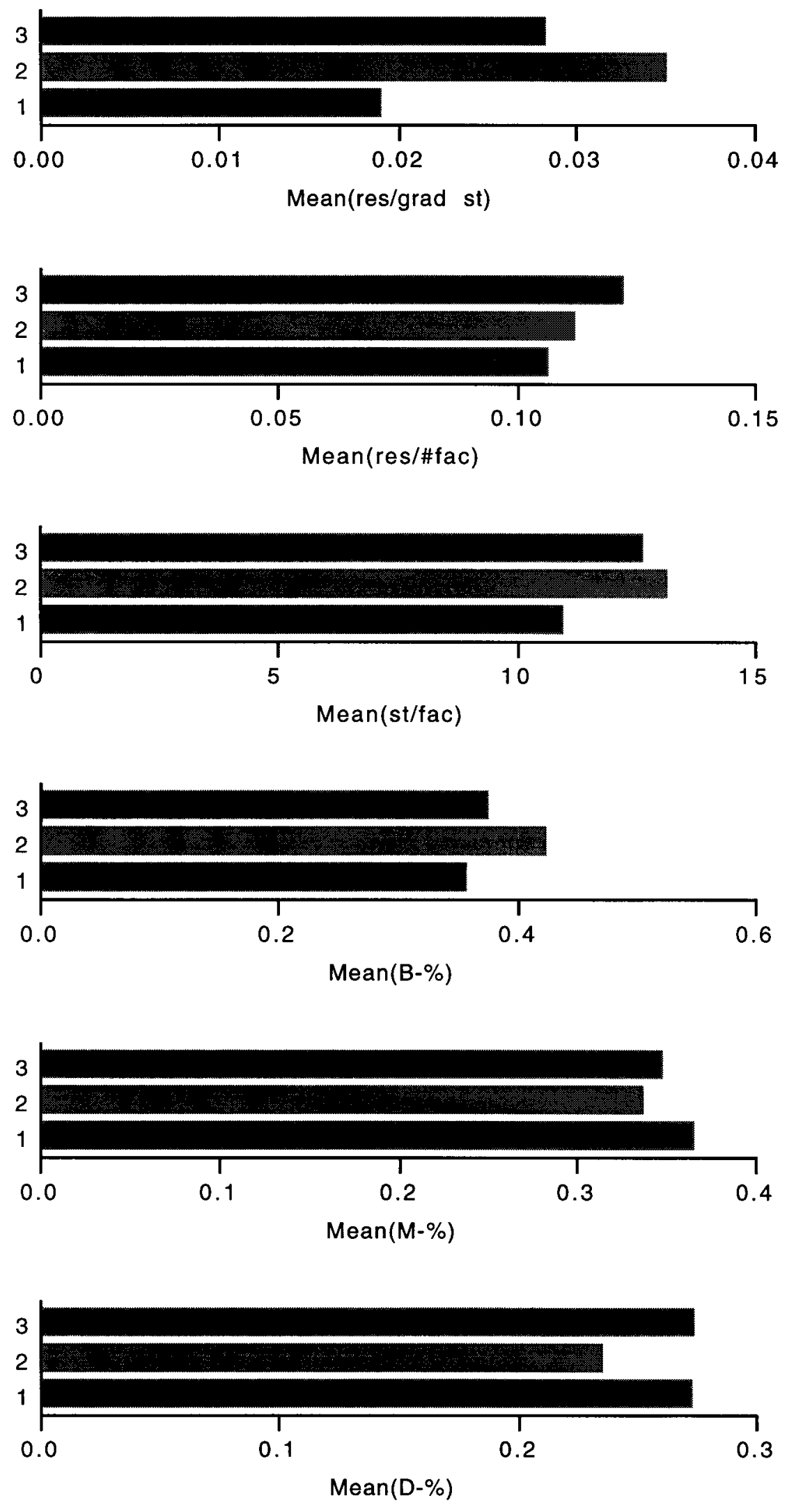


\title{
Abstract
}

\section{The Evaluation of Research for Promotion and Tenure: An Organizational Perspective}

\author{
by Elsa G. Nadler
}

The literature on promotion and tenure in institutions of higher education includes a substantial amount of research on various aspects of faculty productivity. Yet other research concentrates on the organizational structure of higher education. In his 1986 book, Burton Clark called for research that would examine how what he called the enterprise (the local university as opposed to the statewide system) and departments within it interact in important arenas.

This dissertation takes up Clark's challenge to examine the interaction of enterprise and department in promotion and tenure in three areas: goals, structure and operations. Content analysis of faculty handbooks from 25 Research I, land-grant institutions revealed that most of those institutions (18 of them) can be classified as having a sharedgovernance authority structure (on the basis of the involvement of administrators and committees in the promotion and tenure process); three are collegial, four bureaucratic. Interviews with department chairs and chairs of promotion and tenure committees elicited information on how the department orchestrates promotion and tenure, how it interacts with disciplinary members outside of the enterprise, and how it interacts with the enterprise. Interviews with administrators in charge of personnel issues examined the goals of the enterprise with respect to promotion and tenure and how it operated to attain those goals.

Analysis of interview transcripts indicate that there is little effect of enterprise on department in the establishment of the department's authority structure for P\&T evaluations. Neither is there much effect on the actual process. And, although the enterprise would like to perceive itself as setting criteria for evaluation of faculty, in fact the departments adhere to their own particularistic processes and structures, criteria and agendas. Those criteria, however, are not always the same within disciplines across enterprises. What does remain the same across all entities is the statement of goals that seek faculty who are of the highest quality, the most productive, the most promising, the best teachers, the most creative, and who have a sustainable and continuing research program. 


\title{
Curriculum Vita
}

\author{
of \\ Elsa G. Nadler
}

\section{Education}

Ed.D. in Higher Education Administration, West Virginia University, 1999

Master of Science in J ournalism, West Virginia University, 1984

Bachelor of Arts in Modern Foreign Languages, University of Georgia, 1965

Graduating Class Valedictorian, Isidore Newman School, New Orleans, 1961

\section{Professional Background}

Office of Sponsored Programs, West Virginia University (1983-present)

Title: Editor/Program Representative

Responsibilities include writing and editing articles for the university's research magazine Inquiry, designing the magazine and overseeing its production, writing instructional material for faculty and staff, designing and maintaining several administrative databases running under SPIRES (Stanford Public Information Retrieval System), editing grant proposals and other documents, and writing and designing brochures, pamphlets, booklets and other items produced by the office. I also serve as faculty liaison, consultant and ombudsman, inform faculty of funding opportunities and help keep faculty abreast of developments in areas of interest to them. Additional responsibilities involve designing and maintaining office Web pages, acting as computer consultant and teaching short courses and seminars on computer software and basic writing skills. The position requires a thorough knowledge of layout and graphics, printing, purchasing procedures, the use of PC software and hardware, and mainframe editing, databases and electronic mail.

West Virginia Network for Educational Telecomputing (1979-1983)

Title: Administrative Assistant

Responsibilities included writing and editing computer documentation and memos and notices to staff, account holders, administrative personnel, university and government officials, and vendors; assisting in the production of a newsletter and other publications; and maintaining online information for three computer systems (CMS, VAX and WYLBUR). 